\title{
Snow Surface Energy Exchanges and Snowmelt in a Shrub-Covered Bog in Eastern Ontario, Canada
}

\author{
by
}

\section{Sara Knox}

A thesis submitted to the Faculty of Graduate and Postdoctoral Affairs in partial fulfillment of the requirements for the degree of

\author{
Master of Science
}

in

Geography and Environmental Studies

\author{
Carleton University \\ Ottawa, Ontario
}

\author{
(C) 2011 \\ Sara Knox
}




$\begin{array}{ll}\begin{array}{l}\text { Library and Archives } \\ \text { Canada }\end{array} & \begin{array}{l}\text { Bibliothèque et } \\ \text { Archives Canada }\end{array} \\ \begin{array}{l}\text { Published Heritage } \\ \text { Branch }\end{array} & \begin{array}{l}\text { Direction du } \\ \text { Patrimoine de l'édition }\end{array} \\ \begin{array}{l}\text { 395 Wellington Street } \\ \text { Ottawa ON K1A ON4 } \\ \text { Canada }\end{array} & \begin{array}{l}\text { 395, rue Wellington } \\ \text { Ottawa ON K1A ON4 } \\ \text { Canada }\end{array}\end{array}$

Your file Votre référence ISBN: 978-0-494-83156-4 Our file Notre référence ISBN: 978-0-494-83156-4

NOTICE:

AVIS:

The author has granted a nonexclusive license allowing Library and Archives Canada to reproduce, publish, archive, preserve, conserve, communicate to the public by telecommunication or on the Internet, loan, distribute and sell theses worldwide, for commercial or noncommercial purposes, in microform, paper, electronic and/or any other formats.

The author retains copyright ownership and moral rights in this thesis. Neither the thesis nor substantial extracts from it may be printed or otherwise reproduced without the author's permission.

L'auteur a accordé une licence non exclusive permettant à la Bibliothèque et Archives Canada de reproduire, publier, archiver, sauvegarder, conserver, transmettre au public par télécommunication ou par l'Internet, prêter, distribuer et vendre des thèses partout dans le monde, à des fins commerciales ou autres, sur support microforme, papier, électronique et/ou autres formats.

L'auteur conserve la propriété du droit d'auteur et des droits moraux qui protège cette thèse. $\mathrm{Ni}$ la thèse ni des extraits substantiels de celle-ci ne doivent être imprimés ou autrement reproduits sans son autorisation.
In compliance with the Canadian Privacy Act some supporting forms may have been removed from this thesis.

While these forms may be included in the document page count, their removal does not represent any loss of content from the thesis.
Conformément à la loi canadienne sur la protection de la vie privée, quelques formulaires secondaires ont été enlevés de cette thèse.

Bien que ces formulaires aient inclus dans la pagination, il n'y aura aucun contenu manquant.

\section{Canadä}




\begin{abstract}
The ground heat flux $(G)$ is typically considered a small component of the snowpack energy balance (EB) when compared to radiative and turbulent fluxes.

However, in environments where the soil remains above freezing throughout the winter, $G$ may be an important energy input to the snowpack. To assess the role of $G$ in the snow energy budget of such an environment, the EB components of the snowpack in a peatland were measured and modelled using an EB snowmelt model (SNOBAL) during the 2009-2010 winter. When integrated over the pre-melt period, measured $G$ proved to be a large contributor to the total EB (25\%). Net radiation and $G$ were under-predicted by the model, while turbulent fluxes were considerably over-predicted. Modelled $G$ was found to be sensitive to the temperature gradient between the soil and the snowpack, while turbulent fluxes could be improved by reducing the roughness lengths for heat and vapour relative to momentum.
\end{abstract}




\section{Acknowledgements}

I wish to sincerely thank my supervisor Dr. Sean Carey for his guidance, support and encouragement. I greatly appreciate his consistent enthusiasm for the project and I highly value the time I have spent working with him at Carleton University. I would also like to acknowledge Dr. Elyn Humphreys, a member of my advisory committee, for all her time, patience and help, especially with all things MATLAB.

Many thanks to Dr. Michael Treberg for his technical and logistical assistance, including instrument setup and calibration, and his indispensable help in the field. I am grateful for the dedication and hard work of Jamie Ellis whose help in the field is greatly appreciated. I also wish to thank Tom Brown (University of Saskatchewan) for his assistance with SNOBAL.

I would like to acknowledge the funding agencies that made this research possible: National Sciences and Engineering Research Council (NSERC), Fonds de recherche sur la nature et les technologies (FQRNT), and Carleton University. Support for the flux measurement program in 2009/2010 at Mer Bleue was provided by the Ontario Ministry of the Environment and the Canadian Foundation for Climate and Atmospheric Sciences: Canada Carbon Program. Thanks to the National Capital Commission (NCC) of Ottawa for access to the study site.

I greatly appreciate my family and friends for their interest, encouragement and unwavering support. Thanks also to all of my peers and friends at Carleton for your assistance and advice, and for making my time in Ottawa a truly enjoyable experience. I am especially grateful to my partner and best friend Tyler Reid, who has been very supportive, understanding, and willing to help every step of the way. 


\section{Table of Contents}

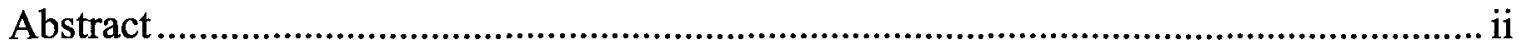

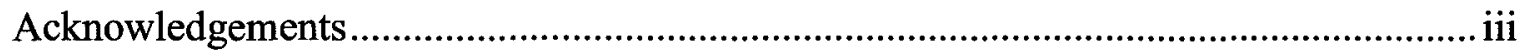

Table of Contents ........................................................................................................ iv

List of Tables ........................................................................................................ vi

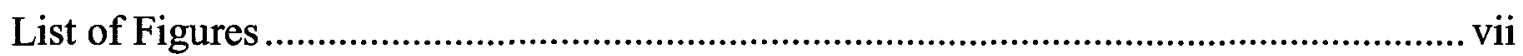

List of Symbols and Abbreviations...............................................................................

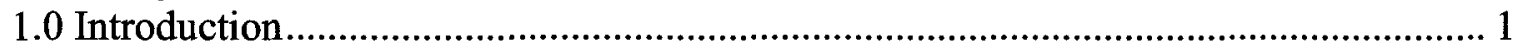

2.0 Background and Theory........................................................................................ 5

2.1 Energy Exchange at the Snow Surface ............................................................... 5

2.2 Net Radiation at the Snow Surface .................................................................... 7

2.3 Sensible and Latent Heat Fluxes......................................................................... 11

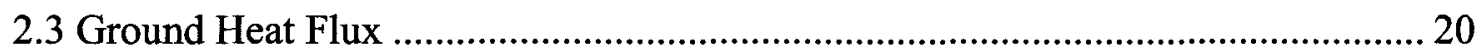

2.4 Advected Heat Transfer to the Snowpack …………............................................... 23

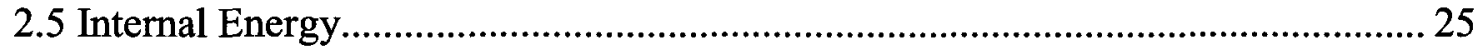

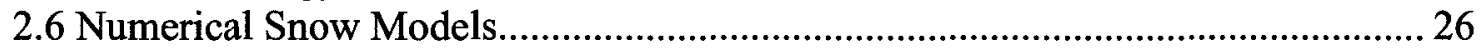

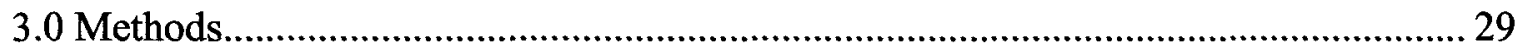

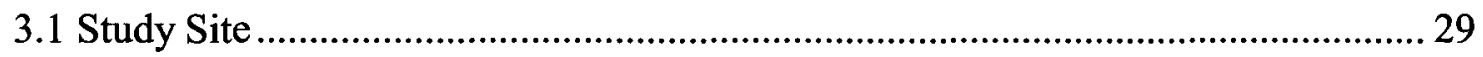

3.2 Snow Energy Balance Measurements.................................................................. 32

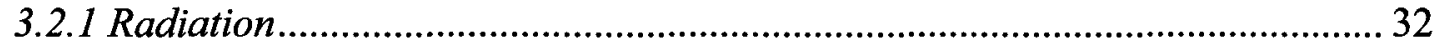

3.2.2 Turbulent Fluxes .......................................................................................... 32

3.2.3 Soil Measurements and Snow Temperatures .................................................... 34

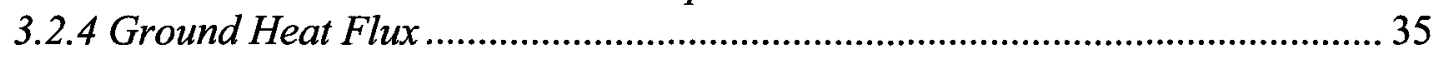

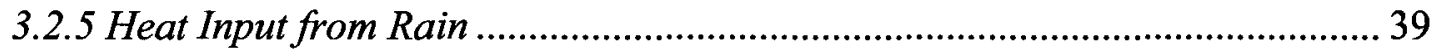

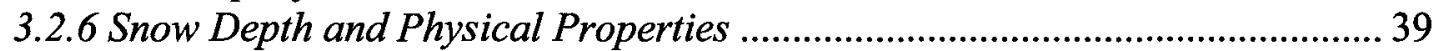

3.2.7 Internal Energy ................................................................................................ 41

3.2.8 Radiative and Turbulent Fluxes and Local Advection during Snowmelt ........ 42

3.2.9 Calculating the Energy Available for Melt from the Water Balance................ 45

3.2.10 Energy Budget Closure and Storage terms................................................. 46

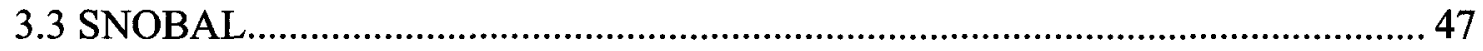

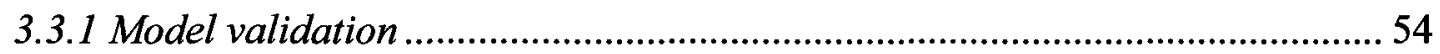

3.4 Reliability of Eddy Fluxes and Flux Corrections ...............................................56

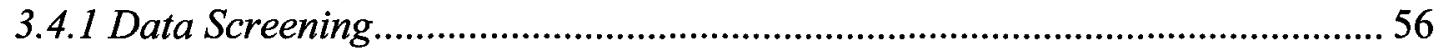

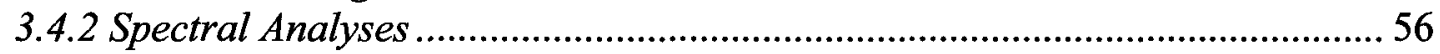

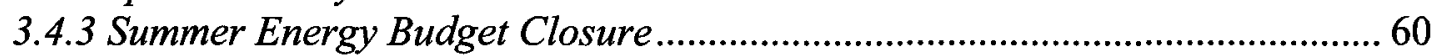

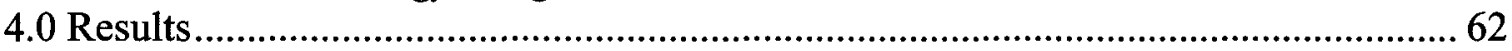

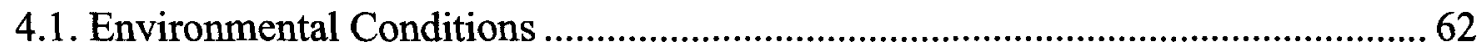



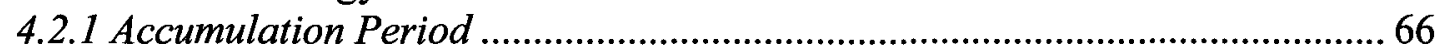

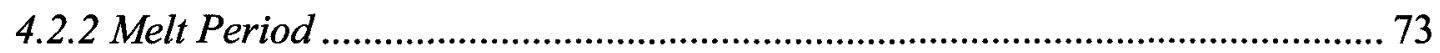

4.3 Energy Balance Closure............................................................................................ 76

4.4 Modelled Versus Measured Snow Cover Energy and Mass Balance....................... 77

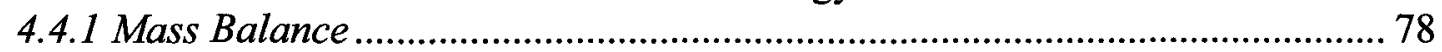

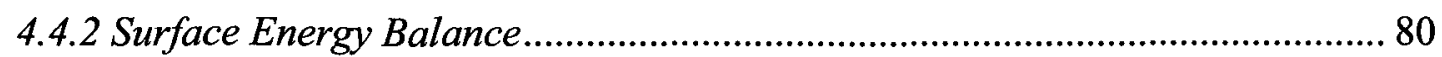

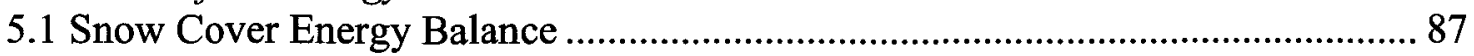


5.1.1 Pre-Melt Energy Balance

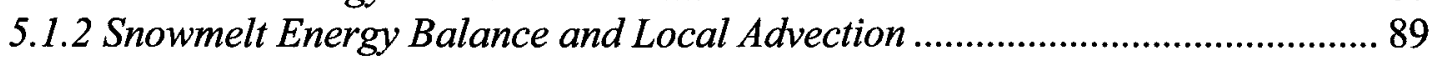

5.2 Causes of the Energy Imbalance............................................................................. 91

5.3 Modelled vs. Measured Fluxes ........................................................................ 96

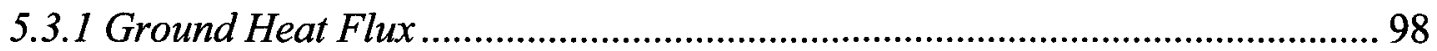

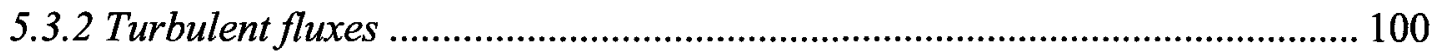

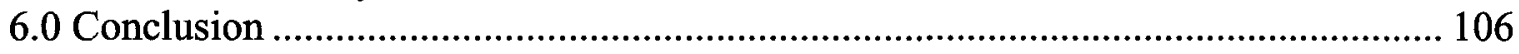

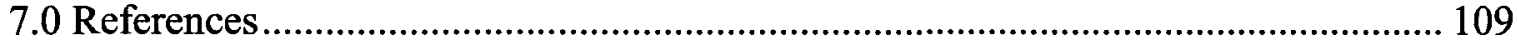

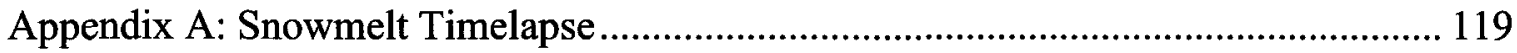




\section{List of Tables}

Table 3.1: Values for unfrozen water parameterization (freezing point temperature, $T_{f}$; threshold temperature when unfrozen water content reaches a minimum, $T_{u, l}$; and minimum unfrozen water content, $\left.\theta_{u, l}\right)$, total volumetric water content $\left(\mathrm{VWC}_{\mathrm{T}}\right)$, and average soil porosity $(\varepsilon)$. Values in brackets represent the SD calculated over the three soil pits.

Table 3.2: State variables predicted by the model and values input as initial conditions, and forcing variables and measurement height.

Table 3.3: Correlation coefficient $\left(\mathrm{r}^{2}\right)$ and RMSD for daily mean sensible and latent heat fluxes for surface layer thicknesses of $0.10,0.05,0.01 \mathrm{~m}$.

Table 4.1: Snowpack energy summary for the snowmelt period. $\overline{\Delta Q}$ was estimated as the sum of the energy balance components and calculated from the water balance. The percent of energy transfer was calculated for each energy flux by dividing it by the sum of the absolute of all the energy fluxes $\left(70.4 \mathrm{~W} \mathrm{~m}^{-2}\right)$.

Table 4.2: Energy budget closure results for rain-free periods when air and snow temperatures were below freezing are indicated by the slope and intercept of the regression between $L_{v} E+H$ and $\Delta Q-\left(R_{n}+G+J\right)$. The number of half-hour measurements used in the linear least squares regression is indicated by $\mathrm{n}$.

Table 4.3: Model fitting statistics. Root mean square difference (RMSD), absolute mean bias difference (AMBD), relative mean bias difference (RMBD), and model efficiency $(\mathrm{ME})$ between measured and simulated snow depth and SWE.

Table 4.4: Measured and modelled snow cover energy flux summary. Average measured and simulated energy flux, and coefficient of determination $\left(\mathrm{r}^{2}\right)$ for three periods of analysis (Early: 21 Dec - 26 Jan; Mid: 27 Jan - 23 Feb; Melt: 24 Feb - 4 March; Overall $\left.{ }^{*}: 21 \mathrm{Dec}-28 \mathrm{Feb}\right)$. Note that since energy fluxes are averaged over the analysis periods, they typically represent a wide range of values. 82

Table 5.1: Performance of bulk transfer parameterization schemes 104 


\section{List of Figures}

Figure 2.1: Conceptual diagram of the energy fluxes at the snow-air and snow-ground interface (modified from Helgason, 2009).

Figure 2.2: Roughness length ratios as described by the Andreas (1987) model. 19

Figure 3.1: Map of the Mer Bleue Bog and research sites (after Roulet et al., 2007)..... 30

Figure 3.2: Photograph of the primary instrument site. 31

Figure 3.3: Schematic diagram of SNOBAL structure and components (from Mazurkiewicz et al., 2008). 48

Figure 3.4: Ensemble average cospectra for sensible heat $\left(f C_{w T} / \overline{w^{\prime} T^{\prime}}\right)$ and water vapour $\left(f C_{w s_{v}} / \overline{w^{\prime} s_{v}^{\prime}}\right)$ (top panels) and transfer functions (TF) (bottom panels) illustrating high frequency loss of $\overline{w^{\prime} s^{\prime}}$ for 39 daytime half hours during melt (left panels) and 34 daytime half hours during August 2009 (right panels).

Figure 3.5: Relationship between correction factor for $L_{v} E$ and half-hour average horizontal wind speed $(u$ ) for 39 daytime half hours during melt and 34 daytime half hours during August 2009.

Figure 4.1: Daily water equivalent of (a) snowfall and (b) rainfall. Data from Ottawa International Airport, Meteorological Services of Canada.

Figure 4.2: (a) Daily average continuous and manual snow depth measurements, and (b) manual SWE measurements. The vertical bars are \pm 1 SD of the mean.

Figure 4.3: (a) Daily average wind speed $(u)$, (b) vapour pressure $\left(e_{a}\right),(\mathrm{c})$ air temperature $\left(T_{a}\right)$ and snow surface temperature $\left(T_{s s}\right)$, and $(\mathrm{d})$ soil temperature $\left(T_{g}\right) \ldots . .65$

Figure 4.4: Measured (a) daily average net solar $\left(K^{*}\right)$, net thermal ( $\left.L^{*}\right)$ radiation, and net all-wave radiation $\left(R_{n}\right)$, (b) latent heat flux $\left(L_{v} E\right)$, (c) sensible heat fluxes $(H)$, (d) ground heat flux $(G)$, (e) advected heat flux $(M)$, and (f) sum of the energy balance terms $(\Delta Q)$. Vertical dotted line separates the accumulation from the melt period. Note the change in vertical axis following panel (a).

Figure 4.5: energy balance components on a weekly time step. 68

Figure 4.6: Relative contribution of each energy flux term to weekly average energy balance during the period when the snow cover is continuous (21 December 2009 to 28 February 2010). Values are calculated as the ratio of each energy flux term and the sum 
of the absolute magnitude of each term such that the height of each bar is $100 \%$. Positive contributions indicate energy fluxes towards the snowpack.

Figure 4.7: Measured daily mean shortwave albedo.

Figure 4.8: Cumulative sum of energy balance components from 21 December 2009 to 12 March 2010.

Figure 4.9: 30-minute average sensible (light gray grey bars) and latent (dark gray bars) heat flux frequency distribution.

Figure 4.10: (a) Snow-covered area, (b) air temperature, and estimated snow surface and bare ground temperature, and (c) daily average energy balance terms for the snow cover from 24 February 2009 to 9 March 2010.

Figure 4.11: Energy budget closure ( $L_{v} E+H$ vs. $\left.\Delta Q-\left(R_{n}+G+J\right)\right)$ for 232 and 223 nighttime and daytime half hours, respectively, for rain free periods when air and snow temperatures were below freezing.

Figure 4.12: Measured and simulated (a) snow depth, (b) SWE, and (c) modelled daily snowmelt at the base of the snowpack. The vertical bars are \pm 1 SD of the mean. ....... 79

Figure 4.13: Measured (dotted line) and modelled (gray line) (a) net radiation $\left(R_{n}\right)$, (b) latent heat flux ( $\left.L_{v} E\right)$, (c) sensible heat flux $(H)$, (d) ground heat flux $(G)$, and (e) advected energy from rain $(M)$.

Figure 4.14: Comparison of daily mean (a) net radiation $\left(R_{n}\right)$, (b) latent heat flux $\left(L_{v} E\right)$, (c) sensible heat flux $(H)$, and (d) ground heat flux $(G)$ prior to the development of a patchy snow cover.

Figure 4.15: Measured (dotted line) and modelled (grey line) (a) snow surface temperature $\left(T_{s s}\right)$, (b) net radiation $\left(R_{n}\right)$, (c) sensible heat flux $(H)$, and (d) latent heat flux $\left(L_{v} E\right)$ for select days during the mid period, illustrating typical diurnal trends. .... 86

Figure 5.1: (a) Comparison of daily melt rate calculated as the residual of the energy balance and daily melt calculated from the water balance, and (b) comparison of $H_{c}$ as measured from the eddy covariance system (line with triangles) and as estimated from equation (5.1) (line with circle).

Figure 5.2: Comparison of 30-minute latent heat flux $\left(L_{v} E\right)$ measurement from the LI7000 closed path IRGA against the LI-7200 enclosed path IRGA. Data are from 9-31 January 2011.

Figure 5.3: Cumulative measured (thin black line) and SNOBAL simulated ground heat flux with (a) varying thermal conductivity: $K_{g}=0.15 \mathrm{~W} \mathrm{~m}^{-1} \mathrm{~K}^{-1}$ (thick black line); $K_{g}=$ 
$0.56 \mathrm{~W} \mathrm{~m}^{-1} \mathrm{~K}^{-1}$ (dashed line); and $K_{g}=1.2 \mathrm{~W} \mathrm{~m}^{-1} \mathrm{~K}^{-1}$ (grey line); and (b) varying depth of the soil measurement: $0.10 \mathrm{~m}$ (thick black line); $0.20 \mathrm{~m}$ (dashed line); and $0.40 \mathrm{~m}$ (grey line).

Figure 5.4: Estimation of measured (black line) and modelled (grey line) sensible (a $-\mathrm{d}$ ) and latent $(\mathrm{e}-\mathrm{h})$ heat fluxes using various bulk transfer parameterization scenarios. .. 102 


\section{List of Symbols and Abbreviations}

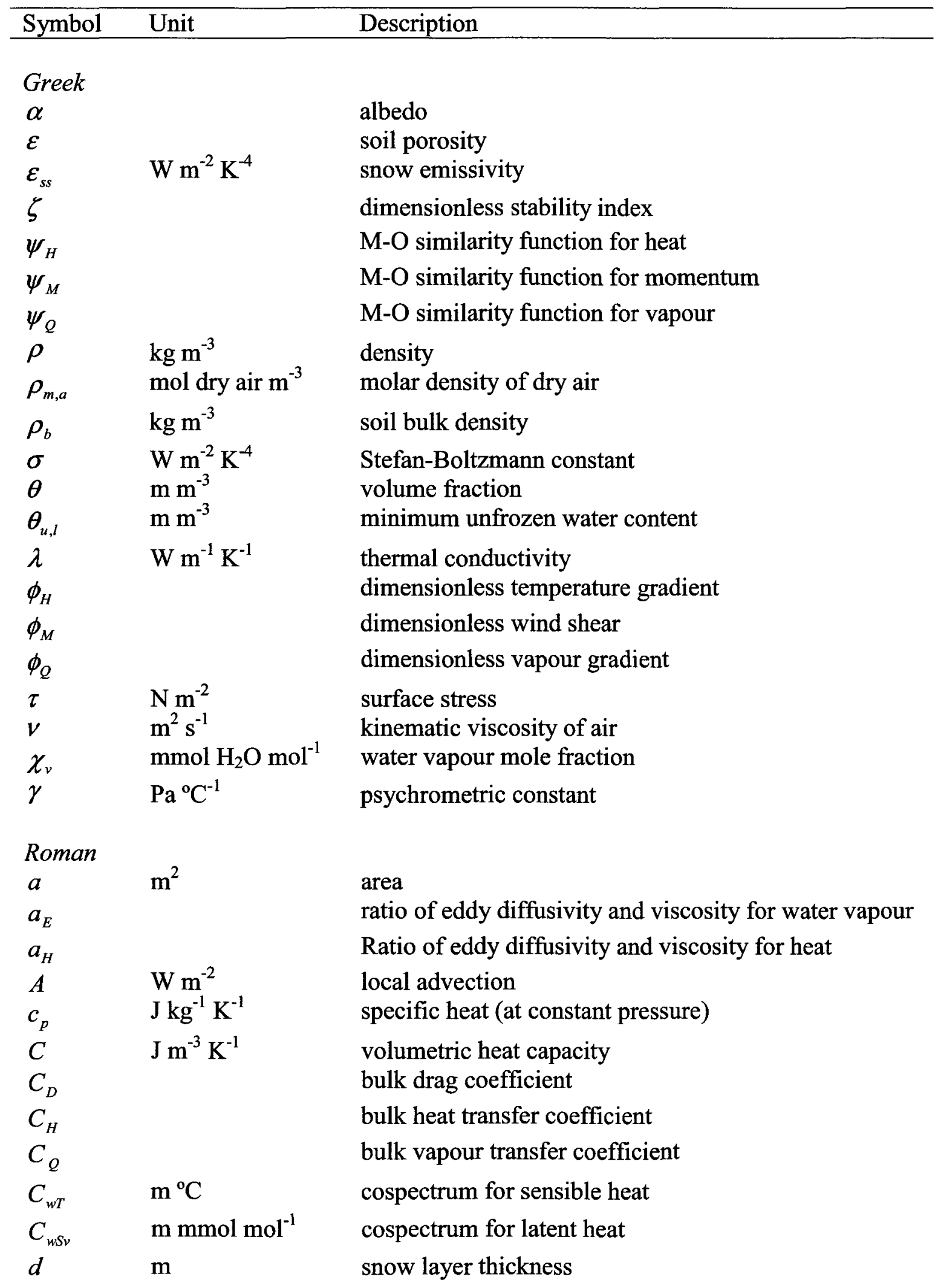




\begin{tabular}{|c|c|c|}
\hline$d_{0}$ & $\mathrm{~m}$ & zero-plane displacement \\
\hline$D_{0}$ & $\mathrm{~m}^{2} \mathrm{~s}^{-1}$ & $\begin{array}{l}\text { effective vapour diffusion coefficient at sea level air } \\
\text { pressure and } 0.0^{\circ} \mathrm{C}\end{array}$ \\
\hline$D_{e}$ & $\mathrm{~m}^{2} \mathrm{~s}^{-1}$ & effective vapour diffusion coefficient \\
\hline $\begin{array}{l}e \\
E \\
F_{s}\end{array}$ & $\begin{array}{l}\mathrm{Pa} \\
\left(\mathrm{kg} \mathrm{m}^{-2} \mathrm{~s}^{-1}\right)\end{array}$ & $\begin{array}{l}\text { vapour pressure } \\
\text { evaporation mass flux } \\
\text { advection efficiency term }\end{array}$ \\
\hline$f$ & $\mathrm{~Hz}$ & frequency or weighing factor (dimensionless) \\
\hline$f_{c o}$ & $\mathrm{~Hz}$ & cut-off frequency \\
\hline$g$ & & shape factor \\
\hline $\begin{array}{l}g \\
G\end{array}$ & $\begin{array}{l}\mathrm{m} \mathrm{s}^{-2} \\
\mathrm{~W} \mathrm{~m}^{-2}\end{array}$ & $\begin{array}{l}\text { acceleration due to gravity } \\
\text { ground heat flux }\end{array}$ \\
\hline$H$ & $\mathrm{~W} \mathrm{~m}{ }^{-2}$ & sensible heat flux \\
\hline$H_{b}$ & $\mathrm{~W} \mathrm{~m}^{-2}$ & sensible heat from the bare areas \\
\hline $\begin{array}{l}J \\
k\end{array}$ & $\mathrm{~W} \mathrm{~m}^{-2}$ & $\begin{array}{l}\text { rate of total energy storage in the air } \\
\text { von Karman constant }\end{array}$ \\
\hline$K \downarrow$ & $\mathrm{W} \mathrm{m} \mathrm{m}^{-2}$ & incoming short-wave radiation flux \\
\hline$K \uparrow$ & $\mathrm{W} \mathrm{m} \mathrm{m}^{-2}$ & outgoing short-wave radiation flux \\
\hline$K_{e}$ & $\mathrm{~J} \mathrm{~m}^{-1} \mathrm{~K}^{-1} \mathrm{~s}^{-1}$ & effective thermal conductivity (SNOBAL) \\
\hline $\begin{array}{l}K \\
L \downarrow\end{array}$ & $\begin{array}{l}\mathrm{J} \mathrm{m}^{-1} \mathrm{~K}^{-1} \mathrm{~s}^{-1} \\
\mathrm{~W} \mathrm{\textrm {m } ^ { - 2 }}\end{array}$ & $\begin{array}{l}\text { base thermal conductivity (SNOBAL) } \\
\text { incoming long-wave radiation flux }\end{array}$ \\
\hline$L \uparrow$ & $\mathrm{W} \mathrm{m}^{-2}$ & outgoing long-wave radiation flux \\
\hline$L_{f}$ & $\mathrm{~J} \mathrm{~kg}^{-1}$ & latent heat of fusion \\
\hline$L_{v}$ & $\mathrm{~J} \mathrm{~kg}^{-1}$ & latent heat of vapourization or sublimation \\
\hline$L_{v} E$ & $\mathrm{~W} \mathrm{~m}^{-2}$ & latent heat flux \\
\hline $\begin{array}{l}M \\
M_{a}\end{array}$ & $\begin{array}{l}\mathrm{W} \mathrm{m} \mathrm{m}^{-2} \\
\mathrm{~g} \mathrm{~mol}^{-1}\end{array}$ & $\begin{array}{l}\text { energy due to advection from external sources } \\
\text { molecular weight of dry air }\end{array}$ \\
\hline$M_{v}$ & $\mathrm{~g} \mathrm{~mol}^{-1}$ & molecular weight of water vapour \\
\hline $\begin{array}{l}\text { MLT } \\
n\end{array}$ & (m) & $\begin{array}{l}\text { melt during a given time period } \\
\text { total number of observations }\end{array}$ \\
\hline$P$ & & fraction of the site \\
\hline$q$ & $\mathrm{~g} \mathrm{~kg}^{-1}$ & specific humidity \\
\hline$\Delta Q$ & $\mathrm{~W} \mathrm{~m}{ }^{-2}$ & change in internal energy content of the snowpack \\
\hline$r$ & $\mathrm{~mm} \mathrm{~d}^{-1}$ & rainfall rate \\
\hline$r^{2}$ & & coefficient of determination \\
\hline$R_{a}$ & $\mathrm{~W} \mathrm{~m}^{-2}$ & available energy flux density \\
\hline$R_{f}$ & $\mathrm{~m} \mathrm{~s}^{-1}$ & rate of freezing \\
\hline$R_{m}$ & $\mathrm{~m} \mathrm{~s}^{-1}$ & rate of melting \\
\hline$R_{n}$ & $\mathrm{~W} \mathrm{~m}^{-2}$ & net radiation flux density ( $K \downarrow-K \uparrow+L \downarrow-L \uparrow)$ \\
\hline$R$. & & roughness Reynold's number \\
\hline
\end{tabular}




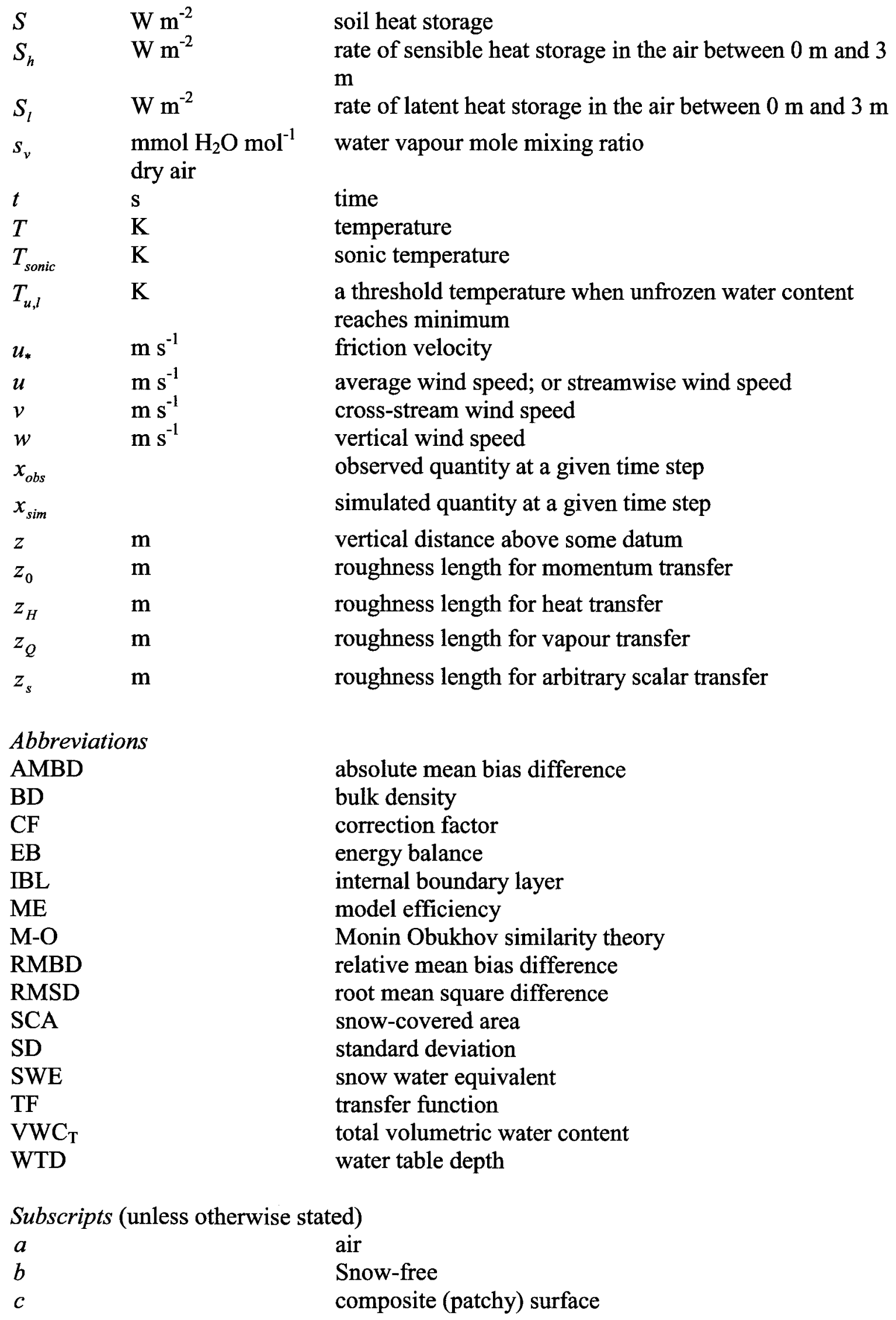




\begin{tabular}{ll} 
app & apparent \\
$f$ & frozen \\
$g$ & ground \\
$i$ & ice \\
$m$ & melt \\
$o$ & organic \\
$q$ & vapour \\
$r$ & reference depth/rain \\
$s$ & snow/ solid/snow-covered \\
$s, 0$ & SNOBAL upper snow layer \\
$s, l$ & SNOBAL lower snow layer \\
$s s$ & snow surface \\
$t$ & temperature \\
$u$ & unfrozen/wind \\
$v$ & vapour \\
$w$ & liquid water \\
$z$ & reference height \\
\hline
\end{tabular}




\subsection{Introduction}

The energy exchange between the base of the snowpack and the ground (i.e. the ground heat flux, $G$ ) is often considered a negligible component of the daily or weekly energy balance (EB) of a snowpack when compared to radiative and turbulent fluxes (Male and Gray, 1981; Oke, 1987). However, Mazurkiewicz et al. (2008) found that in the Pacific Northwest, modelled ground heat flux contributed a large amount of energy to the snowpack (up to $29 \%$ ) over the entire simulation period. These large inputs reflected the positive temperatures that were measured in the soil profile throughout the winter. Modelled ground heat flux has also been found to be important early in the snow season as energy is released from the soil as it cools and freezes (Marks and Dozier, 1992; Link and Marks; 1999a; Sensoy et al., 2006). However, direct observations of $G$ throughout the snow-covered period are rare and were not available to support model results. Smith et al. (2008) found that in a mountainous catchment in southeast British Columbia, snowmelt, as measured with lysimeters, regularly exceeded $1 \mathrm{~mm} \mathrm{~d}^{-1}$ at several sites while daily maximum air temperatures were well below zero, suggesting that $G$ generated the mid-winter snowmelt, but again $G$ was not directly measured.

The ground heat flux in northern peatlands may be considerably greater than in other environments, as the deep saturated soils represent a large thermal mass that can remain unfrozen under an appreciable snow cover (Lafleur et al., 2003). However, past studies have focused on both measuring and modelling the snow cover energy and mass balance in mountainous, tundra, prairie, and forested terrain (Ohmura, 1982; Male and Gray, 1981; Marks and Dozier, 1992; Harding and Pomeroy, 1996; Marsh and Pomeroy, 1996; Pomeroy et al., 1998; Nakai et al., 1999; Link and Marks, 1999a; Marks et al., 
2008), and studies investigating the snow cover energy balance in northern peatlands are lacking.

Northern peatlands are located primarily in Canada, the USA, Russia, many of the former Soviet republics, and the Fennoscandian countries, and comprise over $80 \%$ of the world's peatlands (Gorham, 1991). These ecosystems have important ecological, social, political, and economic significance: they contain up to one-third of the world's soil carbon and may play an important role in the global carbon budget (Lafleur et al., 2003); they are used extensively by waterfowl and a wide variety of mammals (Mitsch and Gosselink, 2007); they are valued for their capacity to store, filter and provide water (Mitsch and Gosselink, 2007), and they are used for agriculture, forestry and peat extraction (Gorham, 1991). Snow is an integral component of these environments and greatly influences many aspects of peatland processes (Laudon et al., 2007).

Snow generally comprises a large fraction of the annual precipitation of these ecosystems, covering the landscape for a significant portion of the year (Laudon et al., 2007). The snow cover has a strong influence on winter emissions of $\mathrm{CO}_{2}$ from these environments, which are thought to represent a significant component of the annual carbon balance (Bubier et al., 2002; Lafleur et al., 2003). Seasonal snow cover effectively insulates the soils from extreme freezing temperatures and thus is one of the critical factors influencing ground thermal regimes (Zhang, 2005). Studies have shown that winters with more snowfall yield larger $\mathrm{CO}_{2}$ emissions than those with less snowfall since a thicker snowpack generally results in warmer soil temperatures, which in turn promotes decomposition, whereas a thin snow cover reduces winter $\mathrm{CO}_{2}$ losses due to cooler soil temperatures (Lafleur et al., 2003). 
In addition, the hydrology of these environments is typically dominated by snowmelt during spring and early summer, which can comprise over $50 \%$ of the total annual water yield (Laudon et al., 2007). The timing, volume, and duration of snowmelt affect water table depth, flow patterns, and flooding which in turn influence the biogeochemistry, sediment and nutrient transport of these systems, and are major factors in determining the biota of peatlands (Mitsch and Gosselink, 2007). Climate change is likely to affect snow cover in northern latitudes (Bubier et al., 2002), which may have important repercussions for peatland functioning (Mitsch and Gosselink, 2007). Since snow is a critical component of these important ecosystems, it is therefore significant to investigate the processes governing snow accumulation and snowmelt in these environments.

The objectives of this study are two-fold: first, this study seeks to characterize mass and energy exchange at the snow surface in a northern peatland in order to quantify the potentially important role of ground heat flux to snow energy budgets. A thorough investigation of the snow cover energy balance at the Mer Bleue peatland (Ottawa, $45^{\circ} 40^{\prime} \mathrm{N}, 75^{\circ} 50^{\prime} \mathrm{W}$ ) is conducted over a near complete snow season (21 December 2009 to 12 March 2010). Each form of energy transfer (radiation, sensible and latent heat flux, ground heat flux and heat flux by mass advection) is measured directly to quantify its relative importance in the seasonal energy balance. Particular emphasis is placed on the ground heat flux as this term is hypothesized to be greater in peatlands than in other environments due to warm soils.

Second, a widely applied and validated point energy balance snowmelt model (SNOBAL) is used to simulate the mass and energy balance of the snow cover. 
Simulated fluxes are compared with observations with the objective of providing an evaluation of model components that could lead to an improved modelling approach. This is one of the few studies where continuous measurements of $G$ are available to compare with modelled $G$. This study also provides an opportunity to compare modelled and measured turbulent fluxes over snow as few datasets such as this exist for model comparison or validation (Marks et al., 2008). There is considerable interest in being able to better model the interactions between the snow cover and the atmosphere/soil including improved prediction of snowmelt rates for hydrological purposes, and a better determination of land surface - atmosphere interactions for climate modelling and weather predictions. 


\subsection{Background and Theory}

\subsection{Energy Exchange at the Snow Surface}

The energy balance equation (2.1) is the fundamental physical framework for snowmelt studies (Pomeroy et al., 2007). In a seasonal snowpack, newly fallen snow is thermodynamically unstable, and undergoes a process of metamorphism that continues until melting is complete (Colbeck, 1982). Various mechanisms are responsible for this process (c.f. Male and Gray, 1981; Dingman, 1994), and nearly all the processes of metamorphism lead to a progressive increase in density throughout the snowaccumulation period. These metamorphic changes and final melting of the snowpack are driven by temperature and vapour density gradients within the snowpack, which are caused by heat exchange at the snow surface and at the snow-soil interface (Colbeck et al., 1979; Male and Gray, 1981). The energy balance of a snowpack may be defined as:

$$
\Delta Q=R_{n}+H+L_{\nu} E+G+M
$$

where $\Delta Q$ is the change in snowpack energy $\left(\mathrm{W} \mathrm{m}^{-2}\right), R_{n}$ is net radiation $\left(\mathrm{W} \mathrm{m}^{-2}\right), H$ is turbulent flux of sensible heat $\left(\mathrm{W} \mathrm{m}^{-2}\right), L_{v} E$ is turbulent flux of latent heat $\left(\mathrm{W} \mathrm{m}^{-2}\right), G$ is ground heat flux $\left(\mathrm{W} \mathrm{m}^{-2}\right), M$ is the energy due to advection from external sources $\left(\mathrm{W} \mathrm{m}^{-2}\right)$, such as heat added by falling rain and heat derived from patches of soil lying adjacent to patches of snow. This equation is applied to a volume of snow whose upper and lower boundaries are the snow-air and snow-ground interfaces respectively (Male and Gray, 1981) (Figure 2.1). The sign convention followed throughout the thesis is that fluxes directed towards the snowpack are positive, and those directed away from the snowpack are negative. 


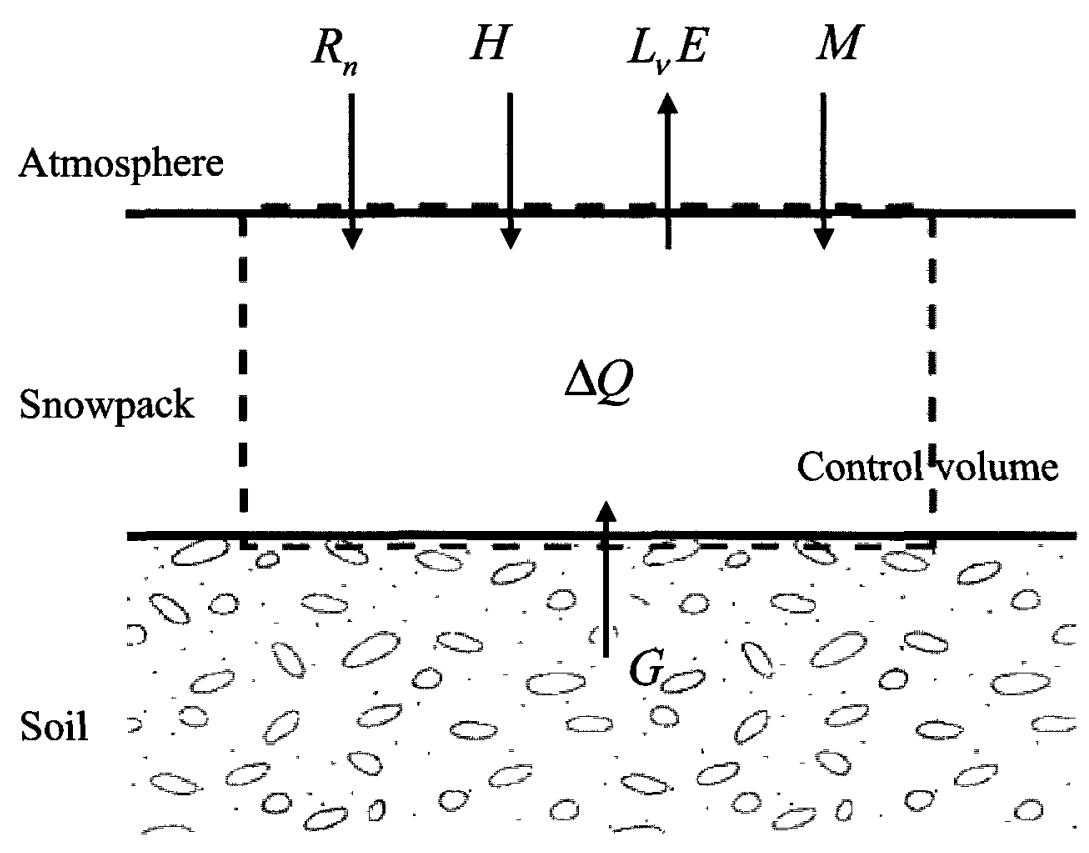

Figure 2.1: Conceptual diagram of the energy fluxes at the snow-air and snow-ground interface (modified from Helgason, 2009).

The period when snowpack water equivalent (SWE) (i.e. the depth of water that would result from the complete melting of the snowpack) increases is the accumulation period (Male and Gray, 1981). During this period, the net inputs of energy to the snowpack are typically negative and the mean temperature of the snow is decreasing (Marks and Dozier, 1992). The melt period of a seasonal snowpack starts when the net input of energy to it becomes more or less continuously positive, and it can be divided into three phases (Dingman, 1994): (i) the warming phase, during which the mean snowpack temperature increases steadily until the entire snowpack has reached $0^{\circ} \mathrm{C}$ (i.e. isothermal); (ii) the ripening phase, throughout which melting occurs, but the meltwater is retained in the snowpack, and once this phase is complete, the snowpack is isothermal at $0^{\circ} \mathrm{C}$ and cannot retain any more liquid water; (iii) the output phase during which additional inputs of energy result in water output. Melt is primarily considered to occur 
at or near the surface of the snow since this is where the majority of the energy available for melt arrives. Most studies report that during melt, the radiation fluxes are generally greater than sensible and latent heat fluxes, which are in turn larger than advective and ground heat fluxes (Male and Gray, 1981; Kuusisto, 1986). Each term in the energy balance equation will be discussed in greater detail below.

\subsection{Net Radiation at the Snow Surface}

Radiative inputs of energy are typically the most important energy exchange mechanisms for melt (Male and Gray, 1981; Link and Marks, 1999a). Radiative heat transfer consists of absorption and reflection of incoming solar radiation $(0.2-3.0 \mu \mathrm{m})$ and absorption and emission of longwave radiation $(3.0-50 \mu \mathrm{m})$. The net all-wave radiation $\left(R_{n}\right)$ is given by:

$$
R_{n}=K \downarrow-K \uparrow+L \downarrow-L \uparrow
$$

where $K \downarrow$ is the flux of solar energy incident on the snowpack surface (W m${ }^{-2}$ ) and $K \uparrow$ is the reflected flux $\left(\mathrm{W} \mathrm{m}^{-2}\right)$; and $L \downarrow$ is the incident flux emitted by the atmosphere, clouds, and overlying canopy $\left(\mathrm{W} \mathrm{m}^{-2}\right)$ and $L \uparrow$ is the outgoing radiation from the snowpack $\left(\mathrm{W} \mathrm{m}^{-2}\right)$.

Shortwave radiation exchange is strongest at the snow surface, however, due to the translucent nature of snow, transmission of solar radiation into the snowpack is quite important. The downward flux of solar radiation extinguishes roughly exponentially with depth due to absorption and scattering (Wiscombe and Warren, 1980; Male and Gray, 1981). Incoming solar radiation is a function of latitude, season, aspect, slope, cloud cover, and the radiative transmissivity of the atmosphere (Male and Gray, 1981; Tarboton 
and Luce, 1996). Shortwave energy fluxes are strongly influenced by the snow albedo. The albedo of snow is generally greatest after a fresh snow event, in the range of $80-90 \%$, but can be as low as $50 \%$ for old, wet snow (Male and Gray, 1981). The albedo of snow varies widely depending on factors such as particle size, snowpack wetness, impurities, direction of incoming radiation, and snowpack depth (Warren and Wiscombe, 1980; Wiscombe and Warren, 1980; Gray and Landine, 1987). The albedo of snow also varies with wavelength, being highest for the shortest wavelengths and decreasing substantially in the near infra-red (Oke, 1987).

Snow albedo decreases as grain size and liquid water content increases (Wiscombe and Warren, 1980; Warren, 1982). In addition, small highly absorbing particles, such as dust and soot, present in concentrations of less than 1 part per million by weight can lower snow albedo in the visible waveband by as much as $5-15 \%$ (Warren and Wiscombe, 1980). As with most surfaces, the albedo of snow increases as sun nears the horizon due to more specular reflection at high zenith angles (Warren, 1982). Cloud cover also influences the snow spectral albedo by converting direct radiation into diffuse radiation, thus changing the effective zenith angle since the diffuse fraction has an effective zenith angle near $50^{\circ}$ (Wiscombe and Warren, 1980).

The snowpack depth is another important factor controlling albedo. In a shallow snow cover, solar radiation can penetrate to the ground surface, and if absorbed may be returned to the snow through conduction or by longwave emission, thus enhancing melt (Gray and Landine, 1987; Baker et al., 1991). Typically there is little penetration of solar radiation below $0.10 \mathrm{~m}$ (Dingman, 1994). However, since the attenuation of radiation by snow is dependant on several factors such as particle size, density, structure, wetness, 
foreign matter content and wavelength, it is difficult to estimate an exact depth below which the ground influences the energetics of a snowpack (Gray and Landine, 1987). Vegetation protruding above the snow surface also affects albedo. Pomeroy and Granger (1997) found that in shrub-covered clearings of the boreal forest, net radiation during melt was enhanced as low shrub vegetation was exposed, decreasing albedo. Similar findings were reported by Pomeroy et al. (2006) over arctic shrub tundra; as short shrubs became exposed due to melt, net radiation increased with increasing shrub exposure due to the decreased reflectance of shortwave radiation despite the increased longwave emission from relatively warm and dark shrubs.

Due to topographic effects, incoming solar radiation is spatially variable. This is important in both mountainous (Marks et al., 1992) and low relief regions (Pohl and Marsh, 2006). Pohl et al. (2006a) found that small-scale variations in solar radiation could lead to differences in melt of up to $50 \mathrm{~mm}$ snow water equivalent (SWE) within a small arctic basin.

The net longwave radiation exchange occurs at the snow-air interface (Male and Gray, 1981). Incoming longwave radiation is a function of the atmospheric conditions and the temperature and configuration of the surrounding terrain and vegetation (Link and Marks, 1999a). Since the emissivity of snow is spectrally rather flat (Dozier and Warren, 1982), the spectral variability in incoming thermal radiation can be neglected. Considerable effort has gone into development of simple models of thermal irradiance from the atmosphere, but most of these are applicable only to clear sky periods (Marks and Dozier, 1992). Cloud cover increases thermal irradiance at the surface, however, this effect is not easily modelled (Marks and Dozier, 1992). 
Thermal exitance is a function of the snow surface temperature and emissivity. The emissivity of snow ranges between 0.97 and 0.99 , increasing slightly with grain size (Dozier and Warren, 1982). Over the thermal infrared portion of the radiative spectrum snow can be considered a "blackbody" (Zhang, 2005). Nighttime longwave radiation losses under clear skies result in considerable cooling of the snow surface and the development of intense inversions at the surface, consequently, the surface boundary layer over snow-covered surfaces in generally stably stratified (Oke, 1987) However, heat loss from the snowpack is restricted by the small thermal conductivity of the snow.

Net all-wave radiation is the sum of net solar and net thermal radiation (equation ((2.2)). Numerous studies around the world have shown that net radiation is the major energy source for melt, although this varies with time of year, cloud cover, wind conditions, relative humidity, and air temperature (Male and Gray, 1981). Marks and Dozier (1992), found that during snowmelt, $R_{n}$ accounted for $66-90 \%$ of the energy available for melt at two alpine sites near Emerald Lake in the Sierra Nevada of California. Similarly, Hayashi et al., (2005), who monitored all energy exchanges during the snowmelt period in 2004 in Tokachi, Japan, found that $R_{n}$ provided $75 \%$ of the total energy input to melt, while $G$ and $H$ provided the remaining $4 \%$ and $21 \%$, respectively. Twenty percent of the incoming energy was consumed by sublimation, and $80 \%$ went to melt. Cline (1997) made measurements of the surface energy balance of an alpine snowpack in the Colorado front ranges during snowmelt and found that net radiation accounted for $75 \%$ of the energy for melt, while turbulent fluxes accounted for only $25 \%$. Pluss and Mazzoni (1994) also reported that net radiation was the dominant energy 
source of melt in an inner alpine region near Davos, Switzerland. Mazurkiewicz et al. (2008) noted that $R_{n}$ dominated the snowmelt energy balance in the Pacific Northwest, with contributions ranging from $49-80 \%$, but that the annual variability in the EB components reflected the length of the snow-covered period; snowpacks that lingered into the spring resulted in higher radiation as a percentage of total EB components, while transient snowpacks in some years resulted in higher percentages of turbulent fluxes and ground heat flux.

\subsection{Sensible and Latent Heat Fluxes}

The sensible heat flux represents the energy which is transferred through convection (either forced, free, or mixed) between the snow cover and the overlying atmosphere. Evaporation and condensation of liquid water and sublimation of ice occurring at the snow surface comprise latent heat fluxes. Together, $H$ and $L_{v} E$ are referred to as the turbulent fluxes. As snow is a porous medium, turbulent fluxes are generally considered to be a result of temperature conditions some distance into the snowpack, however, there is considerable uncertainty about the effective thickness of the exchange layer within the snow cover (Marks et al., 2008).

Turbulent heat exchanges are generally considered of secondary importance in most situations when compared to radiative exchanges (Male and Gray, 1981; Dingman, 1994). Nonetheless, these fluxes can be more important than net radiation during the accumulation season (Marks and Dozier, 1992) and on cloudy and rainy days and in open, wind-swept environments (Kuusisto, 1986; Marks et al., 1998, Marks et al., 1999). Turbulent fluxes are generally important for determining the rate of melt (Male and Gray, 1981). 
Prior to snowmelt, sensible and latent heat transfer have often been found to be of similar magnitude, but opposite in sign, with $H$ directed toward the snow cover and $L_{v} E$ directed away from the snowpack, resulting in a net turbulent flux near zero (Marks and Dozier, 1992; Marks et al., 1998, Marks et al., 1999; Marks et al., 2008). Marks and Winstral (2001) observed that at a relatively sheltered site at the Reynolds Creek watershed near Boise, Idaho $H$ and $L_{v} E$ approximately cancelled each other during the snow season. However, at the 'ridge' site, where average wind speed was more than twice that of the sheltered site, $H$ was considerably greater in magnitude, and therefore $H+L_{v} E$ was positive and fairly large. Helgason (2009) also observed that sensible heat fluxes tended to be larger than latent heat fluxes over a homogeneous and flat prairie snow cover during mid-winter; a large proportion ( $65 \%)$ of 30 -minute average latent heat fluxes were near zero $\left( \pm 5 \mathrm{~W} \mathrm{~m}^{-2}\right)$, with fluxes rarely exceeding $-15 \mathrm{~W} \mathrm{~m}^{-2}$, whereas $H$ was somewhat larger with fluxes typically less than $30 \mathrm{~W} \mathrm{~m}^{-2}$. Link and Marks (1999a), found that simulated $H$ below boreal forest canopies oscillated in direction during the snow season, while latent heat fluxes tended to be negative throughout the season.

In a review of the turbulent transfer processes over snow and ice surfaces, Morris (1989) found that sensible heat input to the snowmelt energy balance can be up to twice the net radiation during cloudy, warm, and windy periods, although it is often only around $40 \%$ of $R_{n}$, while latent heat fluxes can be of the same order as net radiation, but are generally around $10 \%$. Similar findings were reported by Kuusisto (1986) in a review of over 20 snowmelt studies; on cloudy and rainy days, turbulent heat exchange dominated, and very high snowmelt rates are usually caused by intense positive turbulent 
heat exchange. Marks et al. (1998) and Marks et al. (2001) found that during a large rainon-snow (ROS) event in the Owyhee Mountains in the Pacific Northwest (PNW) of the USA, sensible and latent heat exchanges contributed $60-90 \%$ of the energy available for melt due to high temperatures, humidity and relatively high winds. This event generated significant snowmelt from open sites. Marks and Winstral (2001) noted that $H$ was the dominant form of energy input to the snow cover during melt at the ridge site, since meltout occurred when net radiation was small and still negative.

Snow sublimation is also an important component of regional water balances. Since snowmelt often plays a critical role in regulating annual runoff, winter sublimation losses can have an important role on the hydrology of cold regions. Measurements by Bengtsson (1980) in Sweden showed that mean springtime sublimation from a snowpack was $0.36 \mathrm{~mm} \mathrm{~d}^{-1}$, as measured with lysimeters. Based on these measurements and other theoretical considerations, the author estimates that seasonal sublimation rarely exceeds 10 to $20 \mathrm{~mm}$ in northern regions, nonetheless $L_{v} E$ is still of great importance since it limits the input of sensible heat available for snowmelt. Hayashi et al. (2004) found that sublimation rates calculated during melt in an open field for the years 1997-2004 were on average $0.24 \mathrm{~mm} \mathrm{~d}^{-1}$, but could be as high as $2.2 \mathrm{~mm} \mathrm{~d}^{-1}$, indicating that typically sublimation plays a somewhat minor role in the overall water balance of the snowpack. Surface sublimation rates during mid-winter periods have been estimated to be $0.1 \mathrm{~mm}$ $\mathrm{d}^{-1}$ on average for a prairie snow cover (Male and Granger, 1979), between 0.14 and 0.29 $\mathrm{mm} \mathrm{d}^{-1}$ in the Sapporo region of Japan (Kojima et al., 1985), $0.21 \mathrm{~mm} \mathrm{~d}^{-1}$ and $0.41 \mathrm{~mm}$ $\mathrm{d}^{-1}$ at subalpine sites of the Rocky Mountains of Colorado (Marks et al., 2008 and 
Molotch et al., 2007, respectively), and $0.75 \mathrm{~mm} \mathrm{~d}^{-1}$ in open mountainous locations (Fassnacht, 2004).

Blowing snow events also cause significant sublimation loss of snow, since snow particles transported by wind are well ventilated and undergo sublimation in an unsaturated atmosphere (Pomeroy et al., 1993). Blowing snow sublimation losses on the order of $15-41 \%$ of annual snowfall have been reported for the Canadian prairies (Pomeroy and Gray, 1995), 28\% of the annual snowfall over western Canadian Arctic tundra (Pomeroy et al., 1997), and 18-25\% of winter precipitation over the Alaskan Arctic (Liston and Strum, 2002).

Currently, the most direct method of measuring turbulent transfer over snow is with the eddy covariance (EC) method (Baldocchi et al., 1988). The EC technique will be presented in more detail in Chapter 3. This methodology has been shown to successfully measure turbulent fluxes over snow (Harding and Pomeroy, 1996; Nakai et al., 1999; Turnipseed et al., 2002; Pomeroy et al., 2003; Lee and Mahrt, 2004; Mahrt and Vickers, 2005a; Mahrt and Vickers, 2005b; Molotch et al., 2007; Marks et al., 2008; Reba et al, 2009). Reba et al. (2009) evaluated eddy covariance data collected over three snow-seasons and found no unique issues associated with applying the EC technique of snow-covered surfaces, but advised that the full suite of corrections and post-processing, including data filtering, air density corrections, sensor heating, axis rotation, and exclusion of nonstationary data, be applied to obtain flux observations which are of sufficient reliability for snow hydrology. Helgason (2009) also found that at moderate to high wind speeds, the turbulent fluxes were well defined by the 30 -minute averaging period, the co-spectra were similar to the neutral Kansas data (Kaimal et al., 1972), and 
there was no obvious reason to consider these fluxes as incorrect from turbulent characteristics alone. Helgason (2009) did, however, observe a large EB residual, which he took to indicate that the EC technique was unable to capture all of the turbulent energy. He concluded that an unmeasured transfer of sensible heat was occurring which was strongly correlated with the longwave radiation balance, and hypothesized mechanisms for this relationship.

Due to the complexities and cost of the EC method, turbulent fluxes are frequently determined using a simplified set of turbulent transport equations, along with some variation of a first order turbulence closure scheme (e.g. flux-gradient, K-theory, bulk transfer method), with the Monin-Obukhov (M-O) similarity theory used to account for the effect of density stratification on the flow. These techniques are presented in detail by numerous authors (e.g. Garratt, 1992; Brutsaert, 2005; Helgason, 2009), however a brief description of the technique is provided here using the bulk transfer method as an example. From equations $(2.3)-(2.5)$, the surface stress $\left(\tau, \mathrm{N} \mathrm{m}^{-2}\right)$, the sensible heat flux $\left(H, \mathrm{~W} \mathrm{~m} \mathrm{~m}^{-2}\right)$ and the latent heat flux $\left(L_{v} E, \mathrm{~W} \mathrm{~m}^{-2}\right)$ can be determined from wind speed $\left(u, \mathrm{~m} \mathrm{~s}^{-1}\right)$ at a reference height (subscript $\left.z\right)$, and gradients of temperature $(T, \mathrm{~K})$ and specific humidity $\left(q, \mathrm{~g} \mathrm{~kg}^{-1}\right)$ between the reference height and the snow surface (subscript $s$ ):

$$
\begin{aligned}
& \tau=C_{D} u_{z}{ }^{2} \\
& H=\rho_{a} c_{p, a} C_{H} u_{z}\left(T_{z}-T_{s}\right) \\
& L_{\nu} E=\rho_{a} L_{\nu} C_{Q} u_{z}\left(q_{z}-q_{s}\right)
\end{aligned}
$$

where $\rho_{a}$ is the density of air $\left(\mathrm{kg} \mathrm{m}^{-3}\right), c_{p, a}$ is the specific heat of air at constant 
pressure $\left(\mathrm{J} \mathrm{kg}^{-1} \mathrm{~K}^{-1}\right), L_{v}$ is the latent heat of vapourization or sublimation $\left(\mathrm{J} \mathrm{kg}^{-1}\right)$, and $C_{D}, C_{H}$, and $C_{Q}$ are the bulk transfer coefficients for momentum, sensible heat, and water vapour, respectively. In order to calculate fluxes using equations $(2.3)-(2.5)$ it is necessary to determine the bulk transfer coefficients that depend on both surface roughness and atmospheric stability.

The bulk transfer coefficients are related to the integrated forms of the surface layer similarity theory by:

$$
\begin{aligned}
& C_{D}=k^{2}\left[\ln \left(\frac{z}{z_{0}}\right)-\psi_{M}\left(\frac{z}{L}\right)\right]^{-2} \\
& C_{H}=k^{2}\left[\ln \left(\frac{z}{z_{0}}\right)-\psi_{M}\left(\frac{z}{L}\right)\right]^{-1}\left[\ln \left(\frac{z}{z_{H}}\right)-\psi_{H}\left(\frac{z}{L}\right)\right]^{-1} \\
& C_{Q}=k^{2}\left[\ln \left(\frac{z}{z_{0}}\right)-\psi_{M}\left(\frac{z}{L}\right)\right]^{-1}\left[\ln \left(\frac{z}{z_{Q}}\right)-\psi_{Q}\left(\frac{z}{L}\right)\right]^{-1}
\end{aligned}
$$

$k$ is the von Karman constant $(0.40), z_{0}, z_{H}$, and $z_{Q}$ are the roughness lengths for momentum, heat, and water vapour (all in m) respectively, and $\psi_{M}, \psi_{H}$, and $\psi_{Q}$ are the corresponding integrated forms of the surface layer similarity $\phi_{\xi}$ :

$$
\psi_{\xi}\left(\frac{z}{L}\right)=\int_{\zeta_{0}}^{\zeta}\left(1-\phi_{\xi}(\zeta)\right) \frac{d \zeta}{\zeta} \quad \xi=M, H, Q ; \quad \zeta_{0}=z_{0}, z_{H}, z_{Q}
$$

The surface layer similarity functions $\left(\phi_{\xi}\right)$ express how profiles of wind speed, temperature, and humidity deviate from the logarithmic forms that are observed under neutral conditions. These functions depend only on the dimensionless height $\zeta=z / L$, where $L$ is the Obukhov length (m) defined as: 


$$
L=\frac{u_{*}^{3} \rho_{a}}{k g\left(\frac{H}{T_{a} c_{p, a}}+0.61 E\right)}
$$

and

$$
u_{*}^{2}=\frac{\tau}{\rho_{a}}
$$

where $u_{*}$ is the friction velocity $\left(\mathrm{m} \mathrm{s}^{-1}\right), T_{a}$ is the mean air temperature $(\mathrm{K})$ in the layer of depth $z$, and $g$ is the acceleration due to gravity $\left(9.81 \mathrm{~m} \mathrm{~s}^{-2}\right)$.

A stable boundary layer is a common feature of the atmosphere over a snow cover. The mildly stable boundary layer is still well described by M-O theory (Mahrt, 1999), however, with increasing stability, turbulence near the ground may be greatly reduced due to the suppression of vertical motions, and may become only intermittently turbulent. Under very stable conditions, similarity theories generally fail, which poses a considerable challenge to model development (Mahrt, 1998).

In order to use bulk transfer estimation techniques, parameterization is required in two areas: (1) the stability corrections, and (2) the turbulent transfer coefficients.

With respect to the profile corrections, there are no unique concerns related to the use over snow surfaces per se, however, under increasingly stable conditions, there is considerable uncertainty as to the accuracy of the existing profile functions (Mahrt, 1998). The review of Andreas (2002) recommends using the equations of Holtslag and de Bruin (1988) since they allow flux under very stable conditions (equation (2.12)).

$$
\psi_{M}=\psi_{H}=\psi_{Q}=-0.7 \zeta-0.75(\zeta-14.29) \exp (-0.35 \zeta)-10.72
$$

The adequate selection of roughness lengths for momentum, heat, and water vapour is also key to parameterizing turbulent transport. However, their values over 
snow and ice are still unclear. The starting point for discussion of the theory for heat transfer coefficients if that of Andreas (1987), since it is one of the few theories developed specifically for application over snow and ice surface. The model's basic result is an equation that predicts the scalar roughness $\left(z_{s}\right.$, i.e. $z_{H}$, and $\left.z_{Q}\right)$ from the roughness Reynold's number $R_{*}=\frac{u_{*} z_{0}}{v}$, where $v$ is the kinematic viscosity of air $\left(\mathrm{m}^{2}\right.$ $\mathrm{s}^{-1}$ ) (Figure 2.2). A distinction is made between aerodynamically smooth and rough surfaces. If $R_{*} \leq 0.135$, the surface roughness elements are imbedded in the viscous sublayer and the surface is aerodynamically smooth. In this case, $z_{s}>z_{0}$ and $z_{s} / z_{0}$ is independent of $R_{*}$ since molecular effects control the exchange of both momentum and scalars (i.e. both scale similarly with $u_{*}$ ). If $R_{*} \geq 2.5$, the roughness elements poke through the viscous sublayer and the surface is aerodynamically rough. For aerodynamically rough flow, the viscous boundary layer continually thins with increasing $u_{*}$, the surface roughness elements protrude farther above this layer, and pressure forces become more important in transferring momentum. In this case, $z_{0}$ increases with $u_{*}$, while $z_{s}$ does not change as rapidly. Hence, $z_{s} / z_{0}$ is a monotonically decreasing function of $R_{*}$ for rough flow, and $z_{s}<z_{0}$. 




Figure 2.2: Roughness length ratios as described by the Andreas (1987) model.

Although Andreas (1987) initially presented this theory with little support from measurements, he has since provided more support in Andreas (2002) where he reexamined several previously published datasets from the literature. However, there is substantial scatter (order of magnitude) within the log-log plots of $z_{s} / z_{0}$ vs. $R_{*}$, suggesting that considerable uncertainty remains. In addition, other authors have noted dissimilar findings. King and Anderson (1994) found that $z_{H}$ was substantially larger than $z_{0}$ for measurements over an ice shelf in Antarctica and Calanca (2001) observed erratic $z_{H}$ values that were much larger than $z_{0}$ as measured on the Greenland ice sheet for melting conditions. Helgason (2009) presents a few examples of measurement of the roughness lengths of momentum and heat (refer to Table 2.1). In general, the data do support that the roughness lengths for heat are usually smaller than that of momentum since natural surfaces are generally aerodynamically rough. The exception is King and Anderson (1994) who found the opposite. Nonetheless, as values of $z_{H}$ and $z_{Q}$ are still 
under discussion in the literature, in many studies the values of the roughness lengths are set as being equal (e.g. Arck and Schierer, 2002).

\subsection{Ground Heat Flux}

The ground heat flux represents the energy exchange between the bottom of the snow cover and the underlying medium (e.g. soil, peat, or rock). During the snowmelt season, the ground heat flux is usually small compared with the other EB terms (Male and Gray, 1981; Dingman, 1994; Pomeroy et al., 1998). During this period, soil temperatures are generally near $0^{\circ} \mathrm{C}$ with melt water removing the remaining temperature gradient (Dingman, 1994). Daily average ground heat fluxes generally fall in the range of 0 to $4.6 \mathrm{~W} \mathrm{~m}^{-2}$ (Pomeroy et al., 1998).

Although $G$ may be a minor component in daily or weekly energy balance of a snowpack, it does not normally change direction throughout the winter months and consequently its cumulative effect can be significant over a season (Male and Gray, 1981). During the accumulation season, this flux also influences the temperature regime of snow near the ground surface and contributes to the conditioning of the snowpack for melt. In regions where snow temperatures remain near zero, melt can be generated as a result of the ground heat flux (Male and Gray, 1981). Male and Gray (1981) and Smith et al. (2008) found that $G$ can produce melting at the base of the snowpack (i.e. ground melt), at rates exceeding $1 \mathrm{~mm} \mathrm{~d}^{-1}$. Even if the amount of water produced from ground melt is small, its effect on the thermal properties and infiltration characteristics of the underlying soil may be significant. The ground heat flux also affects the state of the soil (i.e. unfrozen, partially or entirely frozen), which in turn influences the infiltration rate at the time of melt (Male and Gray, 1981). 
There are times during the winter when the ground heat flux has been found to be quite important. It is important to note that the studies described below, except that of Pomeroy and Essery (1999), are based on modelled results using a physically based snow energy and mass balance model (SNOBAL); few studies have measured $G$ for the entire snow season as most studies have focused on the snowmelt period. Several studies have found large ground heat fluxes early in the snow season as energy is released from the soil as it cools and freezes. Link and Marks (1999a) found that earlier in the snow season, the ground heat flux at sites in the boreal forest comprised up to $50 \%$ of the energy balance. Marks and Dozier (1992), at Emerald Lake in the Sierra Nevada Mountains, found that on a monthly time scale $G$ made up $12 \%$ of the snow EB in November. The authors also commented that although $G$ was small, it produced significant melt during midwinter. Sensoy et al. (2006) also found that the ground heat flux occasionally accounted for over $50 \%$ of the 5 day average energy balance early in the snow season.

Pomeroy and Essery (1999) reported a large ground heat flux $\left(15-20 \mathrm{~W} \mathrm{~m}^{-2}\right)$ during a blowing snow event from 31 December, 1998 to 1 January, 1999 at Kernen Farm near Saskatoon, Canada; measured $G$ was often greater than the other EB components, and thus provided a relatively large and steady source of energy to the snowpack during the event.

Marks and Winstral (2001) found that at the ridge site, $G$ was approximately the same magnitude as net radiation during melt, but of opposite sign, therefore essentially cancelling it. As noted above, this was the result of melt-out occurring prior to the 
crossover from negative to positive net radiation, and sensible heat flux was the dominant form of energy input to the snow cover during melt.

Mazurkiewicz et al. (2008) found that the ground heat flux is an important component of the snow energy balance in the Pacific Northwest. On an annual time scale, ground heat flux contributions to melt ranged from $8-55 \%$ at the upper site and from $42-85 \%$ at the lower site. Soil temperature measurements did not go below freezing throughout the winter, which caused the modelled ground heat flux to be a significant potion of the energy budget. $G$ was greatest in low snow years, as shallow snow accumulations in early winter were subject to warm ground temperatures, which caused fast melt out.

Temperatures in the soil below snowpacks generally increase with depth due to thermal energy stored during the summer and geothermal heat. In these circumstances, the unidirectional conduction of heat to the snowpack is given by:

$$
G=\lambda \frac{\partial T_{g}}{\partial z}
$$

where $\lambda$ is the thermal conductivity of the soil $\left(\mathrm{W} \mathrm{m}^{-1} \mathrm{~K}^{-1}\right), T_{g}$ is the soil temperature $(\mathrm{K})$, and $z$ is the distance below the ground surface (m).

Thermal conductivities of soils depend on soil texture, soil density, and moisture content, and vary considerably spatially and temporally (Dingman, 1994). The latter has an especially strong influence on $\lambda$. Since the thermal conductivity of ice is approximately four times that of water, frozen soils have a somewhat higher $\lambda$ than unfrozen soils with the same moisture content.

The ground heat flux can be measured using several different methods: gradient, calorimetric, combination, or soil heat flux plate. A comprehensive review of ground 
heat flux measurement techniques is given by Sauer and Horton (2005). These are summarized briefly below, and the combination technique is described in detail in Section 3.2.4. The gradient method is a direct application of equation (2.13); in the absence of significant moisture movement, $G$ can be calculated from measurements of the soil temperature profile immediately below the snow cover. The simplicity of this approach is offset by difficulties in obtaining accurate $\lambda$ measurements and it is difficult to make measurements right at the surface since it is irregular and poorly defined. Due to the difficulties in accurately measuring $\lambda$ near the surface, the gradient method is generally applied at a reference depth of at least $0.2 \mathrm{~m}$, where the thermal conductivity is often less variable with time. The calorimetric method is used to account for the rate of change of heat stored in the soil above the reference depth. Coupling the calorimetric and gradient methods is referred to as the combination method.

Alternatively, $G$ can be measured using a soil heat flux plate placed generally 0.02 to $0.10 \mathrm{~m}$ below the soil surface. The change in soil heat storage above the heat flux plate can be accounted for using the calorimetric method.

\subsection{Advected Heat Transfer to the Snowpack}

Advected heat transfer at the snow surface occurs when precipitation (rain or snow), is added to the snow cover. If there is a temperature difference between the snowpack and the added precipitation, the energy transfer is determined by the mass added and the magnitude of the temperature gradient (Marks and Dozier, 1992). If precipitation is warmer than the snowpack, $M$ will be positive. Advection will be relatively small unless the temperature difference is large, which is not usually the case (Marks and Dozier, 1992). Consequently, the heat input from rain tends to be small when 
compared to the seasonal energy balance of the snowpack and is often negligible (Male and Gray, 1981; Marks and Dozier, 1992; Dingman, 1994; Mazurkiewicz et al., 2008).

Due to differential snow accumulation and/or melt, the snow cover often becomes patchy during melt (Marsh and Pomeroy, 1996). When calculating snowmelt over a patchy snow cover, the energy advected from the adjacent bare soil to the snow surface is an important consideration (Weisman, 1977; Liston, 1995; Essery, 1997; Marsh and Pomery, 1996; Shook and Gray, 1997; Neumann and Marsh, 1998; Granger et al., 2002; Granger et al., 2006). Snow-free ground has a substantially lower albedo than snow, and is not constrained by a maximum temperature of $0^{\circ} \mathrm{C}$, so it can become considerably warmer than the surrounding snow, and upward sensible heat fluxes from the bare ground warm the overlying air. As this warmer air flows over a snow patch, heat fluxes are directed downwards, cooling the air and warming the snow; heat is therefore advected from snow-free ground to snow patches, providing an added source of energy for melt around edges of snow patches (Granger et al., 2006). As the air flows over the snow patch, and internal boundary layer (IBL) develops, controlled by the difference in surface propertied between the upwind bare surface and the snow surface (Granger et al., 2002). Above the height of the IBL, the regional boundary layer and vertical turbulent transfer of sensible heat remain unaffected by the underlying snow. Consequently, the air immediately above the snow surface is stable, whereas the regional boundary layer and the air over the exposed surface are generally unstable (Granger et al., 2006). Marsh and Pomeroy (1996) introduced an advection efficiency term $F_{s}$ that quantifies the fraction of sensible heat originating from bare ground areas that is actually advected to adjacent 
snow patches, and Neumann and Marsh (1998) found that $F_{s}$ decreased exponentially with decreasing snow cover fraction.

Local scale advection of sensible heat has been documented in a variety of environments including arctic and alpine tundra, grasslands, and agricultural fields (Olyphant and Isard, 1988; Neumann and Marsh, 1998; Marsh and Pomeroy, 1998;

Granger et al., 2006). Considerable research has also focused on modelling local-scale advection (e.g. Weisman, 1977; Liston, 1995; Essery, 1997; Essery et al., 2006).

Numerical studies have shown that local advection of sensible heat increases melt, with the greatest effect being immediately downwind of the snowpatch edge. Liston (1995) also conducted model studies of advection over multiple snow patches, and found that total advection increased with decreasing patch area and patch size, with a maximum increase in mean melt of $30 \%$. However, measuring and modelling local scale advection in patchy snow-covered areas is complicated by the gradually changing area and size distribution of snow patches during melt.

\subsection{Internal Energy}

The internal energy content of the snow cover $(Q)$ depends on the snow density, the temperature and volume of liquid water. It can be computed for a snow cover with depth $d(\mathrm{~m})$ as equation (2.14), where $\rho$ is density $\left(\mathrm{kg} \mathrm{m}^{-3}\right), c_{p}$ is specific heat $\left(\mathrm{J} \mathrm{kg}^{-1}\right.$ $\left.\mathrm{K}^{-1}\right), \theta$ is the fraction of the volume occupied by a particular constituent $\left(\mathrm{m}^{3} \mathrm{~m}^{-3}\right)$, and $T_{m}$ is the mean snow temperature $(\mathrm{K})$. The subscripts $i, a$, and $w$ refer to ice, air and liquid water, respectively.

$$
Q=d\left(\rho_{i} c_{p, i} \theta_{i}+\rho_{a} c_{p, a} \theta_{a}+\rho_{w} c_{p, w} \theta_{w}\right) T_{m}
$$


During snowmelt, shallow snow covers and the upper layer of deep snowpacks typically exhibit diurnal cycles in melt water release patterns, i.e. snow melts in the late morning and early afternoon, and refreezes during the evening and night (Gray and Landine, 1987). Thus, the nighttime energy deficit must be overcome the following day before the snow cover releases water. For a shallow snow cover, therefore, changes in internal energy directly affect the energy available for melt and the timing of meltwater release (Gray and Landine, 1987).

\subsection{Numerical Snow Models}

From the above discussion, it can be noted that the major state variables which characterize a snow cover are SWE, depth, vertical temperature and density profiles, albedo, and liquid water content. Many snowmelt models have been developed to simulate the evolution of some or all of these variables. Fundamentally, the conservation of energy is the foundation of all snowmelt models (Gray and Landine, 1987), but the complexity of models is highly variable, ranging from: (i) simple index methods (e.g. the

Snowmelt Runoff Model (SRM) (Martinec et al., 1998)); (ii) energy budget methods (e.g. Utah Energy Balance Snow Accumulation and Melt Model (UEB) (Tarboton and Luce, 1996), The Snowcover Energy and Mass-Balance Model (SNOBAL) (Marks and Dozier, 1992), The Spatially Distributed Energy and Mass-Balance Model (ISNOBAL) (Marks et al., 1999), and The Energy-Budget Snowmelt Model (EBSM) (Gray and Landine, 1987;

Gray and Landine, 1988)); (iii) full solutions of the equations of flow of energy and mass (e.g. A One-Dimensional Temperature Model for a Snow Cover (SNTHERM) (Jordan, 1991), and The Simultaneous Heat and Water Model (SHAW) (Flerchinger, 2000)). With regards to modeling turbulent fluxes, some models use empirical relations for $H$ 
and $L_{v} E$ (e.g. Gray and Landing, 1998). However, more recent models typically employ some variation of the bulk transfer method (e.g. SNOBAL, SNTHERM, and UEB).

Etchevers et al. (2004) compared 23 snow models using observed meteorological parameters from two mountainous alpine sites, and focused on validation of the snow energy budget simulations. They found that model complexity was a primary factor affecting the net longwave radiation calculation. Emission of longwave radiation is a function of the temperature of the snow surface which in turn is the result of a complex equilibrium in the snowpack. Thus, the models which explicitly simulate internal snow processes were best able to simulate the snow surface temperature. Conversely, model complexity had little to do with the simulation of the net shortwave radiation; this flux was largely controlled by the albedo parameterization. Albedo parameterization could be classified into three groups: parameterization based on snow age (accurate for melting periods); surface-temperature-based parameterization or a constant albedo value (which were accurate for non-melting periods); more complex parameterization based on snow type and grain characteristics (which generally simulated the differing albedo decrease rates well). This inter-comparison also found that parameterization techniques for turbulent fluxes were highly variable, and that the uncertainty in the estimates were on the same order as the fluxes. Difficulties in estimating turbulent fluxes in winter have thus largely precluded an adequate evaluation of the estimation techniques.

Rutter et al. (2009) evaluated 33 snowpack models of varying complexity and purpose across a wide range of hydrometeorological and forest canopy conditions at five locations in the Northern Hemisphere for up to two winter seasons. Modelled estimates of SWE or depth were compared to observations at forest and open sites. It was found 
that SWE was more difficult to model at forested sites than open sites. In addition, there was no universal "best" model for all sites or locations, and a model which performed well at a forest site was unlikely to perform well at an open site and vice versa. 


\subsection{Methods}

\subsection{Study Site}

The Mer Bleue peatland, located in the Ottawa Valley-St. Lawrence Lowland $\left(45^{\circ} 40^{\prime} \mathrm{N}, 75^{\circ} 50^{\prime} \mathrm{W}\right.$ ) (Figure 3.1), was selected for this study due to its ecological significance as a site for long-term energy, water and carbon studies (Lafleur et al., 2003; Lafleur et al., 2005; Roulet et al., 2007). The climate of the region is cool continental, with a mean annual temperature of $5.8^{\circ} \mathrm{C}$ and annual precipitation of $910 \mathrm{~mm}(78 \%$ of which falls as rain). The snow season at the bog usually extends from December to March, with peak snow accumulations of between 0.6 and $0.8 \mathrm{~m}$. The warmest month is July $\left(20.8^{\circ} \mathrm{C}\right)$ and the coldest month is January $\left(-10.8^{\circ} \mathrm{C}\right)$. Peat accumulation started between 7 and $8.5 \mathrm{kyr}$ BP above $9 \mathrm{~m}$ of marine clay deposited in the glacial Champlain Sea, and the bog phase began $\sim 7100-6800$ years BP (Roulet et al., 2007).

Mer Bleue is a raised ombrotrophic (nutrients fed only by precipitation) bog approximately $2800 \mathrm{ha}$ in area. It is roughly oval in shape and oriented east-west. Two longitudinal lobes of fluvial sand and gravel material dissect the western end of the bog, creating three separate arms. A research site established in May 1998 is located in the north most of these arms. The primary instrument site is a tower located $250 \mathrm{~m}$ from the southern edge of the north arm (Figure 3.2). The eddy covariance technique has been used to measure the fluxes of $\mathrm{CO}_{2}$, heat, and water vapour continuously since the site was established, along with meteorological and environmental data. In this region, the bog is somewhat domed towards the center with peat depths varying from 5-6 $\mathrm{m}$ near the tower site declining to roughly $2 \mathrm{~m}$ at the edge, where a series of small ponds have developed, forming a moat around the bog. Around the instrument site, the bog surface has a 
hummock-hollow microtropography, with an average relief of $0.25 \mathrm{~m}$ between the tops of the hummocks and the hollow bottoms. $70 \%$ of the surface is composed of hummocks which have a median diameter of about $1.0 \mathrm{~m}$. Typically, the water table is at or below the bottom of the hollows and varies considerably during the growing season (Lafleur et al., 2005).

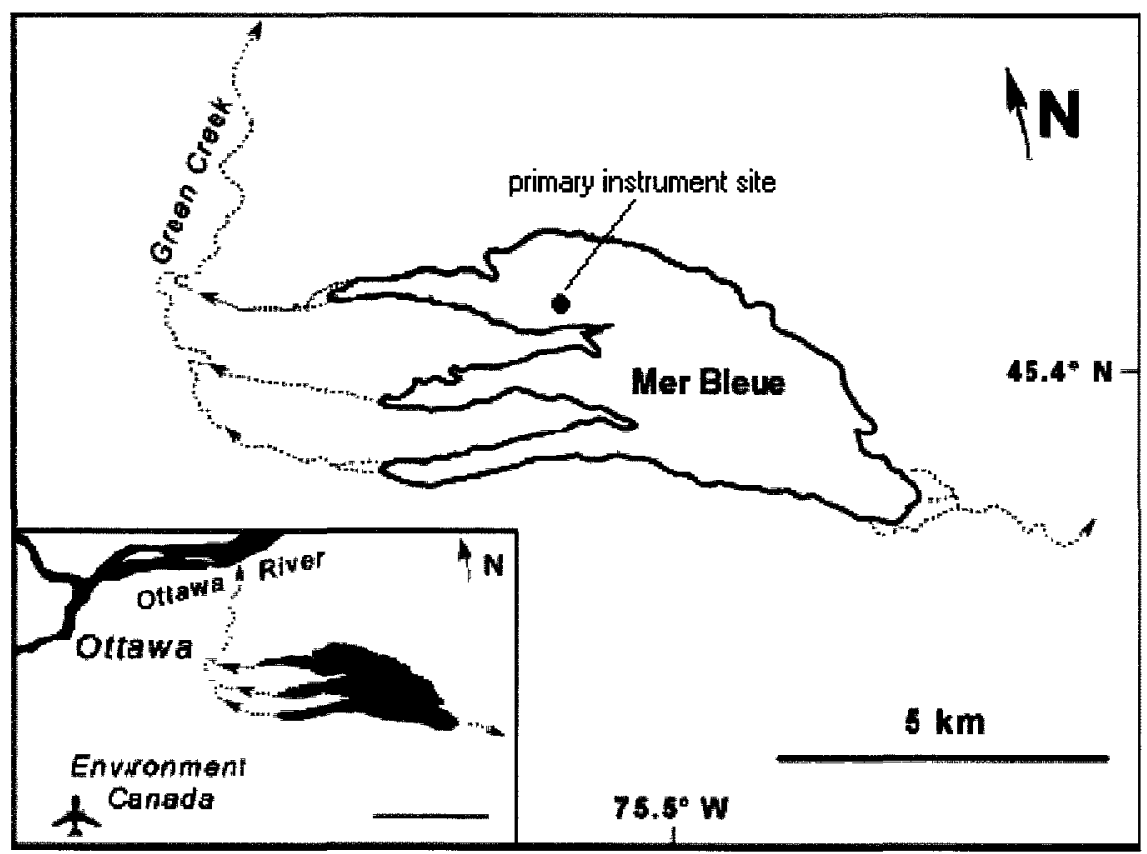

Figure 3.1: Map of the Mer Bleue Bog and research sites (after Roulet et al., 2007).

Vegetation is dominated by mosses (Sphagnum angustifolium, S. rubellum, $S$. magallanicum) and scattered sedges (Eriophorum vaginatum), both in the raised hummocks and lower lying hollows. Shrubs (Chamaedaphne calyculata, Ledum groenlandicum, Kalmia angustifolia) are also present on the hummocks. The shrub canopy is between 0.20 and $0.30 \mathrm{~m}$ in height, and the total leaf area index of the shrubs is 
about 1.3 (Moore et al., 2002). Trees (Picea mariana and Larix laricina) occur in scattered patches throughout the bog, but are largely absent from the study site. Above and below ground vascular plant biomass averages $356 \pm 100 \mathrm{~g} \mathrm{~m}^{-2}$ and $1820 \pm 660 \mathrm{~g} \mathrm{~m}^{-2}$ respectively, and $144 \pm 30 \mathrm{~g} \mathrm{~m}^{-2}$ for the Sphagnum capitula (Moore et al., 2002).



Figure 3.2: Photograph of the primary instrument site. 


\subsection{Snow Energy Balance Measurements}

\subsubsection{Radiation}

Net radiation at the bog was measured with a net radiometer (CNR1, Kipp \& Zonen, Netherlands), which consists of upward and downward facing pyranometers and pyrgeometers to measure shortwave and longwave radiation, respectively. This instrument was located at a height of $5 \mathrm{~m}$ on the instrument tower and was monitored on a CR7 data logger (Campbell Scientific, Logan, UT, USA). Signals were scanned every $5 \mathrm{~s}$, and $30 \mathrm{~min}$ averages were computed. The ratio between incoming and reflected shortwave radiation was used to calculate surface albedo.

\subsubsection{Turbulent Fluxes}

Fluxes of sensible heat and water vapour were measured using the eddy covariance technique. A three-dimensional sonic anemometer-thermometer (model R350, Gill Instruments, Lymington, UK) was used to measure high frequency wind velocity in three coordinates $\left(u, v\right.$, and $\left.w, \mathrm{~m} \mathrm{~s}^{-1}\right)$ and temperature $\left(T_{\text {sonc }}, \mathrm{K}\right)$. High frequency air temperature $(T, \mathrm{~K})$ was computed from sonic temperature, $T_{\text {sonc }}$, following Aubinet et al. (2000). High frequency $\mathrm{H}_{2} \mathrm{O}$ mole fraction $\left(\chi_{v}, \mathrm{mmol} \mathrm{H}_{2} \mathrm{O}\right.$ mol $^{-1}$ moist air) was measured with a model LI7000 closed-path IRGA (LI-COR Inc., Lincoln, NB, USA), which was housed in a thermostated box with air drawn at $17 \mathrm{~L} \mathrm{~min}^{-1}$ through a $3 \mathrm{~m}$ sampling tube. A three-axis coordinate rotation was used to align the streamlines with the surface of the bog, resulting in zero mean $w, v$ and covariance of $v$ and $w$. The effects of air density fluctuations on $L_{\nu} E$ were accounted for by converting mole fractions to mole mixing ratios ( $s_{v}, \mathrm{mmol} \mathrm{H}_{2} \mathrm{O} \mathrm{mol}{ }^{-1}$ dry air). As such, $L_{v} E$ and $H$ 
were determined as the instantaneous deviations of vertical wind velocity $\left(w^{\prime}\right)$ and molar mixing ratio of water vapour $\left(s_{v}{ }^{\prime}\right)$ or temperature $\left(T^{\prime}\right)$, respectively, as follows:

$$
\begin{aligned}
& L_{v} E=-L_{v} \rho_{m, a} \frac{M_{v}}{1000} \overline{w^{\prime} s^{\prime}} \\
& H=-\rho_{a} c_{p, a} \overline{w^{\prime} T^{\prime}}
\end{aligned}
$$

where the overbar represents a time-averaged mean of the instantaneous product of $w^{\prime}$, $s_{v}{ }^{\prime}$ or $T^{\prime}$ (i.e. the covariance of these quantities), $L_{v}$ is the latent heat of vaporization (J $\left.\mathrm{kg}^{-1}\right), \rho_{m, a}$ is the molar density of dry air (mol dry air $\left.\mathrm{m}^{-3}\right), M_{v}$ is the molecular weight of water vapour $(0.01802 \mathrm{~kg} / \mathrm{mol}), \rho_{a}$ is the density of moist air $\left(\mathrm{kg} \mathrm{m}^{-3}\right)$, and $c_{p, a}$ is the specific heat capacity of moist air $\left(\mathrm{J} \mathrm{kg}^{-1} \mathrm{~K}^{-1}\right)$.

The eddy covariance instrumentation was mounted on the instrument tower at a height of $3.0 \mathrm{~m}$ from the mean height of the hummock tops on a boom $0.50 \mathrm{~m}$ long oriented into the prevailing wind direction (northwest). Digital signals from these sensors were recorded at $20 \mathrm{~Hz}$ using a computer, and fluxes were computed for $30 \mathrm{~min}$ periods. Average $30 \mathrm{~min}$ air temperature and surface pressure were used to calculate $\rho_{m, a}, \rho_{a}$ and $L_{v}$, which were measured with a PT100 (Omega, Connecticut, USA) in an aspirated radiation shield (Met-One, TX, USA), and a CS105 Barometric Pressure Sensor (Campbell Scientific, Logan, UT, USA). Measurements were taken every $5 \mathrm{~s}$ on a CR7 datalogger.

Friction velocity $\left(u_{*}\right)$ was derived from sonic anemometer measurements:

$$
u_{*}=\left({\overline{u^{\prime} v^{\prime}}}^{2}+{\overline{v^{\prime} w^{\prime}}}^{2}\right)^{0.5}
$$




\subsubsection{Soil Measurements and Snow Temperatures}

Soil and snow temperatures were measured with type E thermocouples mounted on a vertical wooden post, which was installed in a hummock. Temperatures were recorded at depths of $0.02,0.05,0.10,0.20,0.40$, and $0.60 \mathrm{~m}$ below the surface, and at heights of $0.02,0.05,0.10,0.20,0.30,0.40,0.50,0.60,0.80,1.00 \mathrm{~m}$ above the surface. Output from the thermocouple sensors were first sent to a multiplexer (AMP25T, Campbell Scientific, Logan, UT, USA) and then to a data logger (CR1000, Campbell Scientific, Logan, UT, USA). Thermocouple readings were taken at intervals of $2 \mathrm{~s}$, and 30 min averages were calculated.

Soil moisture probes (EC-5, Decagon, USA) were buried at depths of $0.02,0.05$, $0.10,0.20,0.40$, and $0.60 \mathrm{~m}$ below the surface and were located near the soil temperature measurements. Signals every 30 min were monitored on Em5b data loggers (Decagon, USA). Volumetric moisture content was computed from $\mathrm{mV}$ readings using a relationship determined in the lab with Mer Bleue peat (Adkinson, 2009). As the upper $\sim 0.20 \mathrm{~m}$ of the peat was already frozen once the Decagon probes were installed, half hour averages of soil moisture at the bog were also obtained using water content reflectometers (model CS 615, Campbell Scientific, USA) installed near the tower at depths of $0.10,0.20,0.30,0.40$, and $0.50 \mathrm{~m}$ below the hummock surface. The reflectometers were not calibrated, however their signals were converted to soil moisture values using a relationship for mineral soil (Campbell Scientific, 1996). Half hour averages were normalized so that all readings fell between 0.93 and $0.07 \mathrm{~m}^{3} \mathrm{~m}^{-3}$, which is an estimate of the porosity of the moss and the volume of water associated with air-dried moss. 
Depth of the water table (WTD) with respect to the average peat hummock was measured continuously in two wells using pressure transducers (Solinst Levelogger Junior, model 3001, and Solinst Barologger Gold, model 3001 to barometrically compensate Levelogger readings), which were set to measure every $30 \mathrm{~min}$.

\subsubsection{Ground Heat Flux}

The ground heat flux was estimated by coupling the gradient and calorimetric methods (ie. the combination method) (Sauer and Horton, 2005). The combination approach begins at a reference depth $\left(z_{r}, \mathrm{~m}\right)$ and determines the ground heat flux at this depth from the vertical temperature $(T, \mathrm{~K})$ gradient and thermal conductivity $\left(\lambda, \mathrm{W} \mathrm{m}^{-1}\right.$ $\mathrm{K}^{-1}$ ), and the calorimetric method is applied to successive layers between the reference depth and the soil surface. $G$ was calculated as:

$$
G=-\lambda \frac{\partial T}{\partial z}+\frac{\partial S}{\partial t}
$$

where $z$ is the depth below the soil surface $(\mathrm{m})$, and $\frac{\partial S}{\partial t}$ is the change in heat storage (W $\left.\mathrm{m}^{-2}\right)$

Typically the reference depth should be at least $0.20 \mathrm{~m}$ since the sensitivity of equation (3.4) to measurement errors decreases with depth (Liebethal et al., 2005; Sauer and Horton, 2005). Therefore, $z_{r}$ selected for this method was $0.30 \mathrm{~m}$, and $\frac{\partial T}{\partial z}$ was calculated from the thermocouples at 0.20 and $0.40 \mathrm{~m}$ below the hummock surface.

Thermal conductivity was estimated using de Vries' parameterization (1963) as it is commonly employed and recommended for soils that undergo a freeze/thaw cycle 
(Zhang et al., 2008). De Vries (1963) method, which is based on a phase mixing model and the weighted volume fraction of soil constituents, estimates $\lambda$ as:

$$
\begin{aligned}
& \lambda=\left(\theta_{w} \lambda_{w}+f_{a} \theta_{a} \lambda_{a}+f_{S} \theta_{s} \lambda_{s}\right) /\left(\theta_{w}+f_{a} \theta_{a}+f_{s} \theta_{s}\right) \\
& f_{S}=\frac{1}{3}\left\{2 /\left[1+\left(\lambda_{s} / \lambda_{w}-1\right) 0.125\right]+1 /\left[1+\left(\left(\lambda_{s} / \lambda_{w}-1\right) 0.75\right]\right\}\right. \\
& f_{a}=\frac{1}{3}\left\{2 /\left[1+\left(\lambda_{a} / \lambda_{w}-1\right) g_{a}\right]+1 /\left[1+\left(\left(\lambda_{a} / \lambda_{w}-1\right) g_{c}\right]\right\}\right. \\
& g_{a}= \begin{cases}0.333-(0.333-0.035) \theta_{a} / \theta_{o} & \theta_{w}>0.09 \\
0.013+0.944 \theta_{w} & \theta_{w} \leq 0.09\end{cases} \\
& g_{c}=1-2 g_{a}
\end{aligned}
$$

where $\theta_{w}, \theta_{a}$, and $\theta_{s}$ are the volume fractions of soil occupied by water, air, and solids respectively $\left(\mathrm{m}^{3} \mathrm{~m}^{-3}\right) ; \lambda_{w}, \lambda_{a}$, and $\lambda_{s}$ are the thermal conductivities of water, air, and solids respectively ( $\left.\mathrm{W} \mathrm{m}^{-2} \mathrm{~K}^{-1}\right) ; f_{S}$ and $f_{a}$ are weighting factors depending on the shape and orientation of soil particles and air-pores, respectively; and $g_{a}$ and $g_{c}$ are called shape factors.

The change in heat storage $(S)$ was calculated as:

$$
\begin{aligned}
& \frac{\partial S}{\partial t}=\int_{0}^{r} C_{a p p} \frac{\partial T}{\partial t} d z \\
& C_{a p p}= \begin{cases}C_{u} & T \geq T_{f} \\
C_{f}+L_{f}\left(\partial \theta_{u} / \partial T\right) & T<T_{f}\end{cases}
\end{aligned}
$$

where $C_{a p p}$ is the apparent heat capacity which accounts for latent heat that is absorbed/released during soil thaw/freeze $\left(\mathrm{J} \mathrm{m}^{-3} \mathrm{~K}^{-1}\right), C_{u}$ and $C_{f}$ are the heat capacity of the soil when it is unfrozen and frozen, respectively $\left(\mathrm{J} \mathrm{m}^{-3} \mathrm{~K}^{-1}\right), L_{f}$ is the latent heat of 
fusion $\left(3.38 \times 10^{8} \mathrm{~J} \mathrm{~m}^{-3}\right), \theta_{u}$ is the unfrozen water content $\left(\mathrm{m}^{3} \mathrm{~m}^{-3}\right)$, and $T_{f}$ is the freezing point temperature (K). The integration between the surface and $z_{r}$ in equation (3.10) was done by dividing the layer into several sub-layers according to the temperature measurement depths.

Unfrozen water content in frozen soils was parameterized as (Zhang et al., 2008):

$$
\theta_{u}= \begin{cases}\theta_{w}-\left(\theta_{w}-\theta_{u, l}\right)\left(T-T_{f}\right) /\left(T_{u, l}-T_{f}\right) & T \geq T_{u, l} \\ \theta_{u, l} & T<T_{u, l}\end{cases}
$$

where $\theta_{w}$ is the volumetric fraction of liquid water $\left(\mathrm{m}^{3} \mathrm{~m}^{-3}\right), \theta_{u, l}$ is the minimum unfrozen water content $\left(\mathrm{m}^{3} \mathrm{~m}^{-3}\right)$, and $T_{u, l}$ is a threshold temperature when unfrozen water content reaches a minimum $(\mathrm{K})$.

Accurate freezing characteristic curves could not be developed from either type of soil moisture sensor. Therefore, $T_{f}, T_{u, l}$, and $\theta_{u, l}$ were estimated based on values obtained for other peat soils from Zang et al. (2008) (Table 3.1). The total volumetric water (ice + liquid) content $\left(\mathrm{VWC}_{\mathrm{T}}\right)$ in frozen soil layers was assumed to be constant throughout the period of observation (Table 3.1). This is supported by reflectometer values from previous years (1999-2006) which showed very little variation throughout the winter period (November to March), even during rain-on-snow and mid-winter melt events. In addition, WTD throughout the 2009-2010 winter varied minimally; average WTD was $0.25 \mathrm{~m}$ with a standard deviation (SD) of $\pm 0.02 \mathrm{~m}$. VWC $\mathrm{VW}_{\mathrm{T}}$ was based on soil moisture values taken from the Decagon probes prior to soil freeze-up. For soil layers which were already frozen during set-up, the $\mathrm{VWC}_{\mathrm{T}}$ was estimated from 1999-2006 average reflectometer values on 1 December (i.e. prior to the soil freeze-up). In soil layers which did not freeze throughout the study, $\mathrm{VWC}_{\mathrm{T}}$ was based on Decagon values. 
Table 3.1: Values for unfrozen water parameterization (freezing point temperature, $T_{f}$; threshold temperature when unfrozen water content reaches a minimum, $T_{u, l}$; and minimum unfrozen water content, $\left.\theta_{u, l}\right)$, total volumetric water content $\left(\mathrm{VWC}_{\mathrm{T}}\right)$, and average soil porosity $(\varepsilon)$. Values in brackets represent the SD calculated over the three soil pits.

\begin{tabular}{llccll}
\hline Soil Layer $(\mathrm{m})$ & $T_{f}$ & $T_{u, l}$ & $\theta_{u, l}$ & $\mathrm{VWC}_{\mathrm{T}}$ & $\varepsilon$ \\
\hline $0-0.03$ & 0 & -0.5 & 0.08 & 0.115 & $0.982(0.003)$ \\
$0.03-0.07$ & 0 & -0.5 & 0.08 & 0.115 & $0.981(0.005)$ \\
$0.07-0.15$ & 0 & -0.5 & 0.08 & 0.115 & $0.981(0.002)$ \\
$0.15-0.3$ & -0.05 & -0.3 & 0.18 & 0.24 & 0.963 \\
$0.3-0.5$ & \multicolumn{5}{c}{ Layer did not freeze } \\
\hline \multicolumn{5}{c}{} \\
\hline
\end{tabular}

Soil heat capacity was estimated from:

$$
C=C_{o} \theta_{o}+C_{w} \theta_{w}+C_{l} \theta_{t}
$$

where $C_{o}, C_{w}$, and $C_{\imath}$ are the heat capacities for organic matter $\left(2.49 \mathrm{MJ} \mathrm{m}^{-3} \mathrm{~K}^{-1}\right)$, liquid water $\left(4.18 \mathrm{MJ} \mathrm{m}^{-3} \mathrm{~K}^{-1}\right)$, and ice $\left(1.95 \mathrm{MJ} \mathrm{m}^{-3} \mathrm{~K}^{-1}\right)$, respectively, and $\theta_{o}, \theta_{u}$, and $\theta_{\imath}$ are the volume fractions of soil occupied by organic matter, and liquid water, and ice, respectively $\left(\mathrm{m}^{3} \mathrm{~m}^{-3}\right)$.

The volumetric fraction of organic matter was determined from bulk density $\left(\rho_{b}\right.$, $\left.\mathrm{kg} \mathrm{m}^{-3}\right)$, and the density of soil organic matter $\left(\rho_{o}, 1300 \mathrm{~kg} \mathrm{~m}^{-3}\right)$, where $\theta_{o}=\rho_{b} / \rho_{o}$. To determine bulk density, soil cores of a known volume were extracted from three pits at $0.05 \mathrm{~m}$ increments in the soil profile up to a depth of $0.20 \mathrm{~m}$ (i.e. depth of frozen soil), and bulk density values at depths greater than this were obtained from literature values for Mer Bleue (Dimitrov et al., 2010). The samples were then oven dried and weighed.

Average soil porosity $\left(\varepsilon=1-\frac{\rho_{b}}{\rho_{o}}\right)$ is given in Table 3.1. 


\subsubsection{Heat Input from Rain}

The heat transferred to the snow by rain which falls on a snowpack that is at the freezing point is given as (Dingman, 1994):

$$
M=\rho_{w} C_{w} r\left(T_{r}-T_{m}\right)
$$

where $\rho_{w}$ is the density of water $\left(1000 \mathrm{~kg} \mathrm{~m}^{-3}\right), C_{w}$ is the heat capacity of water

( $4.18 \times 10^{6} \mathrm{~J} \mathrm{~m}^{-3} \mathrm{~K}^{-1}$ ), $T_{r}$ is the rain temperature $(\mathrm{K})$ (which is assumed to be equal to the dew-point temperature), $T_{m}$ is the melting temperature of a snowpack $(273.16 \mathrm{~K})$ and $r$ is the rainfall rate $\left(\mathrm{mm} \mathrm{d}^{-1}\right)$.

When rain falls on a snowpack below the freezing point, it will first cool to the freezing point, releasing sensible heat, and then freeze, giving up latent heat (Dingman, 1994):

$$
M=\rho_{w} C_{w} r\left(T_{r}-T_{m}\right)+\rho_{w} L_{f} r
$$

Air temperature and relative humidity were measured with a sensor (HMP35, Campbell Scientific, USA) mounted on the tower at $2.0 \mathrm{~m}$ and data was recorded on the CR7 datalogger every $5 \mathrm{~s}$ and averaged every $30 \mathrm{~min} . \quad M$ was calculated on a daily time step using precipitation data from Ottawa International Airport, Meteorological Services of Canada and measured snow surface temperature (Section 3.2.6). In addition, both liquid and solid precipitation was measured by a Geonor weighing rain gauge (T200-B) located roughly $300 \mathrm{~m}$ south of the primary instrument site.

\subsubsection{Snow Depth and Physical Properties}

Snow surveys were conducted on a weekly basis, or every three to four days during snowmelt, to determine snow depth, density and SWE. Snow depth was recorded 
manually with a ruler along a 50 point transect with depth measurements taken every three steps. Due to the lack of tall vegetation and topography at the site, this sampling frequency was believed to adequately capture the spatial variability in snow cover depth (Dingman, 1994). The average snow depth was determined after each survey and included $0.00 \mathrm{~m}$ (snow-free) depths in the calculation when applicable. Five snow pits were excavated at each site to estimate snowpack density from cores taken from each recognizable layer using a $0.030 \mathrm{~m} \times 0.055 \mathrm{~m} \times 0.060 \mathrm{~m}$ snow corer for snow layers and a brass soil corer with a radius of $0.024 \mathrm{~m}$ for ice layers. Two pits at each site were also used to characterize hardness, grain shape and size, and temperature of each snow layer within the snowpack. To estimate SWE for each transect, linear relationships between snow pit depth and SWE were established. The depth-SWE relationships were divided into three distinct periods (21 December - 22 January; 23 January - 25 February, and 26 February - 12 March), based on relatively uniform snowpack density. The depth-SWE relationships were applied to all transect points for each day of measurement and then averaged to estimate transect SWE.

Continuous snow cover depth at the bog was also measured near the instrument tower (SR50, Campbell Scientific, Logan, UT, USA) using an ultrasonic sensor. Signals were measured every $2 \mathrm{~s}$ on a CR7 datalogger and $30 \mathrm{~min}$ averages were computed. Thermocouples were used to measure temperature gradients in the snowpack (Section 3.2.3) and the snow surface temperature $\left(T_{s s}, \mathrm{~K}\right)$ was measured using an infrared temperature transducer (model 4000.4GL, Everest Interscience Inc.) mounted on the tower at $4 \mathrm{~m}$, and pointed toward the bog surface. 


\subsubsection{Internal Energy}

The rate of internal temperature change in the snowpack $(\Delta Q)$ (equation (3.16)), is dependant on the rate of energy which is required or liberated during melting $\left(R_{M}, \mathrm{~m}\right.$ $\left.\mathrm{s}^{-1}\right)$, and re-freezing, $\left(R_{F}, \mathrm{~m} \mathrm{~s}^{-1}\right)$ and the internal energy change associated with each component of the snowpack (ice, $i$; liquid water, $w$; and air, $a$ ) as the temperature of the snow cover $\left(T_{s}, \mathrm{~K}\right)$ of thickness $d(\mathrm{~m})$ varies from a reference state which is generally taken as $0^{\circ} \mathrm{C}$.

$$
\Delta Q=L_{f} \rho_{w}\left(R_{F}-R_{M}\right)-d\left(\rho_{\imath} c_{p, i} \theta_{t}+\rho_{a} c_{p, a} \theta_{a}+\rho_{w} c_{p, w} \theta_{w}\right) \frac{d T_{s}}{d t}
$$

Directly measuring the rate of internal energy change is difficult, and therefore rarely occurs (Male and Gray, 1981). It is instead generally taken as the residual after measuring all terms on the right hand side of equation (2.1). This is because the snow density, liquid water content, and temperature must all be measured. Measuring the liquid water content is particularly problematic since it is difficult to obtain continuous measurements (Male and Gray, 1981). However, during cold mid-winter periods when the liquid water content of the snowpack is negligible, the situation can be simplified to:

$$
\Delta Q=d\left(\rho_{\imath} c_{p, \imath} \theta_{\imath}+\rho_{a} c_{p, a} \theta_{a}\right) \frac{d T_{s}}{d t}
$$

As such, the change in internal energy was only calculated for rain-free periods when air and snow temperatures were below freezing. Two periods during the winter met these criteria: $8-11$ January and 30 January to 8 February. During the first period snow depth remained relatively constant around $0.33 \mathrm{~m}$, air temperatures ranged between -20.8 and $-2.4^{\circ} \mathrm{C}$, and mean wind speed was $2.8 \mathrm{~m} \mathrm{~s}^{-1}$. During the second period, snow depth was $\sim 0.20 \mathrm{~m}$, air temperatures ranged between -23.0 and $-3.4^{\circ} \mathrm{C}$, and wind speeds 
were quite variable with three events with wind speeds greater than $5 \mathrm{~m} \mathrm{~s}^{-1}$ interspersed with calmer periods. The change in internal energy was determined from the depth and density of the snowpack, and the measured internal temperature changes. The change in internal energy was estimated on a 30 min time step based on continuous snow depth measurements from the SR50, linearly interpolated average snow density calculated from snow pit measurements, and a depth weighted $T_{s} . T_{s}$ was calculated by dividing the snowpack into several layers based on snow temperature measurement depths (Section 3.2.3). In addition, the upper $0.01 \mathrm{~m}$ of the snowpack was characterized by $T_{s s}$.

However, melt around the thermocouple wires due to solar heating precluded the use of temperature measurements in the upper levels of the snowpack. The mean of the temperature of the top most buried thermocouple and $T_{s s}$ was therefore used to estimate the temperature in the upper portion of the snowpack. In addition, thermocouple heights may have been inexact due to the weight of the overlying snow which bent the thermocouple wires, however, this was not accounted for. It is also assumed that the snow density had an uncertainty of about $\pm 30 \mathrm{~kg} \mathrm{~m}^{-3}$, which introduced further uncertainty in $\Delta Q$.

\subsubsection{Radiative and Turbulent Fluxes and Local Advection during Snowmelt}

Once the snow cover became patchy, measured $R_{n}, H$ and $L_{v} E$ were no longer representative of fluxes for a point on the snow surface (i.e. equation (2.1)), but were representative of a heterogeneous surface. Local advection of heat over snow patches also becomes an important source of energy for melt as the snow cover becomes discontinuous; as air moves from the warm bare ground to the relatively cold snow 
surface, an internal boundary layer develops, and some of the horizontally transported energy is transferred to the cold surface, resulting in increased melt around the edges of the snow patch (Marsh and Pomeroy, 1996; Granger et al., 2006). Therefore, air immediately above the snow patches remains stable, whereas the regional boundary layer and the air above the bare surface are unstable. Although an accurate estimate of localscale advection could not be quantified due to insufficient measurements, it was roughly estimated.

Equation (2.1) represents the energy balance of a point in a large snowpatch, unaffected by local advection, and will therefore underestimate the average melt for the entire patch. In order to estimate average melt for a patch, an advective energy term $(A)$ must be added to equation (2.1) as follows:

$$
\overline{\Delta Q}=\Delta Q+A
$$

where $\overline{\Delta Q}$ is the average melt for the snow cover $\left(\mathrm{W} \mathrm{m}^{-2}\right), \Delta Q$ is the melt calculated by equation (2.1) for a large patch where melt is not affected by local advection $\left(\mathrm{W} \mathrm{m}^{-2}\right)$, and $A$ is local advection of sensible heat from bare patches to the snowpack ( $\mathrm{W} \mathrm{m}^{-2}$ ).

In order to calculate melt using equation (2.1), fluxes at the snow surface had to be estimated since measured fluxes were not representative of the snow cover once the snow surface became patchy (1 March). Fluxes were calculated from 24 February to 9 March, when snow depth as estimated from continuous measurements reached zero and snow-covered area (SCA) was less than 5\%. Net radiation was calculated based on measured $K \downarrow$ and $L \downarrow$, snow cover albedo $(\alpha)$, and snow surface temperature $\left(T_{s s}, \mathrm{~K}\right)$ and emissivity $\left(\varepsilon_{s s}\right)$ as: 


$$
R_{n}=(1-\alpha) K \downarrow+L \downarrow-\mathcal{E}_{s s} \sigma T_{s s}^{4}
$$

where $\sigma$ is the Stefan-Boltzmann constant $\left(5.67 \times 10^{-8} \mathrm{~W} \mathrm{~m}^{-2} \mathrm{~K}^{-4}\right)$. Snow albedo was assumed to be 0.7 as shrubs generally protruded above the shallow snow cover, $\varepsilon_{s s}$ was set to 0.97 (Dingman, 1994), and $T_{s s}=1.06 T_{a}-0.99\left({ }^{\circ} \mathrm{C}\right)$, which was based on a linear relationship between air and snow surface temperature developed prior to 1 March $\left(\mathrm{r}^{2}=\right.$ 0.94). $T_{s s}$ above freezing were set to $0^{\circ} \mathrm{C}$. A variable snow surface temperature was used instead of assuming an isothermal snowpack since it has been shown to improve computed turbulent fluxes (Marsh and Pomeroy, 1996; Pohl and Marsh, 2006).

Equations (2.4)-(2.5) were used to estimate $H$ and $L_{v} E$ at the snow surface, respectively. For these calculations, air temperature and humidity were measured at $2 \mathrm{~m}$ height and wind speed at $3 \mathrm{~m}$, a surface roughness $\left(z_{o}\right)$ of $0.005 \mathrm{~m}$ was used, and the bulk transfer coefficients were modified to account for stable and unstable conditions (Dunne et al., 1976). The snow surface vapour pressure was assumed to be saturated at the snow surface temperature.

Marsh and Pomeroy (1996) provide a simple parameterization scheme, assuming that all, or a portion of, the sensible heat from the bare areas $\left(H_{b}\right)$ is transferred from the bare areas to the snow patches, so that:

$$
A a_{s}=H_{b} a_{b}
$$

where $a_{s}$ and $a_{b}$ are the areas of snow patches and bare areas, respectively. The energy advected (per unit SCA) to the snow patches can then be given as:

$$
A=\left(\frac{H_{b} P_{b}}{P_{s}}\right)\left(F_{S}\right)
$$


where $P_{b}=a_{b} / a_{t}$ and $P_{s}=a_{s} / a_{t}$ are the fraction of the site snow-free and snowcovered, respectively, $a_{t}$ is the total area, $H_{b}$ is the sensible heat flux from the portions of the basin which are snow-free, and $F_{S}$ is a function expressing the portion of the bare area $H_{b}$ which is advected to the snow patches.

Daily $P_{b}$ and $P_{s}$ were estimated from the images taken by a camera (Game Spy I65 Digital Trail Camera, EBSCO, AL, USA) mounted on the instrument tower which took a picture every $8 \mathrm{~h}$ during the melt period. Equations (3.29)-(3.30) and (3.31)-(3.33) were used to estimate $H_{b}$. For this calculation, air temperature was measured at $2 \mathrm{~m}$ height and wind speed at $3 \mathrm{~m}$, and the surface temperature was estimated from the thermocouple at $0.02 \mathrm{~m}$ above the surface which was exposed to the air by 1 March. $z_{o}$ was set to $1 / 10$ the height of the shrub canopy $(\sim 0.25 \mathrm{~m})$, and $d_{o}$ to $2 / 3$ the height of the canopy (Brutsaert, 2005). A regression equation developed by Pohl and Marsh (2006) was used to estimate $F_{S}$ in this study, where $F_{S}=-0.0430+1.0859 e^{-2.9125 \times P_{B}}$.

\subsubsection{Calculating the Energy Available for Melt from the Water Balance}

The energy available for melt as calculated from the water balance $\left(\overline{\Delta Q}_{\text {water balance }}\right.$, $\mathrm{MJ} \mathrm{m}^{-2}$ ) was determined as (Dingman, 1994):

$$
\overline{\Delta Q}_{\text {water balance }}=M L T \times\left(\rho_{w} L_{f}\right)
$$

where MLT is the amount of snow that melted (m) for a given time period, which is taken as the change in SWE plus snowfall for that time period (Hayashi et al., 2004). 


\subsubsection{Energy Budget Closure and Storage terms}

Energy budget closure on a half-hourly basis is an important independent method used to assess the quality of the measurements of the turbulent fluxes (e.g. Turnipseed et al. 2002, Wilson et al. 2002, Barr et al. 2006). The degree of energy balance closure that can be achieved using the eddy covariance technique has often been studied during summertime periods (e.g. Aubinet et al., 2000, Barr et al., 2006), however, there are very few estimates of the energy balance closure obtained over snow-covered surfaces. The degree of energy balance closure for a snow-covered surface can be determined by taking the slope of the following relation, where $M$ is negligible:

$$
\left(L_{v} E+H\right)=a\left(\Delta Q-\left(R_{n}+G+J\right)\right)+b
$$

where $a$ and $b$ are the slope and y-axis intercept, respectively, for the linear regression between available energy and sum of turbulent fluxes, and $J=S_{h}+S_{l}$ is the rate of energy storage in the air $\left(\mathrm{W} \mathrm{m}^{-2}\right)$, and $S_{h}$ and $S_{l}$ are the rate of sensible and latent heat storage in the air, respectively $\left(\mathrm{W} \mathrm{m}^{-2}\right)$.

$S_{h}$ and $S_{l}$ were calculated as:

$$
\begin{gathered}
S_{h}=\int_{0}^{3 m} \rho_{a} c_{p, a} \frac{d T}{d t} d z \\
S_{l}=\int_{0}^{3 m} \frac{\rho_{a}}{\gamma} \frac{d e_{a}}{d t} d z
\end{gathered}
$$

where $e_{a}$ is vapour pressure $(\mathrm{Pa})$ and $\gamma$ is the psychrometric constant $\left(\mathrm{Pa}^{\circ} \mathrm{C}^{-1}\right)$.

Measurements of temperature and RH using the HMP35CF below the EC instrumentation ( $2 \mathrm{~m}$ ) were used to calculate $S_{h}$ and $S_{l}$. 


\subsection{SNOBAL}

SNOBAL is a physically based two-layer snow energy and mass balance model developed by Marks and Dozier (1992), and described in detail by Marks et al. (1998) (Figure 3.3). The model has been applied to numerous locations including central Canada (Link and Marks, 1999a), Turkey (Sensoy et al., 2006), and the Pacific Northwest (Marks et al., 1998; Marks and Winstral, 2001, Mazurkiewicz et al., 2008). The spatially distributed version has been successfully applied to the Boreal Ecosystem Atmosphere Study (Link and Marks, 1999b), the Boise River Basin (Garen and Marks, 2005), the California Sierra Nevada (Marks et al., 1999), the Reynolds Creek Experimental Watershed (Winstral and Marks, 2002), and the Wasatch Range in Utah (Susong et al., 1999). SNOBAL was run in the cold regions hydrological (CRHM) platform, a flexible object-oriented modeling system (details provided by Pomeroy et al., 2007). 


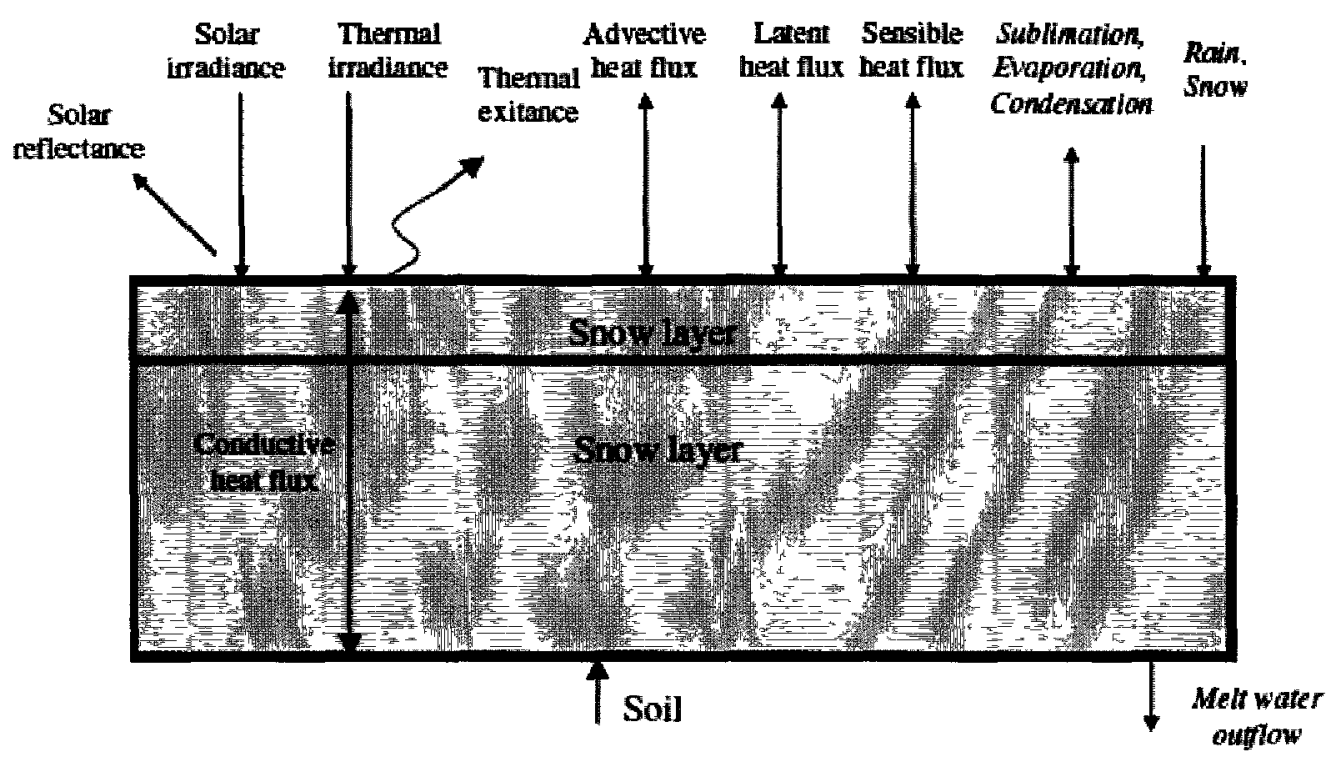

Figure 3.3: Schematic diagram of SNOBAL structure and components (from Mazurkiewicz et al., 2008).

SNOBAL is initialized by measurement heights and snow cover state variables including snow depth, density, temperature and liquid water content if the snow cover exists at the start of the run. It is then driven by independent inputs of net solar radiation, incoming thermal radiation, air temperature, precipitation, wind speed, vapour pressure, and ground temperature to calculate the energy and mass balance and runoff from the snow cover. The model calculates the energy balance of the snow cover using equation (2.1). The state variables and forcing variables required by the model are shown in Table 3.2. State variables are input as initial conditions, and then predicted by the model during the run. Forcing variables are used by the model to predict the state variables and are input at each model time-step. The model time-step in this analysis was $30 \mathrm{~min}$. 
Table 3.2: State variables predicted by the model and values input as initial conditions, and forcing variables and measurement height.

\begin{tabular}{|c|c|c|c|}
\hline \multirow[t]{2}{*}{ State variables } & \multirow{2}{*}{\multicolumn{2}{|c|}{$\begin{array}{ll}\text { Initial } & \text { Forcing variables } \\
\text { conditions } & \end{array}$}} & \multirow[b]{2}{*}{$\begin{array}{l}\text { Instrument height } \\
\text { (above soil surface) }\end{array}$} \\
\hline & & & \\
\hline Snow depth (m) & 0.32 & $\begin{array}{l}\text { Net shortwave } \\
\text { radiation }\left(\mathrm{W} \mathrm{m}^{-2}\right)\end{array}$ & $5 \mathrm{~m}$ \\
\hline Snow density $\left(\mathrm{kg} \mathrm{m}^{-3}\right)$ & 270 & $\begin{array}{l}\text { Incoming thermal } \\
\text { radiation }\left(\mathrm{W} \mathrm{m}^{-2}\right)\end{array}$ & $5 \mathrm{~m}$ \\
\hline $\begin{array}{l}\text { Snow surface layer } \\
\text { temperature }\left({ }^{\circ} \mathrm{C}\right)\end{array}$ & -14 & Air temperature $\left({ }^{\circ} \mathrm{C}\right)$ & $2 \mathrm{~m}$ \\
\hline $\begin{array}{l}\text { Average snow cover } \\
\text { temperature }\left({ }^{\circ} \mathrm{C}\right)\end{array}$ & -14 & Vapour pressure $(\mathrm{Pa})$ & $2 \mathrm{~m}$ \\
\hline \multirow[t]{3}{*}{$\begin{array}{l}\text { Average snow liquid } \\
\text { content }(\%)\end{array}$} & 0 & Wind speed $\left(\mathrm{m} \mathrm{s}^{-1}\right)$ & $3 \mathrm{~m}$ \\
\hline & & Soil temperature $\left({ }^{\circ} \mathrm{C}\right)$ & $0.1 \mathrm{~m}$ depth \\
\hline & & Precipitation (mm) & \\
\hline
\end{tabular}

Measurements from the Geonor weighing rain gauge were used as the precipitation input. Precipitation type was estimated using air temperature at the site. Above a threshold temperature of $0.5^{\circ} \mathrm{C}$ all precipitation was rain, below $0.0^{\circ} \mathrm{C}$ all precipitation fell as snow, and between these temperatures precipitation type was linearly interpolated based on temperature. The threshold was determined by using SNOBAL to test threshold temperatures that would most closely follow measured accumulation patterns (Mazurkiewicz et al., 2008). Newly fallen snow had a density of $100 \mathrm{~kg} \mathrm{~m}^{-3}$. SNOBAL as coded in CRHM does not simulate heat transferred to the snow by rain, and 
therefore simulated $M$ was omitted from the results. This, however, had negligible effects since $M$ is a minor component in the EB of the snow cover.

The model approximates the snow cover as being composed of two layers, a basal layer, and a fixed-thickness surface layer. The model simulates each component of the energy balance in both layers, calculates the addition or loss of mass by deposition, melt, evaporation, or runoff from the base of the snowpack, and adjusts the snow cover mass, thickness and thermal conditions at each time step. The surface layer is generally set to $0.25 \mathrm{~m}$, which represents the active layer that interacts with radiation and the overlying atmosphere. However, as the snow cover was quite thin at Mer Bleue (ranging between $<0.20-0.35 \mathrm{~m}$ during mid-winter), a surface layer of $0.25 \mathrm{~m}$ seems inadequate as it can result in a one-layer snow energy balance model. Marks et al. (2008) found that by reducing the surface layer from 0.25 to $0.10 \mathrm{~m}$, there was a considerable improvement between modelled and measured turbulent fluxes, and that decreasing the thickness of the surface layer further only had a small impact on the results. Surface thicknesses of 0.10 , 0.05 and $0.01 \mathrm{~m}$ were therefore tested. An active layer specification of $0.05 \mathrm{~m}$ appears most appropriate for this study as daily mean sensible and latent heat fluxes were simulated with slightly better accuracy than with a surface layer of $0.10 \mathrm{~m}$ (Table 3.3 ). Decreasing the active layer to $0.01 \mathrm{~m}$ didn't greatly improve estimates of turbulent flux and instead, resulted in a poorer simulation of snowpack depth. 
Table 3.3: Correlation coefficient $\left(\mathrm{r}^{2}\right)$ and RMSD for daily mean sensible and latent heat fluxes for surface layer thicknesses of $0.10,0.05,0.01 \mathrm{~m}$.

\begin{tabular}{lllll}
\hline & \multicolumn{2}{c}{$H$} & \multicolumn{2}{c}{$L_{v} E$} \\
\cline { 2 - 5 } $\begin{array}{l}\text { Surface layer } \\
\text { thickness (m) }\end{array}$ & $\mathrm{r}^{2}$ & $\begin{array}{l}\text { RMSD } \\
\left(\mathrm{MJ} \mathrm{m}^{-2}\right)\end{array}$ & $\mathrm{r}^{2}$ & $\begin{array}{l}\text { RMSD } \\
\left(\mathrm{MJ} \mathrm{m}^{-2}\right)\end{array}$ \\
\hline 0.10 & 0.72 & 0.75 & 0.41 & 0.85 \\
0.05 & 0.75 & 0.72 & 0.42 & 0.85 \\
0.01 & 0.76 & 0.72 & 0.42 & 0.84 \\
\hline
\end{tabular}

SNOBAL treats the soil as a single layer system with thickness equal to the depth of the temperature measurement $\left(z_{g}, \mathrm{~m}\right)$ and a temperature profile defined by input $T_{g}$ (K) at depth $z_{g}$, and the temperature of the lower snow layer $\left(T_{s, l}, \mathrm{~K}\right)$, and thus a vapour gradient between the snow-soil interface and a depth $z_{g}$ defined by saturation vapour pressure at $T_{g}$ and $T_{s, l}$. In this analysis, the base thermal conductivity $\left(K_{g}\right)$ for the soil layer was set as a constant $\left(0.15 \mathrm{~W} \mathrm{~m}^{-1} \mathrm{~K}^{-1}\right)$ based on de Vries (1963) thermal conductivity parameterization (Section 3.2.4). Base thermal conductivities for snow layers are set as functions of layer densities (Yen, 1965). A base diffusion coefficient $\left(D_{0}, \mathrm{~m}^{2} \mathrm{~s}^{-1}\right)$ is estimated for water vapour in snow or a saturated inorganic soil layer with a temperature of $0^{\circ} \mathrm{C}$ at sea level pressure (Yen, 1965). Anderson (1976) developed an empirical relationship that can be used to adjust this base diffusion coefficient $\left(D_{e}, \mathrm{~m}^{2}\right.$ $\left.\mathrm{s}^{-1}\right) . \quad D_{e}$ is then used with base thermal conductivity and layer-specific humidity for the snow or soil to compute an effective thermal conductivity that accounts for both heat conduction and vapour diffusion between layers.

Energy transfer by conduction and diffusion between the soil and the lower layer of the snow cover $\left(G, \mathrm{~W} \mathrm{~m}^{-2}\right)$ is calculated by: 


$$
G=\frac{2 K_{e s, l} K_{e g}\left(T_{g}-T_{s, l}\right)}{K_{e g} z_{s, l}+K_{e s, l} z_{g}}
$$

$K_{e s, l}$ and $K_{e g}\left(\mathrm{~J} \mathrm{~m}^{-1} \mathrm{~K}^{-1} \mathrm{~s}^{-1}\right)$ are effective thermal conductivities for the lower snow layer and soil. The depth of the soil measurement $\left(z_{g}\right)$ is an initial condition, and the soil temperature at $z_{g}\left(T_{g}\right)$ is an input data parameter. The temperature of the lower snow layer $\left(T_{s, l}\right)$ and the thickness of the lower snow layer $\left(z_{s, l}, \mathrm{~m}\right)$ are calculated by the model at each time-step.

In the model, turbulent transfer terms are calculated using a bulk transfer method adapted from Brutsaert (1982) by Marks and Dozier (1992), as a system of non-linear equations that simultaneously solve for the Obukhov stability length $(L, \mathrm{~m})$ the friction velocity $\left(u_{*}, \mathrm{~m} \mathrm{~s}^{-1}\right)$, the sensible heat flux $\left(H, \mathrm{~W} \mathrm{~m}^{-2}\right)$, and the mass flux by sublimation from or condensation to the snow surface $\left(E, \mathrm{~kg} \mathrm{~m}^{-2} \mathrm{~s}^{-1}\right)$ :

$$
\begin{aligned}
& L=\frac{u_{*}^{3} \rho_{a}}{k g\left(\frac{H}{T_{a} c_{p, a}}+0.61 E\right)} \\
& u_{*}=\frac{u k}{\ln \left(\frac{z_{u}-d_{0}}{z_{0}}\right)-\psi_{M}\left(\frac{z_{u}}{L}\right)} \\
& H=\frac{\left(T_{a}-T_{s, 0}\right) a_{H} k u_{*} \rho_{a} c_{p, a}}{\ln \left(\frac{z_{t}-d_{0}}{z_{0}}\right)-\psi_{H}\left(\frac{z_{t}}{L}\right)} \\
& E=\frac{\left(q-q_{s, 0}\right) a_{E} k u_{*} \rho_{a}}{\ln \left(\frac{z_{q}-d_{0}}{z_{0}}\right)-\psi_{Q}\left(\frac{z_{q}}{L}\right)}
\end{aligned}
$$


Here, $\rho_{a}$ is air density $\left(\mathrm{kg} \mathrm{m}^{-3}\right), k$ is the von Karman constant $(0.40), g$ is the acceleration of gravity $\left(9.81 \mathrm{~m} \mathrm{~s}^{-2}\right), c_{p, a}$ is the specific heat of dry air at constant pressure (1005 $\left.\mathrm{J} \mathrm{kg}^{-1} \mathrm{~K}^{-1}\right), d_{0}$ is the zero-plane displacement height $\left(\sim(2 / 3) 7.35 z_{0}\right), a_{H}$ and $a_{E}$ are the ratio of eddy diffusivity for heat and water vapour to eddy viscosity, respectively. Brutsaert (1982) suggests that in the absence of other information, $a_{H}=a_{E}=1.0$. Here $\psi_{M}, \psi_{H}$, and $\psi_{Q}$ are stability functions for mass, heat, and water vapour respectively (Brutsaert, 1982; Marks and Dozier, 1992) which are:

Stable $(\zeta=z / L>0)$

$$
\begin{array}{lr}
\psi_{M}=\psi_{H}=\psi_{Q}=-5 \zeta & 0<\zeta \leq 1 \\
\psi_{M}=\psi_{H}=\psi_{Q}=-5 \ln \zeta & \zeta>1
\end{array}
$$

Unstable $(\zeta=z / L<0)$

$$
\begin{aligned}
& \psi_{M}=2 \ln \left[\frac{1+x}{2}\right]+\ln \left[\frac{1+x^{2}}{2}\right]-2 \arctan (x)+\frac{\pi}{2} \\
& \psi_{H}=\psi_{Q}=2 \ln \left[\frac{1+x^{2}}{2}\right]
\end{aligned}
$$

where $x=(1-16 \varsigma)^{1 / 4}$

The measurement heights for temperature $\left(z_{t}, \mathrm{~m}\right)$, humidity $\left(z_{q}, \mathrm{~m}\right)$, and wind $\left(z_{u}, \mathrm{~m}\right)$ are set as initial conditions and then updated by the model as the depth of the snow cover changes. The roughness length $\left(z_{0}, \mathrm{~m}\right)$ is set as a constant in CRHM. Since it is difficult to estimate how snow surface features change over time, most snow models use approximate snow surface roughnesses that do not vary in time or between sites (Marks and Winstral, 2001). For applications of SNOBAL (e.g. Marks et al., 1998; Link 
and Marks 1999a), snow surface roughness vary from 0.001 to $0.0025 \mathrm{~m}$. In this study, $z_{0}$ was set to $0.005 \mathrm{~m}$ based on sonic anemometer measurements for a period in midJanuary (Section 5.3.2). Measured $z_{0}$ falls within values of 0.0001 to $0.01 \mathrm{~m}$ reported in the literature (Anderson 1976; Moore 1983), although it is on the high end for values estimated for seasonal snow cover. Since the tops of the shrubs protruded slightly above the snow cover throughout the winter, it seems reasonable that $z_{0}$ should be in the upper range of roughness lengths for seasonal snow covers.

Air temperature $\left(T_{a}, \mathrm{~K}\right)$, wind speed $\left(u, \mathrm{~m} \mathrm{~s}^{-1}\right)$, and vapour pressure $\left(e_{a}, \mathrm{~Pa}\right)$, are model inputs, and specific humidity $\left(q, \mathrm{~g} \mathrm{~kg}^{-1}\right)$ is calculated from $e_{a}$ and site air pressure. Snow surface layer temperature $\left(T_{s, 0}, \mathrm{~K}\right)$ is adjusted by the model at the end of each time step, and snow surface specific humidity $\left(q_{s, 0}, \mathrm{~g} \mathrm{~kg}^{-1}\right)$ is calculated as a function of site air pressure and the saturation vapour pressure at $T_{s, 0}$. The latent heat flux $L_{v} E$ is $L_{v} \times E$, where $L_{v}$ is the latent heat of vapourization or sublimation, which depends on temperature and the state of the water (liquid or solid) from $2.501 \times 10^{6} \mathrm{~J} \mathrm{~kg}^{-1}$ for liquid water at $0{ }^{\circ} \mathrm{C}$ (vapourization), or $2.834-2.839 \times 10^{6} \mathrm{~J} \mathrm{~kg}^{-1}$ for ice between $0{ }^{\circ} \mathrm{C}$ and $-30^{\circ} \mathrm{C}$ (sublimation).

\subsubsection{Model validation}

Several standard tests were used to evaluate model performace. A detailed description and a discussion of appropriate use of these tests is presented by Green and Stephenson (1986). The coefficient of determination $\left(r^{2}\right)$ was calculated as: 


$$
r^{2}=\left(\frac{\sum_{i=1}^{n}\left(x_{o b s}-\overline{x_{o b s}}\right)\left(x_{s i m}-\overline{x_{s t m}}\right)}{\sqrt{\sum_{i=1}^{n}\left(x_{o b s}-\overline{x_{o b s}}\right)^{2}} \sqrt{\sum_{t=1}^{n}\left(x_{s u m}-\overline{x_{s u m}}\right)^{2}}}\right)
$$

where $n$ is the total number of observations, $x_{o b s}$ is the observed quantity at a given time step, $\overline{x_{o b s}}$ is the average observed value, $x_{s m}$ is the simulated quantity at the same time step, and $\overline{x_{s l m}}$ is the mean simulated value.

The Nash-Sutcliffe coefficient or model efficiency (ME), which describes the variation in measured values accounted for by the model, calculated as:

$$
M E=1-\left[\frac{\sum_{i=1}^{n}\left(x_{o b s}-x_{s m}\right)^{2}}{\sum_{i=1}^{n}\left(x_{o b s}-x_{\text {avg }}\right)^{2}}\right]
$$

The root mean-square-difference (RMSD) between simulated and observed parameter, calculated as:

$$
R M S D=\sqrt{\frac{\sum_{i=1}^{n}\left(x_{s i m}-x_{o b s}\right)^{2}}{n}}
$$

The absolute mean bias difference (AMBD), or mean deviation of simulated from observed, calculated as:

$$
A M B D=\frac{1}{n} \sum_{i=1}^{n}\left(x_{s u m}-x_{o b s}\right)
$$

The relative mean bias difference (RMBD), calculated as the AMBD divided by the mean of the measured values. 


\subsection{Reliability of Eddy Fluxes and Flux Corrections}

\subsubsection{Data Screening}

All flux measurements were checked for quality assurance, and various filtering techniques were used. Data were first filtered for periods when instrument calibration or maintenance occurred and times when the instrument was known to malfunction. Data were also filtered for the limited fetch direction to the south, which also removed any influence from the tower, board-walk and instrument hut. Data were then examined on a monthly basis for extreme values and values greater than \pm 3 standard deviations were removed from the data set. These procedures removed $11 \%$ of the latent and sensible heat flux measurements throughout the snow-covered period at the bog.

For the calculation of daily and seasonal averages, periods of less than three consecutive half-hour gaps were filled by linear interpolation between the nearest measured data points (Falge et al., 2001). In this study, longer periods were filled using linear regression relationships between $30 \min L_{v} E$ and available energy $\left(R_{a}\right.$, i.e. net radiation minus measured change in total heat storage below the height of the eddy instruments). These relationships were developed for daytime and nighttime periods, using data collected for 50 consecutive hours prior and following the gap. Missing values of $H$ were filled by subtracting the gap-filled $L_{v} E$ from $R_{a}$.

\subsubsection{Spectral Analyses}

With a closed-path IRGA, air is drawn through a tube (sometimes heated) prior to passing through the sample cell. This is advantageous in that temperature fluctuations in the air stream are dampened and only water vapour fluctuations on air density need to be 
accounted for. Also, fluxes may be measured during snowfall and rainfall as long as the sonic anemometer is operating correctly. The disadvantage is that in spite of efforts to attain turbulence within the sampling tube, attenuation of $\mathrm{CO}_{2}$ and $\mathrm{H}_{2} \mathrm{O}$ fluctuations typically occurs due to radial variation in the velocity profile and interactions between water molecules with each other and with the tube walls (Leuning and Judd, 1996). This generally results in a reduction of the covariance between $w$ and $\mathrm{CO}_{2}$ and $\mathrm{H}_{2} \mathrm{O}$, resulting in a loss of flux. The magnitude of this loss is determined by the proportion of flux attributed to frequencies above which concentration fluctuations are damped. The magnitude of this error varies with atmospheric stability, surface characteristics and height above the surface in addition to sample tube length, cleanliness and air flow rate.

To ensure that significant flux loss was not occurring, a comparison of the cospectrum for sensible heat $\left(C_{w T}\right)$ with the cospectrum for $\mathrm{H}_{2} \mathrm{O}\left(C_{w S v}\right)$ (Kaimal and Finnigan, 1994) is shown in Figure 3.4. $C_{w T}$ is considered to present the spectral energy distribution associated with the turbulent transfer of a scalar quantity with the fewest number of sensor effects (Moore, 1986). The lower $C_{w S v}$ in the high frequency range suggests the latent heat flux may have been somewhat underestimated, which is likely due to imperfect turbulent flow within the sampling tube and/or interactions between $\mathrm{H}_{2} \mathrm{O}$ molecules and the walls of the sampling tube. Following a procedure similar to the one outlined in Aubinet et al. (2000), transfer functions were developed using the ratios of $C_{w S v}$ to $C_{w T}$ for a few days during melt and August 2009 (for Section 3.4.3 to assess closure under more 'ideal' conditions) in order to quantify the high frequency flux losses resulting from sensor separation and attenuation of fluctuations of $s_{v}$ down the sampling tube. Mid-winter periods were difficult to assess since extremely small fluxes $(>-5 \mathrm{~W}$ 
$\mathrm{m}^{-2}$ and $<5 \mathrm{~W} \mathrm{~m}^{-2}$ ) made it difficult to obtain good spectral forms. Since the largest $L_{v} E$ occurred during the day, daytime (10h-15h) periods were selected when and $u>0.05 \mathrm{~m}$ $\mathrm{s}^{-1}$, the magnitude of $H<-60 \mathrm{~W} \mathrm{~m}^{-2}$ and $<-180 \mathrm{~W} \mathrm{~m}^{-2}$, and $L_{v} E<-20 \mathrm{~W} \mathrm{~m}^{-2}$ and $<-$ $100 \mathrm{~W} \mathrm{~m}^{-2}$ during melt and August 2009, respectively. Figure 3.4 shows examples of transfer functions developed for the 39 and 34 daytime half hours during melt and August 2009, respectively. The associated transfer function (TF) was:

$$
T F(f)=\exp \left(-(f / a)^{b}\right)
$$

where $f$ is the frequency $(\mathrm{Hz})$, and $a$ and $b$ are coefficients fit to the ratio of $f C_{w s_{v}} / \overline{w^{\prime} s_{v}^{\prime}}$ to normalized $f C_{w T} / \overline{w^{\prime} T}$. The TF can be characterized by the cut-off frequency, $\left(f_{c o}\right.$, i.e. $f$ where TF is $\left.2^{-0.5}=0.71\right)$. For the transfer function in the lower left panel of Figure 3.4, cut-off frequency of the transfer function was $0.42 \mathrm{~Hz}$ and the transfer function parameters were $a=0.69$ and $b=2.2$. Similarly, for the TF shown in the lower right panel, $f_{c o}=0.86, a=0.1 .53$ and $b=1.77$. The same form of function (3.38) was used for both periods for consistency despite relatively poor fit during the melt period. 

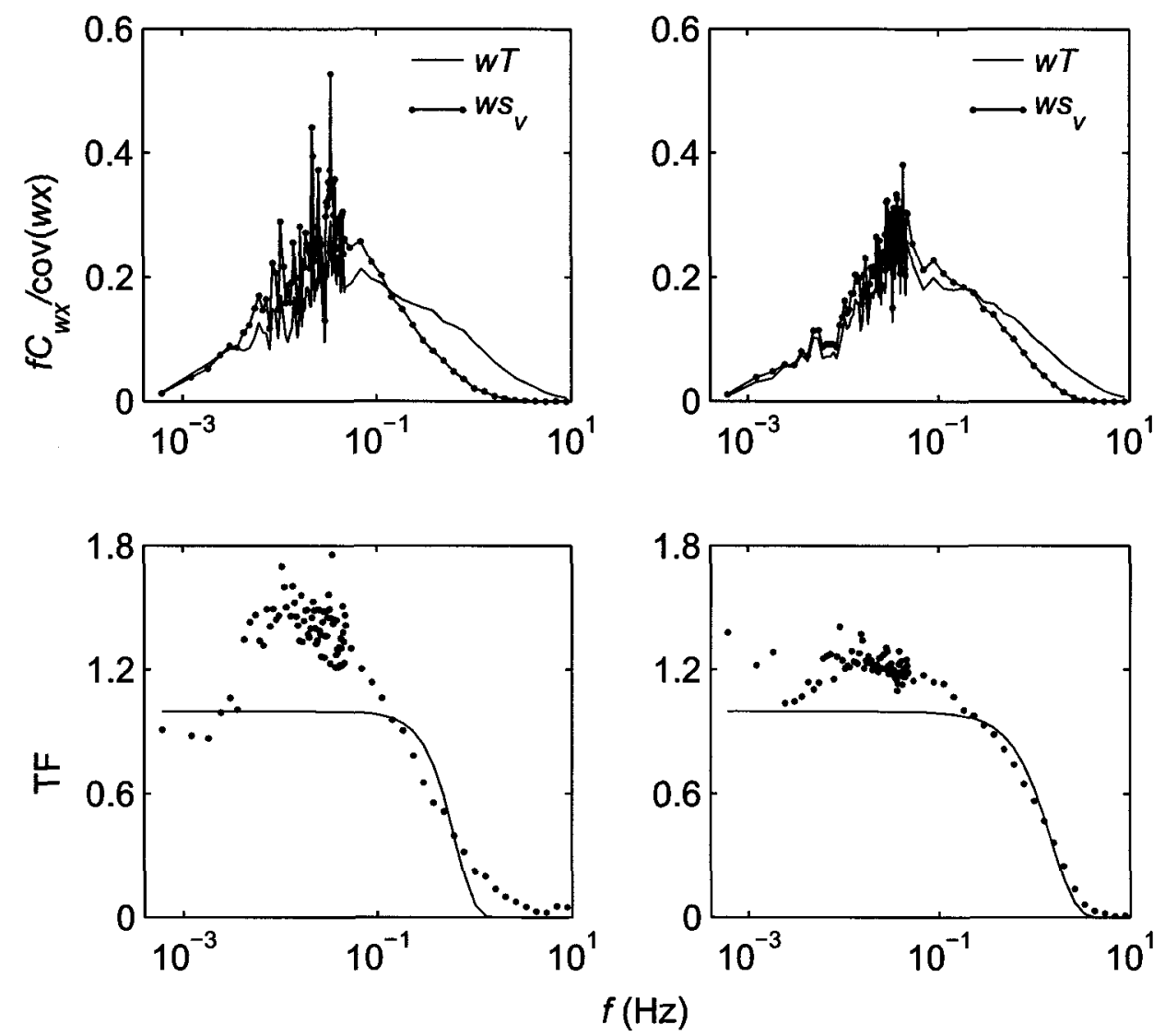

Figure 3.4: Ensemble average cospectra for sensible heat $\left(f C_{w T} / \overline{w^{\prime} T^{\prime}}\right)$ and water vapour $\left(f C_{w s_{v}} / \overline{w^{\prime} s_{v}^{\prime}}\right)$ (top panels) and transfer functions (TF) (bottom panels) illustrating high frequency loss of $\overline{w^{\prime} s_{v}^{\prime}}$ for 39 daytime half hours during melt (left panels) and 34 daytime half hours during August 2009 (right panels).

By developing a relationship between transfer function correction factors (CF) (i.e. the ratio of $\overline{w^{\prime} T^{\prime}}$ to $\overline{w^{\prime} T^{\prime}}$ degraded by the transfer function described above (Aubinet et al., 2000)) and wind speed, the variable effects of high frequency flux loss on $L_{v} E$ can be accounted for. The relationship between $\mathrm{CF}$ and $u$ varied somewhat between the two periods (Figure 3.5). During winter, the $\mathrm{CF}$ applied to $L_{v} E$ was related to half hour wind speed as $C F=0.043 u+1.08\left(r^{2}=0.48\right)$. On average, this increased the magnitude of 
$L_{v} E$ by $21 \%$ for winter fluxes, however, this could be as large as $50 \%$ for the maximum recorded wind speed of $10.0 \mathrm{~m} \mathrm{~s}^{-1} . L_{v} E$ measurements made during August 2009 were adjusted using the relationship $\mathrm{CF}=0.019 u+1.04\left(\mathrm{r}^{2}=0.46\right)$. The mean increase in the magnitude of $L_{v} E$ for this month was $7 \%$, however it could reach $16 \%$ for the maximum observed wind speed of $6.2 \mathrm{~m} \mathrm{~s}^{-1}$.

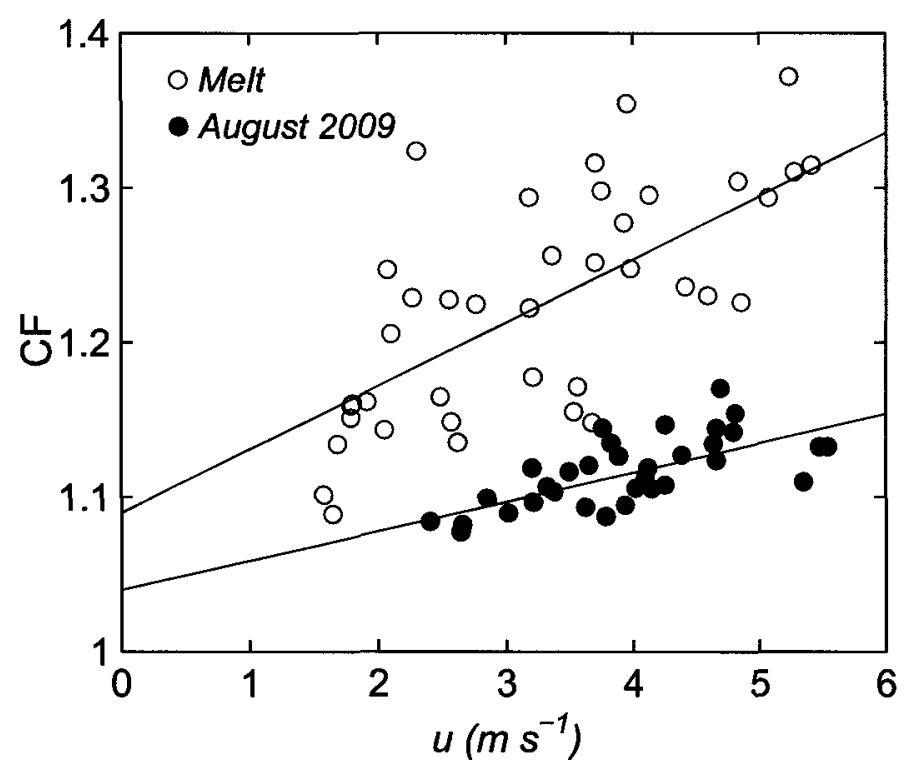

Figure 3.5: Relationship between correction factor for $L_{v} E$ and half-hour average horizontal wind speed $(u)$ for 39 daytime half hours during melt and 34 daytime half hours during August 2009.

\subsubsection{Summer Energy Budget Closure}

In this study, $H$ and $L_{v} E$ were also adjusted to achieve energy balance closure (i.e. Wilson et al., 2000; Barr et al., 2002) during the month of August 2009, when the system was considered to be operating under more 'ideal' conditions and there was no snow 
cover and associated energy terms. The slope of the relationship between net radiation minus the sum of ground heat flux and rate of energy storage in the air $\left(R_{n}-(G+J)\right)$ and the total turbulent flux $\left(H+L_{v} E\right)$ indicated that the eddy covariance underestimated turbulent fluxes by $14 \%$ for all available half-hours during August 2009 (slope $=0.86$, intercept $\left.=3.08 \mathrm{~W} \mathrm{~m}^{-2}, \mathrm{r}^{2}=0.96, \mathrm{n}=989\right)$. A $14 \%$ increase was also applied to $H$ and $L_{v} E$ during the winter study period. 


\subsection{Results}

\subsection{Environmental Conditions}

The $2009-2010$ winter was a low snow year, with total seasonal snowfall $(1.38$ m) $41 \%$ lower than normal (Meteorological Services of Canada, Ottawa International Airport, 2010). During the study period (21 December 2009 - 12 March 2010), there were two major snowfall events ( $1-6$ January and $23-25$ February), and several smaller events (Figure 4.1a). The snowpack reached a maximum snow depth of $0.37 \mathrm{~m}$ following the first major snow event, and SWE reached a maximum value of $90 \mathrm{~mm}$ following the second event (Figure 4.2). There were also two significant rain-on-snow (ROS) events throughout the winter; the first event occurred from 25-26 December, during which $20.2 \mathrm{~mm}$ of rain fell, and the second ROS event occurred from $24-26$ January, depositing $46.8 \mathrm{~mm}$ of rain (Figure $4.1 \mathrm{~b})$. A thick ice layer $(\sim 20 \mathrm{~mm})$ developed following the first rain event, while the second resulted in substantial melt of the snow cover. Snowmelt began around 24 February, and based on the mounted camera (Appendix A), by 1 March the tops of the hummocks were largely snow-free, and by 4 March the snowpack was highly discontinuous. The remaining snow cover melted rapidly from 4-8 March, after which only a few small snow patches remained in the hollows, and finally by 12 March the bog was snow-free. Depth measurements determined via the automated sonic sensor represent a reasonable areal average for the site, although it suggests that complete ablation of the snowpack occurred on 9 March, which is three days earlier than when the site was actually snow-free (Figure 4.2), although by 9 March the snow-covered area (SCA) was less than 5\%. 

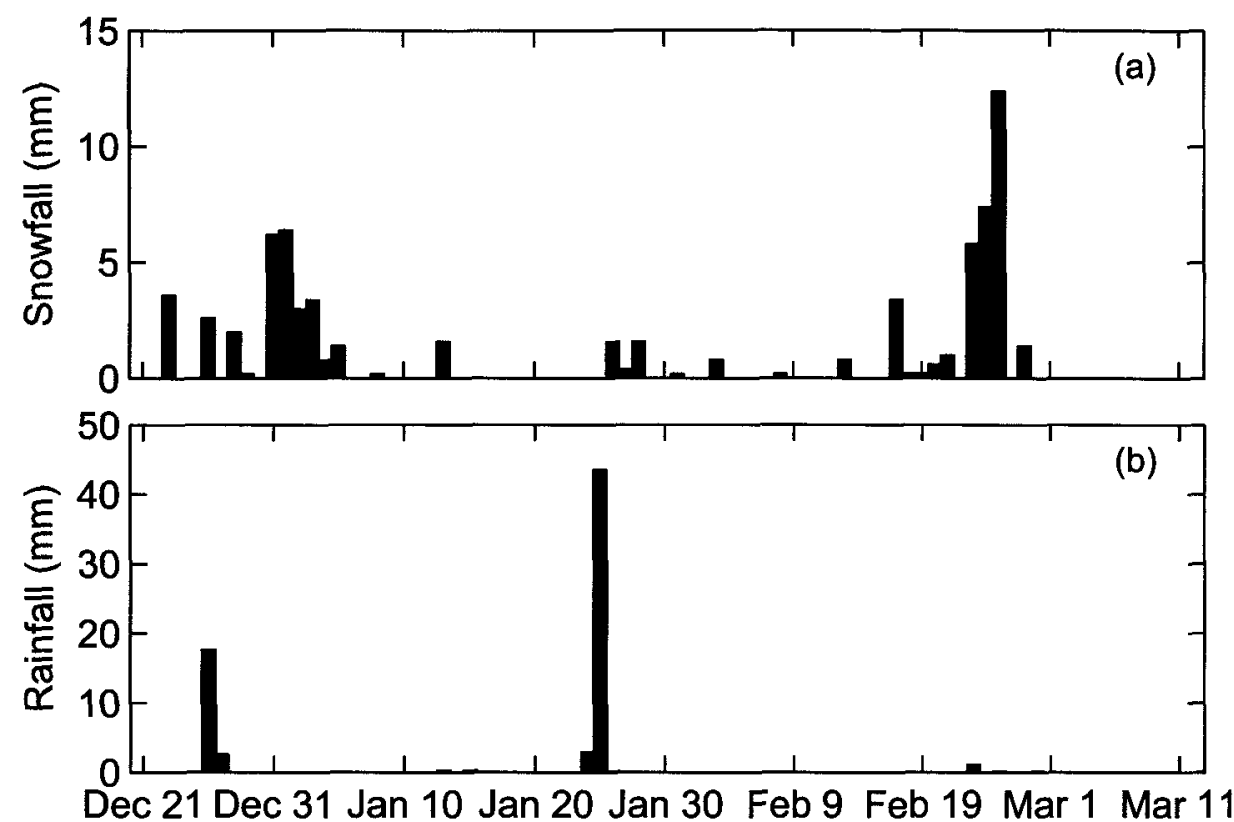

Figure 4.1: Daily water equivalent of (a) snowfall and (b) rainfall. Data from Ottawa International Airport, Meteorological Services of Canada.


Figure 4.2: (a) Daily average continuous and manual snow depth measurements, and (b) manual SWE measurements. The vertical bars are \pm 1 SD of the mean. 
Figure 4.3 shows daily average climate variables for the period of observation. Average daily wind speed $(u)$ was $2.9 \mathrm{~m} \mathrm{~s}^{-1}$, with values exceeding $5 \mathrm{~m} \mathrm{~s}^{-1}$ during significant precipitation events, and reaching a minimum of $0.7 \mathrm{~m} \mathrm{~s}^{-1}$ between events (Figure 4.3a). Average daily air temperatures $\left(T_{a}\right)$ ranged from $-19.7^{\circ} \mathrm{C}$ to $5.7^{\circ} \mathrm{C}$, with a mean value of $-5.3{ }^{\circ} \mathrm{C}$ (Figure $4.3 \mathrm{c}$ ). Air temperatures were well below freezing throughout the snow accumulation period, except during ROS events when temperatures reached or exceeded $0{ }^{\circ} \mathrm{C} . T_{a}$ rose above freezing following 22 February, and remained above or near $0^{\circ} \mathrm{C}$ thereafter. Daily mean snow surface temperatures $\left(T_{s s}\right)$ closely followed air temperatures, ranging from $-21^{\circ} \mathrm{C}$ to $5.3^{\circ} \mathrm{C}$, with a mean value of $-6.6^{\circ} \mathrm{C}$ (Figure 4.3c). The snow cover was largely isothermal during ROS events and following 24 February. Positive $T_{s s}$ observed during melt was the result of a patchy snow cover, as the peat surface became warmer than the snowpack which is constrained at $0{ }^{\circ} \mathrm{C}$. Mean vapour pressure during most of the ablation period was below $611 \mathrm{~Pa}$ (i.e. saturation vapour pressure at $0^{\circ} \mathrm{C}$ ), indicating that the vapour gradient tended to be directed away from the snow cover when the snowpack was actively melting (Figure 4.3b). Thus, the snow cover is expected to lose mass and energy by evaporation, resulting in a cooling of the snow cover. Conversely, during the large $24-26$ January ROS event, there was a modest vapour gradient toward the snow cover, resulting in additional energy for melt. Although the upper $\sim 0.20 \mathrm{~m}$ of peat on the hummocks froze during the winter, soil temperatures at depth remained above freezing throughout the snow-covered period (Figure 4.3d). Daily mean soil temperatures at $0.60 \mathrm{~m}$ ranged from $4^{\circ} \mathrm{C}$ at the start of the study to $1{ }^{\circ} \mathrm{C}$ at the end of melt. There were several periods of soil freeze/thaw in the upper peat layers which corresponded largely to ROS events, and following 24 February, 
soil temperatures in the upper layers increased to $\sim 0{ }^{\circ} \mathrm{C}$ and remained close to freezing until the end of melt.
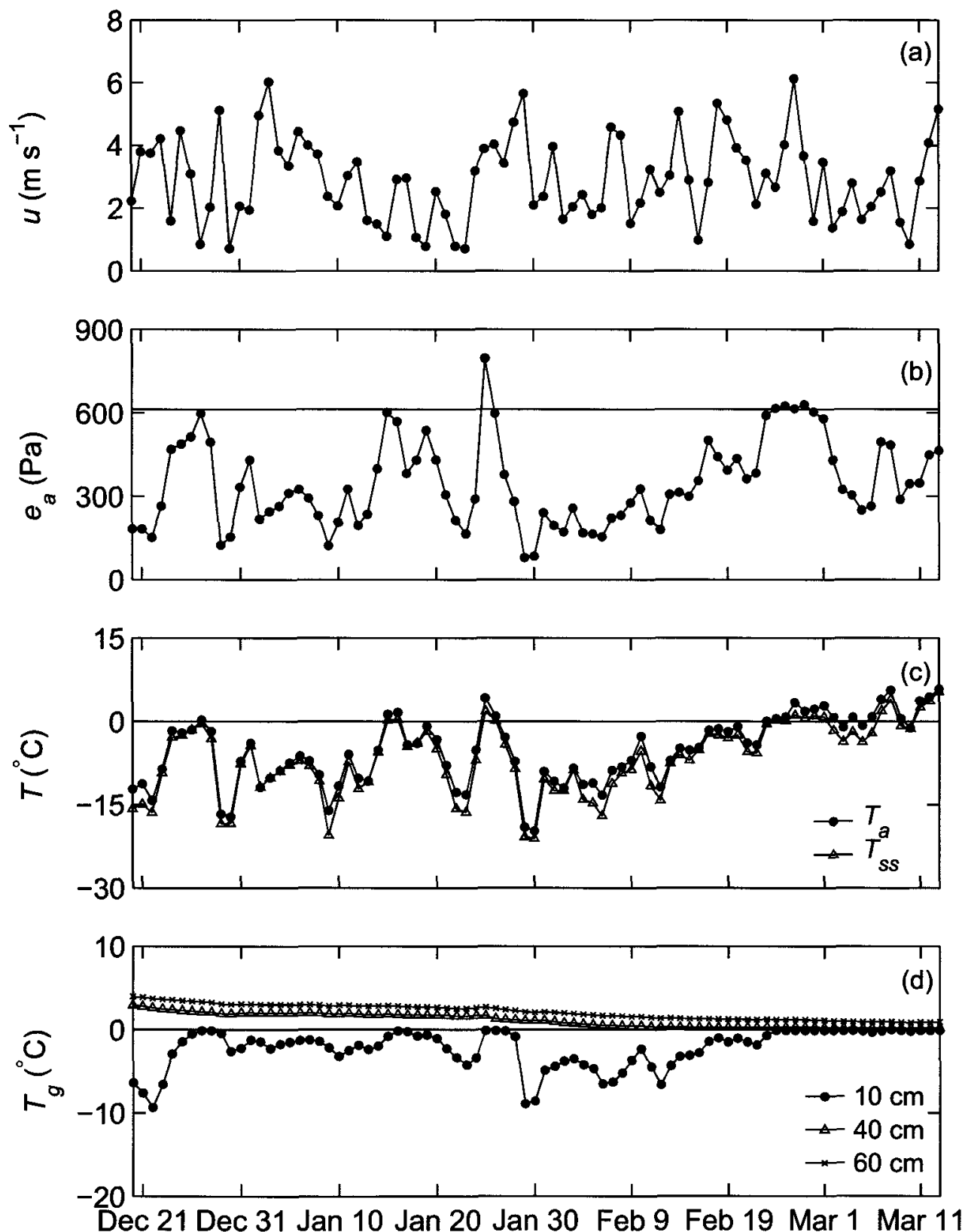

Figure 4.3: (a) Daily average wind speed $(u)$, (b) vapour pressure $\left(e_{a}\right)$, (c) air temperature $\left(T_{a}\right)$ and snow surface temperature $\left(T_{s s}\right)$, and (d) soil temperature $\left(T_{g}\right)$. 


\subsection{Snow Cover Energy Balance}

\subsubsection{Accumulation Period}

Figure 4.4 presents daily mean values for $R_{n}, H, L_{v} E, G, M$, and $\Delta Q$ for the entire snow season, and Figure 4.5 shows weekly average fluxes. Figure 4.6 presents the relative contribution of each $\mathrm{EB}$ component to the total weekly snow cover energy flux when the snow cover was continuous. Values are calculated as the ratio of each energy flux term and the sum of the absolute magnitude of each term such that the height of each bar is $100 \%$, where positive contributions indicate energy fluxes towards the snowpack (e.g. Marks and Dozier, 1992; Marks et al., 1998; Link and Marks, 1999a; Sensoy et al., 2006). Once the snow cover became patchy ( $1 \mathrm{March})$, the relative contribution of the EB components to the energy balance could not be assessed as the measurements were no longer representative of the snowpack (i.e. Equation (2.1)), but were representative of a heterogeneous surface. 

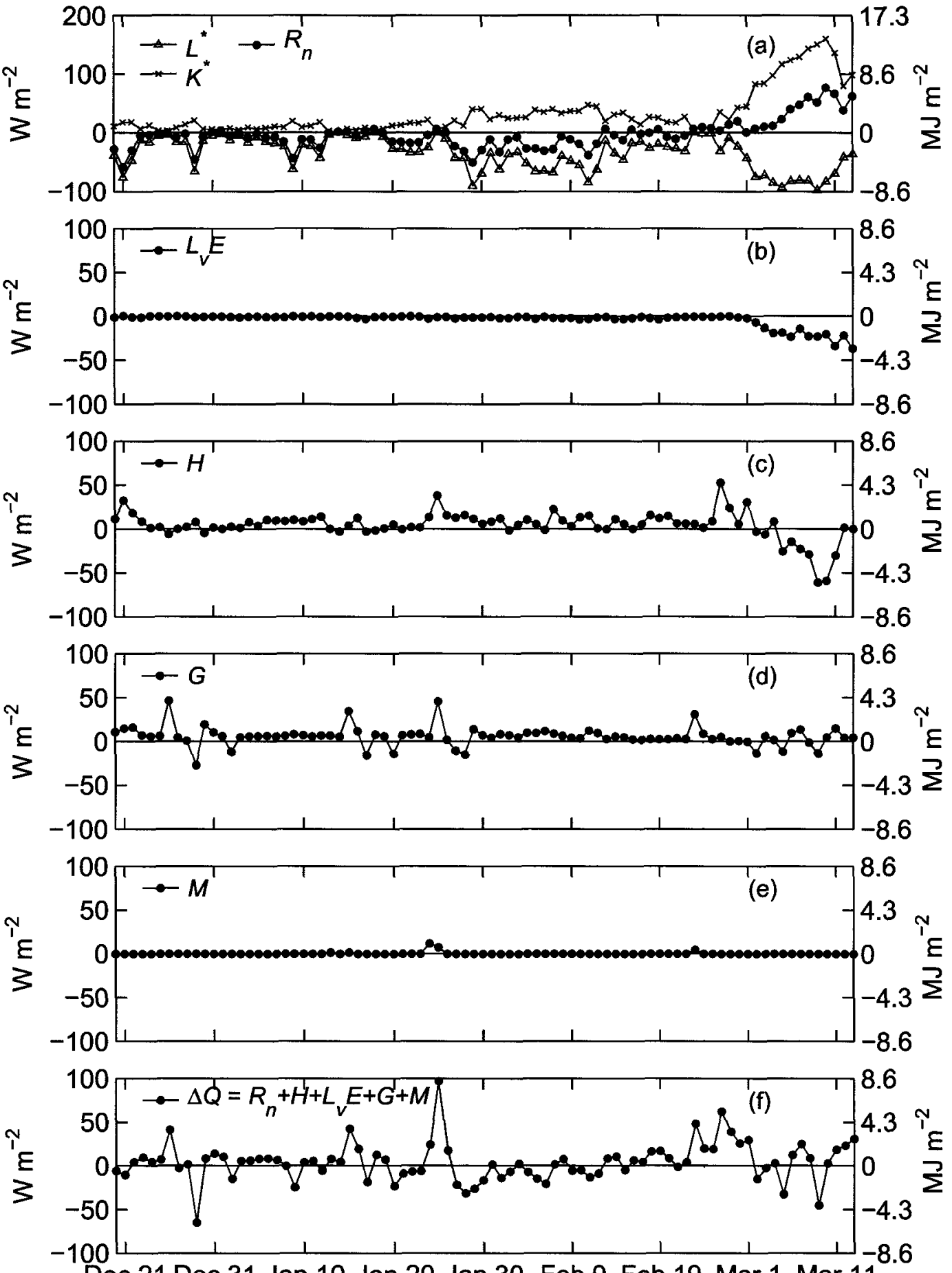

Dec 21 Dec 31 Jan 10 Jan 20 Jan 30 Feb 9 Feb 19 Mar 1 Mar 11

Figure 4.4: Measured (a) daily average net solar $\left(K^{*}\right)$, net thermal $\left(L^{*}\right)$ radiation, and net all-wave radiation $\left(R_{n}\right)$, (b) latent heat flux $\left(L_{v} E\right)$, (c) sensible heat fluxes $(H)$, (d) ground heat flux ( $G$ ), (e) advected heat flux ( $M$ ), and (f) sum of the energy balance terms $(\Delta Q)$. Vertical dotted line separates the accumulation from the melt period. Note the change in vertical axis following panel (a). 




Figure 4.5: energy balance components on a weekly time step.

During the accumulation period, from 21 December 2009 to 23 February 2010 when $\Delta Q$ generally oscillated near zero (Figure $4.4 \mathrm{f}$ ), $R_{n}$ was generally the dominant component of the snow cover energy balance (Figure 4.4a and Figure 4.5). Over this period, $R_{n}$ comprised $43 \%$ of the energy exchanges, with weekly contributions ranging from $13-78 \%$ (Figure 4.6). Net radiation was predominantly negative, resulting in a loss of energy from the snowpack, reaching a minimum daily value of $-59 \mathrm{~W} \mathrm{~m}^{-2}(-5.1$ MJ $\mathrm{m}^{-2} \mathrm{~d}^{-1}$ ), as longwave radiation $\left(L^{*}\right)$ was typically more important than shortwave radiation $\left(K^{*}\right)$. This was due to a combination of low incoming longwave radiation from the atmosphere during clear-sky conditions, low sun angles and a high albedo (Figure 4.7). During this period, albedo remained generally constant, with maximum values 
exceeding 0.90 following snowfall, and reached a minimum value of 0.68 after the $24-$ 26 January ROS event when snow depth was reduced to less than $0.20 \mathrm{~m}$, and shrubs protruded slightly above the snow cover.

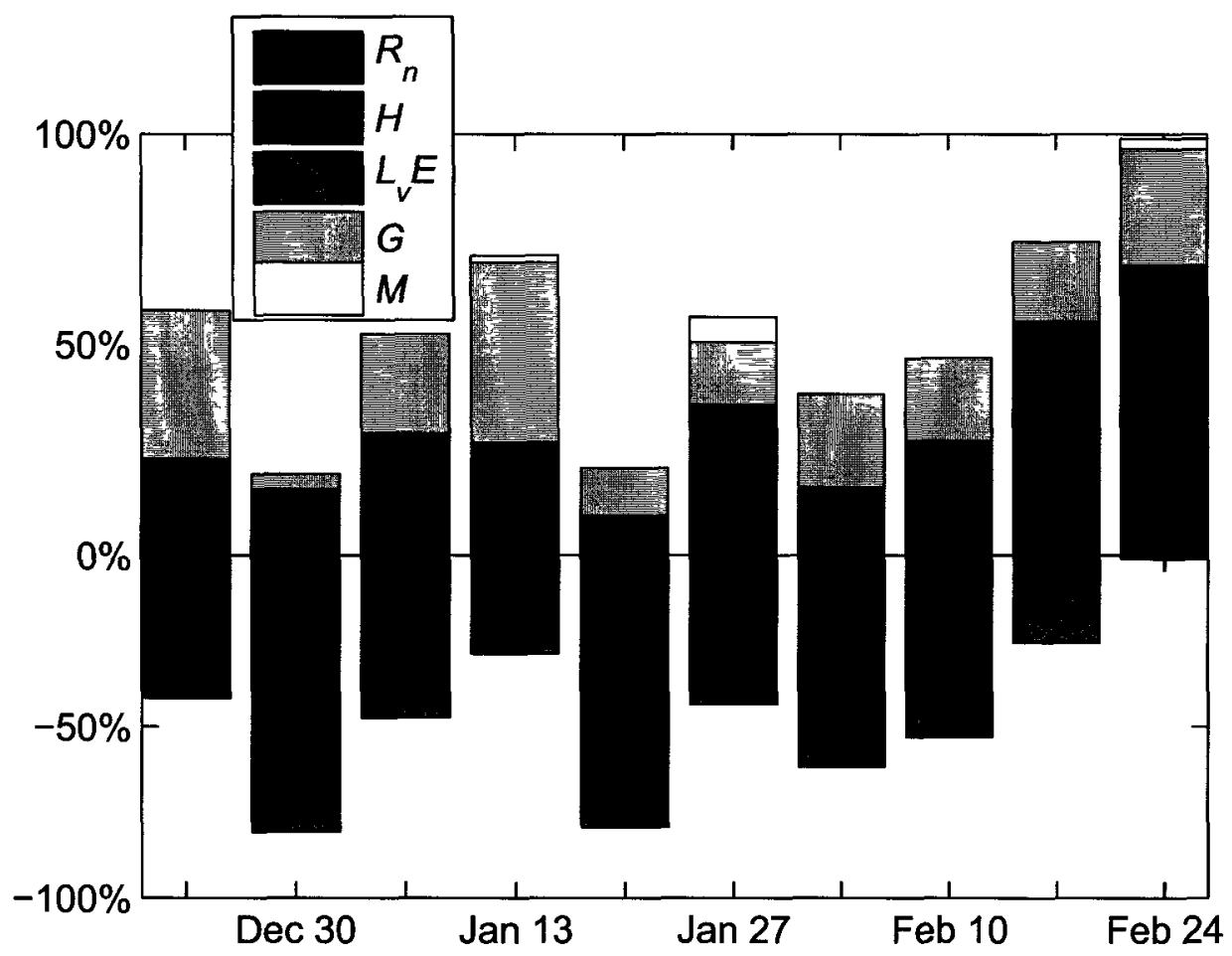

Figure 4.6: Relative contribution of each energy flux term to weekly average energy balance during the period when the snow cover is continuous (21 December 2009 to 28 February 2010). Values are calculated as the ratio of each energy flux term and the sum of the absolute magnitude of each term such that the height of each bar is $100 \%$. Positive contributions indicate energy fluxes towards the snowpack.

Mid-winter daily average latent heat fluxes were near zero, ranging between $\sim 0$ and $-3 \mathrm{~W} \mathrm{~m}^{-2}\left(0\right.$ and $\left.-0.26 \mathrm{MJ} \mathrm{m}^{-2} \mathrm{~d}^{-1}\right)$ (Figure $4.4 \mathrm{~b}$ ), and throughout this period $L_{v} E$ comprised only $\sim 4 \%$ of the overall energy. This small, but sustained negative latent heat flux was due to the fact that except during very cold, calm conditions or during storms, 
the vapour pressure of the air was lower than that of the snow surface. Sublimation was largely continuous at an average rate of $0.03 \mathrm{~mm} \mathrm{~d}^{-1}$, which represents approximately 2.1 mm of SWE over the accumulation season. Even 30-minute average latent heat fluxes rarely exceeded $-5 \mathrm{~W} \mathrm{~m}^{-2}$, as the majority $(81 \%)$ were near zero $\left( \pm 5 \mathrm{~W} \mathrm{~m}^{-2}\right)$ (Figure 4.9$)$.

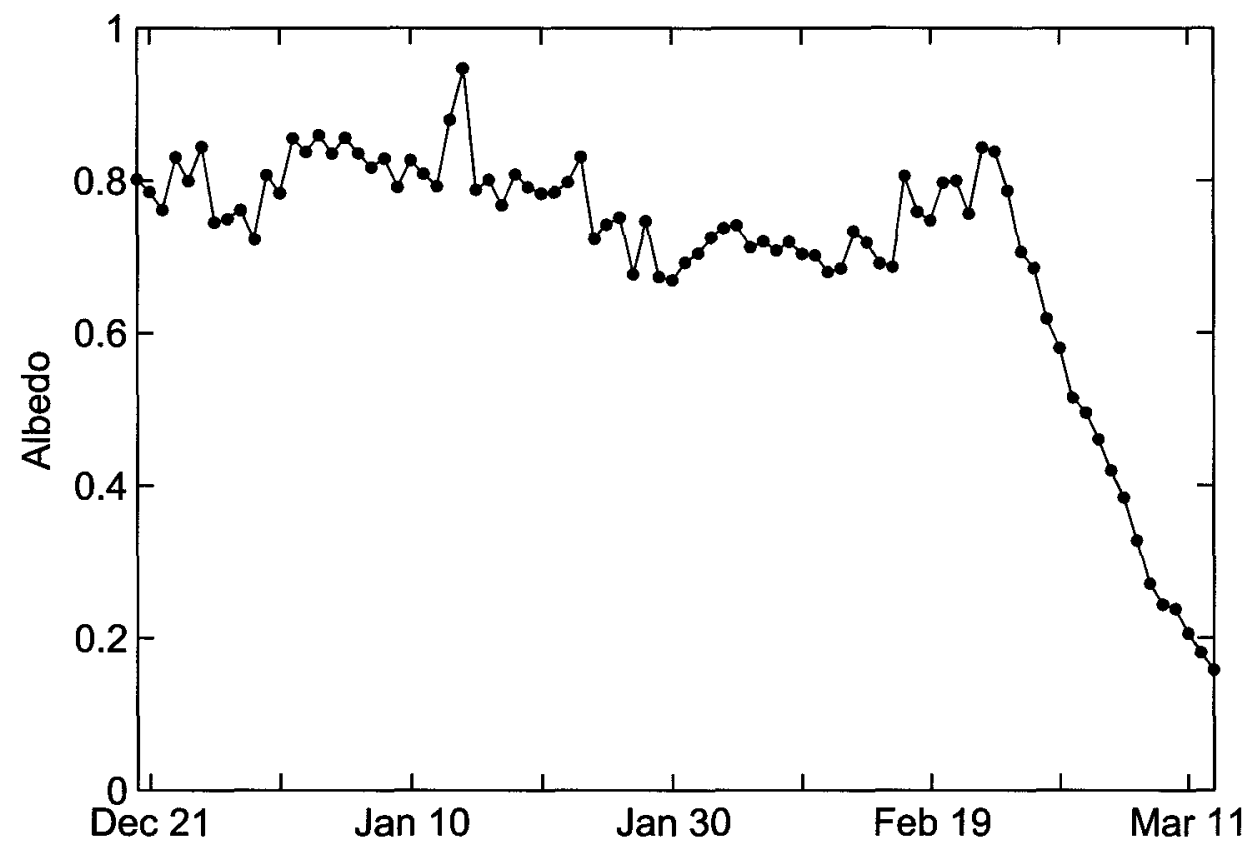

Figure 4.7: Measured daily mean shortwave albedo.

The sensible heat flux was the second most important term in the snow cover energy balance during this period (Figure 4.5 ), contributing between $2 \%$ and $56 \%$ of weekly energy exchanges (Figure 4.6 ), or $27 \%$ when integrated over the accumulation period. The magnitude of daily mean sensible heat flux was considerably greater than that of the latent heat flux, with a mean value of $7.5 \mathrm{~W} \mathrm{~m}^{-2}\left(0.65 \mathrm{MJ} \mathrm{m}^{-2} \mathrm{~d}^{-1}\right)$, and fluxes 
were directed toward the snowpack (Figure 4.4c), as the snow surface was typically cooler than the overlying air. Peak sensible heat flux $\left(38 \mathrm{~W} \mathrm{~m}^{-2}\right.$ or $\left.3.3 \mathrm{MJ} \mathrm{m}^{-2} \mathrm{~d}^{-1}\right)$ was observed during the $24-26$ January ROS event as warm air temperatures in conjunction with increased wind speeds resulted in a large transfer of sensible heat to the snow surface.

During the accumulation season, the snow cover was warmed by sensible heat and cooled by sublimation, however, since $H$ was greater than, but opposite in sign, to $L_{v} E$, the net turbulent flux was generally a source of energy to the snow cover.

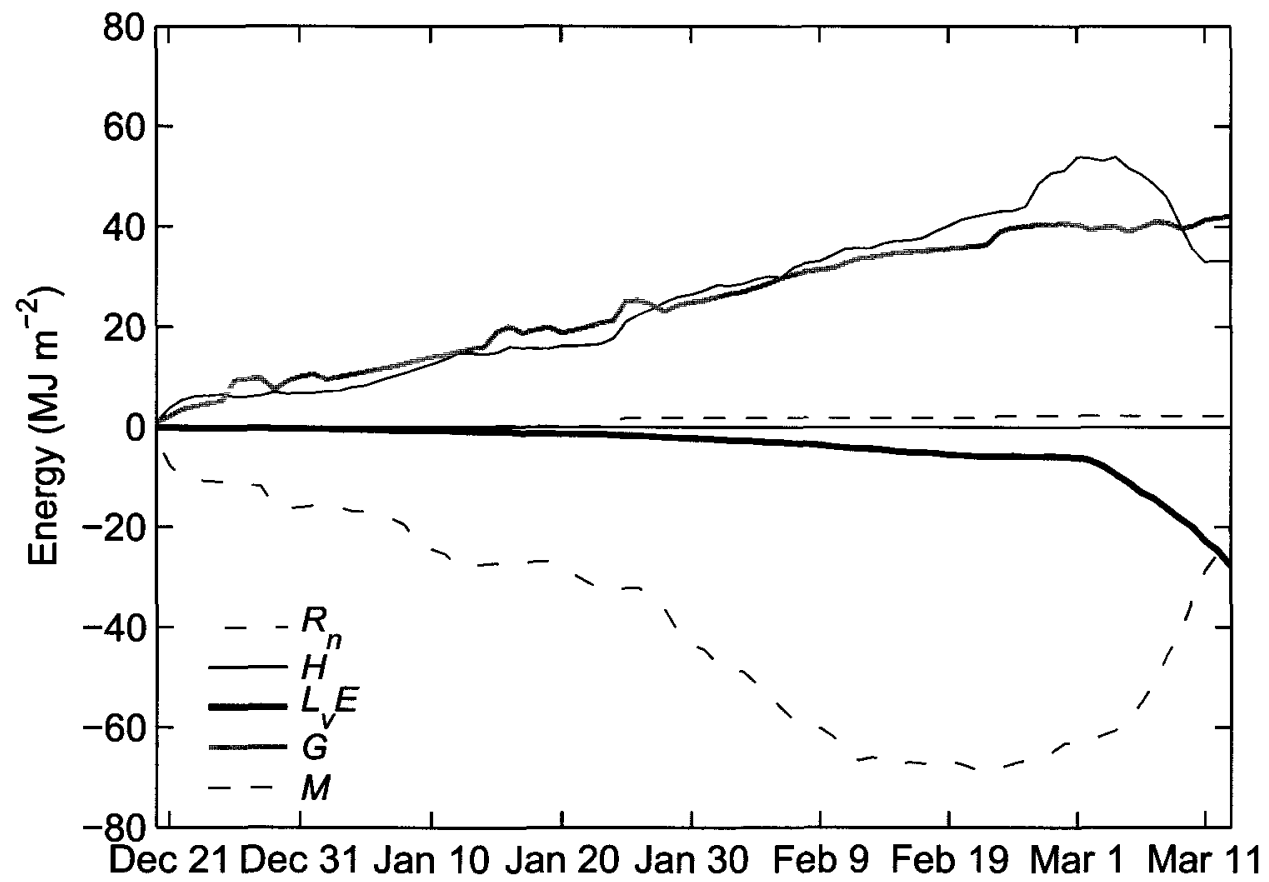

Figure 4.8: Cumulative sum of energy balance components from 21 December 2009 to 12 March 2010. 
On a weekly basis, the ground heat flux was comparable in magnitude and direction with $H$ (Figure 4.5); $G$ comprised $25 \%$ of the energy balance prior to melt, with weekly contributions ranging from $1-40 \%$ (Figure 4.6). Prior to the $24-26$ January ROS event, $G$ provided more energy to the snow cover than $H$ (Figure 4.8), but when integrated over the accumulation season, $G$ contributed slightly less energy than $H$ (39.1 MJ vs. 43.1 MJ, respectively). Daily average ground heat flux was largely directed toward the soil surface, with a mean value of $6.9 \mathrm{~W} \mathrm{~m}^{-2}\left(0.60 \mathrm{MJ} \mathrm{m}^{-2} \mathrm{~d}^{-1}\right)$ (Figure 4.4d). The large positive ( $\left.47 \mathrm{~W} \mathrm{~m}^{-2}\left(4.1 \mathrm{MJ} \mathrm{m}^{-2} \mathrm{~d}^{-1}\right)\right)$, and negative $\left(-27 \mathrm{~W} \mathrm{~m}^{-2}(-2.3 \mathrm{MJ}\right.$ $\left.\mathrm{m}^{-2} \mathrm{~d}^{-1}\right)$ ) peaks in measured daily mean ground heat flux correspond to periods of soil freeze and thaw, respectively, as the large amount of energy involved in phase change of water significantly enhanced the magnitude of $G$. During periods with no soil freeze or thaw, $G$ was smaller, ranging between 2 to $12 \mathrm{~W} \mathrm{~m}^{-2}\left(0.17\right.$ to $\left.1.0 \mathrm{MJ} \mathrm{m}^{-2} \mathrm{~d}^{-1}\right)$, but still remained an important component of the energy balance (Figure 4.5 and Figure 4.6). This sustained positive flux reflects the positive soil temperatures maintained at depth through the winter.

Advected energy from rain was relatively minor, with the only notable contribution during the $24-26$ January ROS (Figure 4.4e). The total heat input from rain throughout the winter was $2.3 \mathrm{MJ}$ (Figure 4.8 ), and $M$ comprised only $\sim 1 \%$ of the overall energy. 


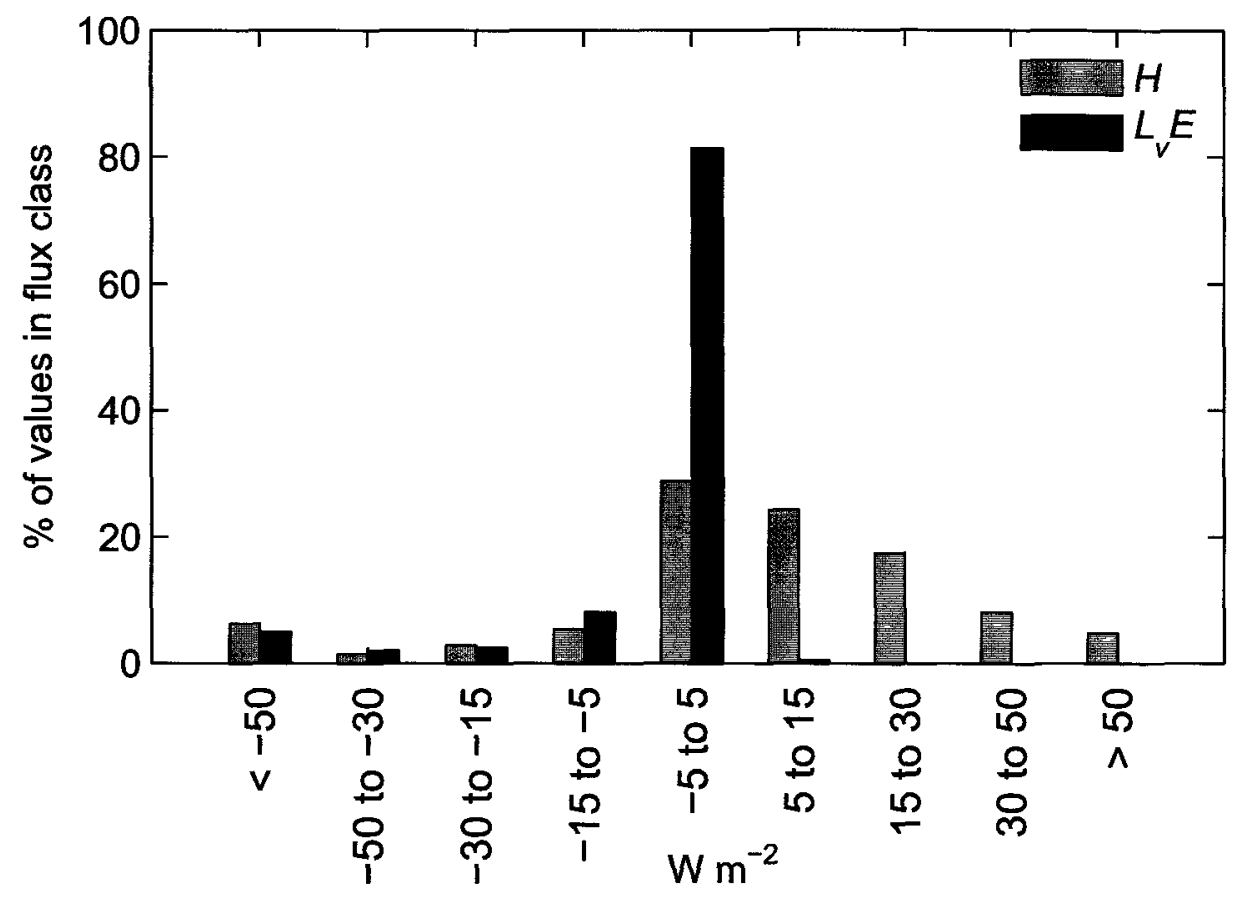

Figure 4.9: 30-minute average sensible (light gray grey bars) and latent (dark gray bars) heat flux frequency distribution.

\subsubsection{Melt Period}

Figure 4.10 shows daily mean $R_{n}, H, L_{v} E, G$, and $A$ for the melt period, from 24 February to 9 March 2010 when $\Delta Q$ was largely positive (Figure $4.4 \mathrm{f}$ ). $R_{n}$ and turbulent fluxes were estimated as measured values following the development of a patchy snow cover were no longer representative of fluxes for a point on the snow surface (i.e. Equation (2.1)) (Section 3.2.8). Table 4.1 presents the summary of the relative magnitude of energy transfer during snowmelt. 

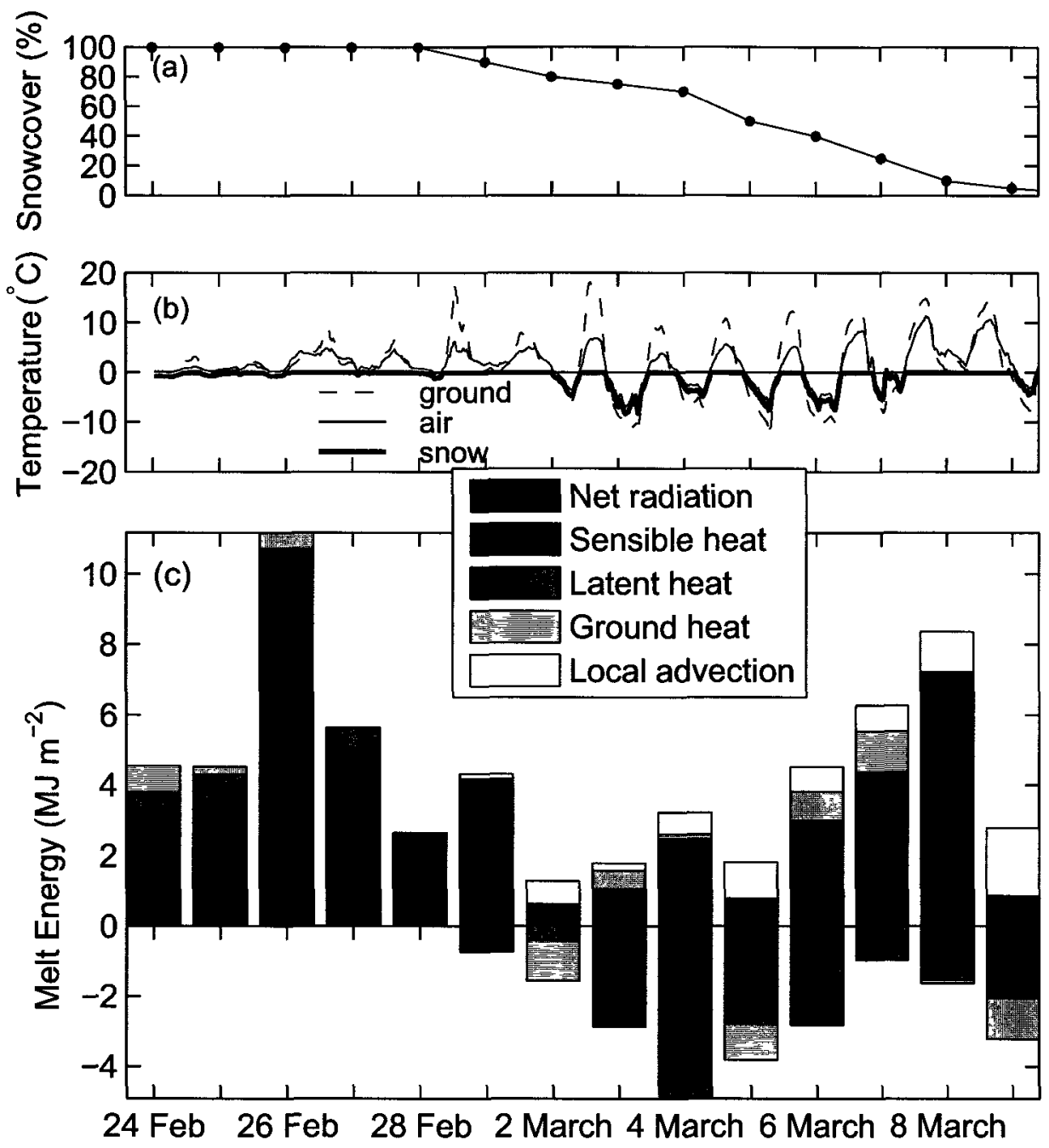

Figure 4.10: (a) Snow-covered area, (b) air temperature, and estimated snow surface and bare ground temperature, and (c) daily average energy balance terms for the snow cover from 24 February 2009 to 9 March 2010.

Sensible heat flux was the dominant form of energy input to the snow cover during melt (Figure $4.10 \mathrm{c}$ ), comprising $52 \%$ of the total energy for snowmelt (Table 4.1). The large contribution from $H$ was due to air temperature rising above freezing while the snow surface remained constrained at $0{ }^{\circ} \mathrm{C}$. Net radiation only comprised $15 \%$ of the energy balance as melt occurred early in the season. Contributions from $G$ were minor 
when integrated over the melt period as soils at depth reached their coolest values of the year at this time (Figure 4.3d) while the upper peat layers hovered around freezing. $L_{v} E$ was a small source of energy to the snow cover early in the melt season, but then reversed sign, increasing in magnitude as melt progressed (Figure 4.10c). The overall negative EB from 2-5 March was due to subfreezing nighttime temperatures (Figure 4.10b), resulting in negative daily mean $R_{n}$ and reduced turbulent transfer, and to a decrease in relative humidity (Figure 4.3b), resulting in an increase in $L_{v} E$ away from the snow surface. Local advection comprised $10 \%$ of the overall melt energy (Table 4.1 ), with its magnitude increasing with increasing snow-free area (Figure 4.10a and c).

Table 4.1: Snowpack energy summary for the snowmelt period. $\overline{\Delta Q}$ was estimated as the sum of the energy balance components and calculated from the water balance. The percent of energy transfer was calculated for each energy flux by dividing it by the sum of the absolute of all the energy fluxes $\left(70.4 \mathrm{~W} \mathrm{~m}^{-2}\right)$.

\begin{tabular}{lccccccc}
\hline & $R_{n}$ & $H$ & $L_{v} E$ & $G$ & $A$ & $\overline{\Delta Q}_{\text {sum of EB components }}$ & $\overline{\Delta Q}_{\text {water balance }}$ \\
\hline $\begin{array}{l}\text { Energy }\left(\mathrm{MJ} \mathrm{m}^{-2}\right) \\
\begin{array}{l}\text { of energy } \\
\text { transfer }\end{array}\end{array}$ & 10.9 & 36.7 & -14.9 & 0.7 & 7.2 & 40.5 & 34.4 \\
\hline
\end{tabular}

Whereas the air immediately above the snow patches remained stable during melt, as indicated from the sensible heat flux directed toward the snow (Figure 4.10c), the increase in measured turbulent fluxes away from the surface following 1 March (Figure $4.4 \mathrm{~b}$ and c) suggests that the regional boundary layer and the air above the bare surface were unstable as is expected for a patchy snow cover (Granger et al., 2006). The large 
increase in measured daily mean $R_{n}$ during melt (up to $164 \mathrm{~W} \mathrm{~m}^{-2}\left(14.2 \mathrm{MJ} \mathrm{m}^{-2} \mathrm{~d}^{-1}\right)$ )

(Figure 4.4a) reflects the rapid decrease in surface albedo (Figure 4.7) combined with higher sun angles and longer days.

\subsection{Energy Balance Closure}

Figure 4.11 shows $L_{v} E+H$ plotted against $\Delta Q-\left(R_{n}+G+J\right)$. Here, only data having friction velocities $\left(u_{*}\right)$ greater than $0.1 \mathrm{~m} \mathrm{~s}^{-1}$ were selected to ensure that the flow was well developed, the turbulence was continuous, and the assumptions required for using the eddy covariance technique were upheld (Helgason, 2009). The data were further sorted into daytime and nighttime periods. Data points lying close to the 1:1 line would suggest that all components of the energy balance were adequately measured.

Table 4.2 summarizes the results of the energy balance closure based on the linear regression of half hour data for rain-free periods when air and snow temperatures were below freezing. Poor energy balance closure was achieved during the winter, with total closure around 54\%, and daytime closure (48\%) somewhat exceeding nighttime closure (43\%). However, all periods had significant scatter, as indicated from $r^{2}$ values ranging from 0.56 for all observations to 0.40 for nighttime values. As will be discussed in Chapter 5, this either suggests limitations in the measurement approach or a gap in our understanding of how the snowpack exchanges energy with the environment. 


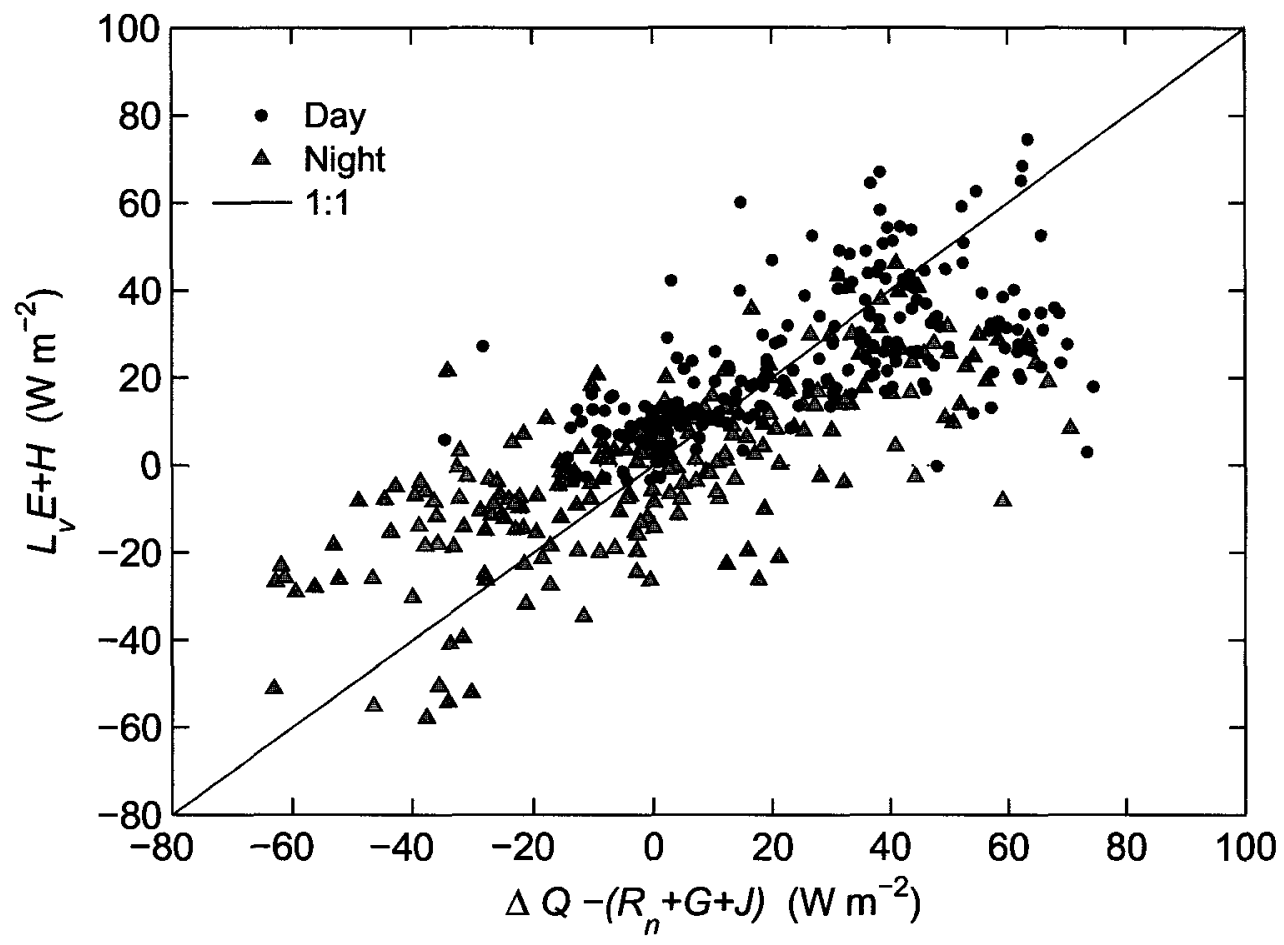

Figure 4.11: Energy budget closure $\left(L_{v} E+H\right.$ vs. $\left.\Delta Q-\left(R_{n}+G+J\right)\right)$ for 232 and 223 nighttime and daytime half hours, respectively, for rain free periods when air and snow temperatures were below freezing.

Table 4.2: Energy budget closure results for rain-free periods when air and snow temperatures were below freezing are indicated by the slope and intercept of the regression between $L_{v} E+H$ and $\Delta Q-\left(R_{n}+G+J\right)$. The number of half-hour measurements used in the linear least squares regression is indicated by $\mathrm{n}$.

\begin{tabular}{lllll}
\hline Period & Slope & $\begin{array}{l}\text { Intercept } \\
\left(\mathrm{W} \mathrm{m} \mathrm{m}^{-2}\right)\end{array}$ & $\mathrm{r}^{2}$ & $\mathrm{n}$ \\
\hline Total & 0.54 & 4.70 & 0.56 & 455 \\
Daytime & 0.48 & -0.43 & 0.53 & 223 \\
Nighttime & 0.43 & 12.38 & 0.40 & 232 \\
\hline
\end{tabular}




\subsection{Modelled Versus Measured Snow Cover Energy and Mass Balance}

\subsubsection{Mass Balance}

Figure 4.12 presents a comparison of simulated and measured snow depth and SWE, and modelled daily melt from the base of the snowpack. The three analysis periods listed in Table 4.4 are also indicated. The accumulation period was divided into the early period and mid period following the $24-26$ January ROS event as there was generally a poorer agreement between modelled and measured values following this event. Model-fitting statistics calculated using both automatic and manual depth measurements are presented in Table 4.3. For the period during which both the continuously (manually) measured and modelled snow depths were available, the RMSD was $0.055 \mathrm{~m}(0.066 \mathrm{~m})$, the relative bias was $-1 \%(-9 \%)$, with a ME of $0.37(0.47)$ (Table 4.3). The low ME and large RMSD can be attributed to the model overestimating snow depth early in the snow season, when there was considerable snowfall, and simulating complete ablation 5 days earlier than the date measured by the sonic depth sampler (SCA $<5 \%$ ) (Figure 4.12a). As indicated by the relative bias, overall simulated depths were underestimated. However, there is good agreement between modelled and simulated depths from 4 January to the onset of snowmelt, as indicated by a RMSD of $0.015 \mathrm{~m}$, a relative bias of $2 \%$, and a ME of 0.94 .

Figure $4.12 \mathrm{~b}$ compares simulated SWE to measured field values. Although the simulated SWE follows the overall trend of measured values, it is over-predicted during the accumulation period and under-predicted during melt (Figure 4.12b), resulting in poor model-fitting statistics (Table 4.3). This is largely due to the model overestimating snowpack density; measured densities ranged between 250 to $400 \mathrm{~kg} \mathrm{~m}^{-3}$, whereas 
modelled densities ranged between 250 and $546 \mathrm{~kg} \mathrm{~m}^{-3}$, with a relative bias of $26 \%$ for the simulation period.

During the mid-winter period, there was only one melt event which exceeded the water-holding capacity of the snowcover (Figure 4.12c). This occurred during the $24-$ 26 January ROS event, and generated $22.2 \mathrm{~mm}$ of melt from the base of the snowpack. Modelled melt with associated runoff production started on 24 February and continued for a period of 9 days, with complete snowpack removal occurring by 4 March (Figure 4.12c). Maximum modelled melt rates during snowmelt exceeded $23.2 \mathrm{~mm} \mathrm{~d}^{-1}$, with an average rate of $12.0 \mathrm{~mm} \mathrm{~d}^{-1}$, which is greater than the measured rate of $7.9 \mathrm{~mm} \mathrm{~d}^{-1}$.
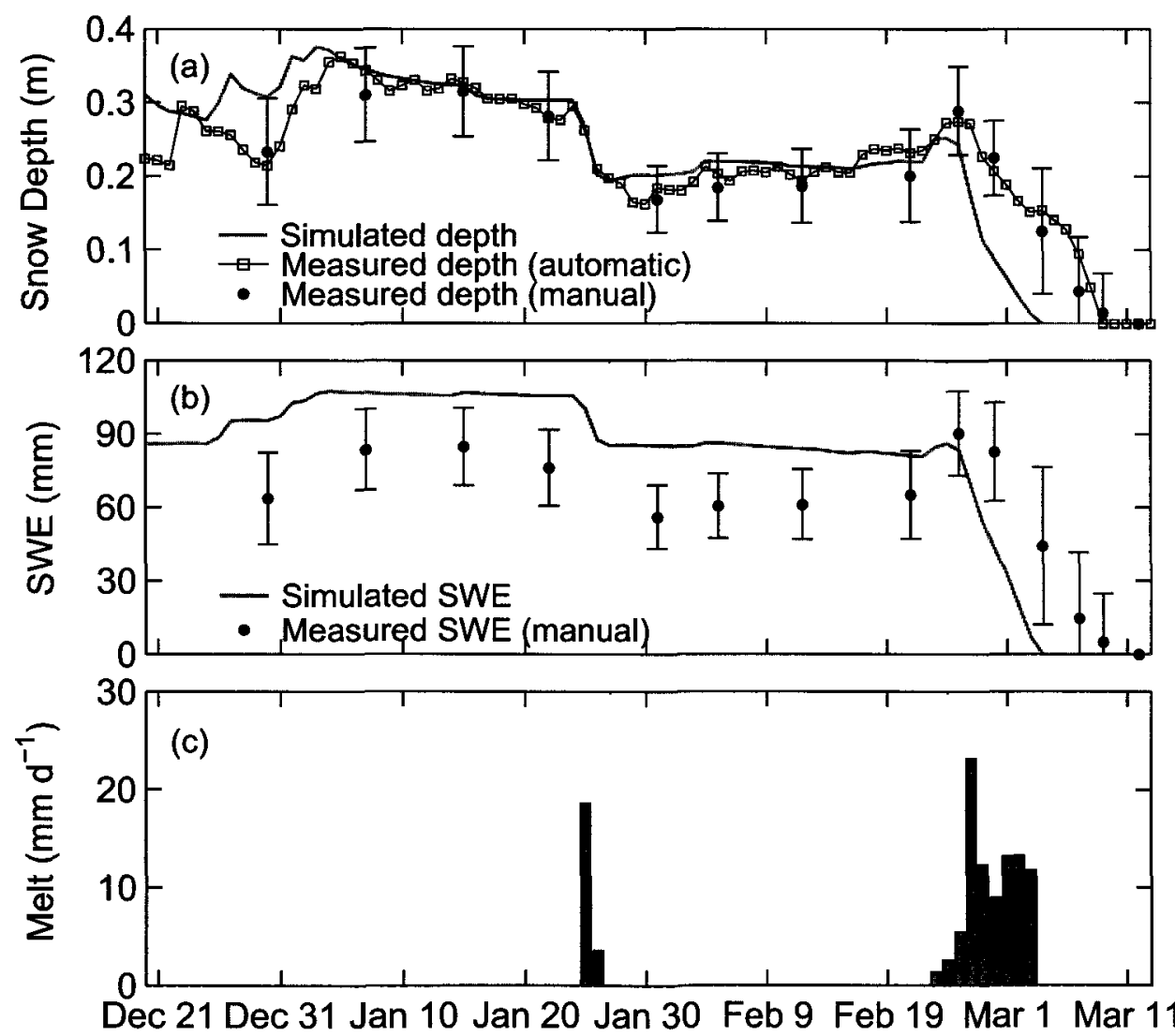

Figure 4.12: Measured and simulated (a) snow depth, (b) SWE, and (c) modelled daily snowmelt at the base of the snowpack. The vertical bars are \pm 1 SD of the mean. 
Table 4.3: Model fitting statistics. Root mean square difference (RMSD), absolute mean bias difference (AMBD), relative mean bias difference (RMBD), and model efficiency (ME) between measured and simulated snow depth and SWE.

\begin{tabular}{llll}
\hline & & Snow Depth & SWE \\
\hline RMSD (m) & continuous & 0.055 & -- \\
& manual & 0.066 & 0.250 \\
AMBD (m) & continuous & -0.002 & -- \\
& manual & -0.017 & 0.053 \\
RMBD (\%) & continuous & -1 & -- \\
& manual & -9 & 8 \\
ME & continuous & 0.37 & -- \\
& manual & 0.47 & 0.02 \\
\hline
\end{tabular}

\subsubsection{Surface Energy Balance}

\section{Net Radiation}

Measured and modelled daily mean $R_{n}$ compared favourably, particularly prior to the 24-26 January ROS event (Figure 4.13a and Figure 4.14a). During the early period, differences between modelled and measured $R_{n}$ were small $\left(1.4 \mathrm{~W} \mathrm{~m}^{-2}\right.$, mean values -8.1 and $-9.8 \mathrm{~W} \mathrm{~m}^{-2}$ ), and the variables showed a strong correspondence, with a coefficient of determination $\mathrm{r}^{2}=0.95$. Differences increased in the mid period to $3 \mathrm{~W} \mathrm{~m}^{-2}$ (mean values -11.1 and $-14.9 \mathrm{~W} \mathrm{~m}^{-2}$ ), and the $\mathrm{r}^{2}$ decreased slightly to 0.93 (Table 4.4). This was due to the model over-estimating the magnitude of nighttime snow surface temperatures when the snowpack was shallow $(\sim 0.20 \mathrm{~m})$ and air temperatures were well below zero (Figure 4.15a), which resulted in a systematic underestimation of the magnitude of $R_{n}$ during the night (Figure 4.15b). When averaged over the period when the snow cover was continuous (21 December 2009 to 28 February 2010) (i.e. when measured and simulated fluxes were representative of the same surface), the discrepancy between simulated and measured net radiation was $2.5 \mathrm{~W} \mathrm{~m}^{-2}$ (mean values -7.8 and $-10.3 \mathrm{~W} \mathrm{~m}^{-2} ; \mathrm{r}^{2}=0.95$ ). 

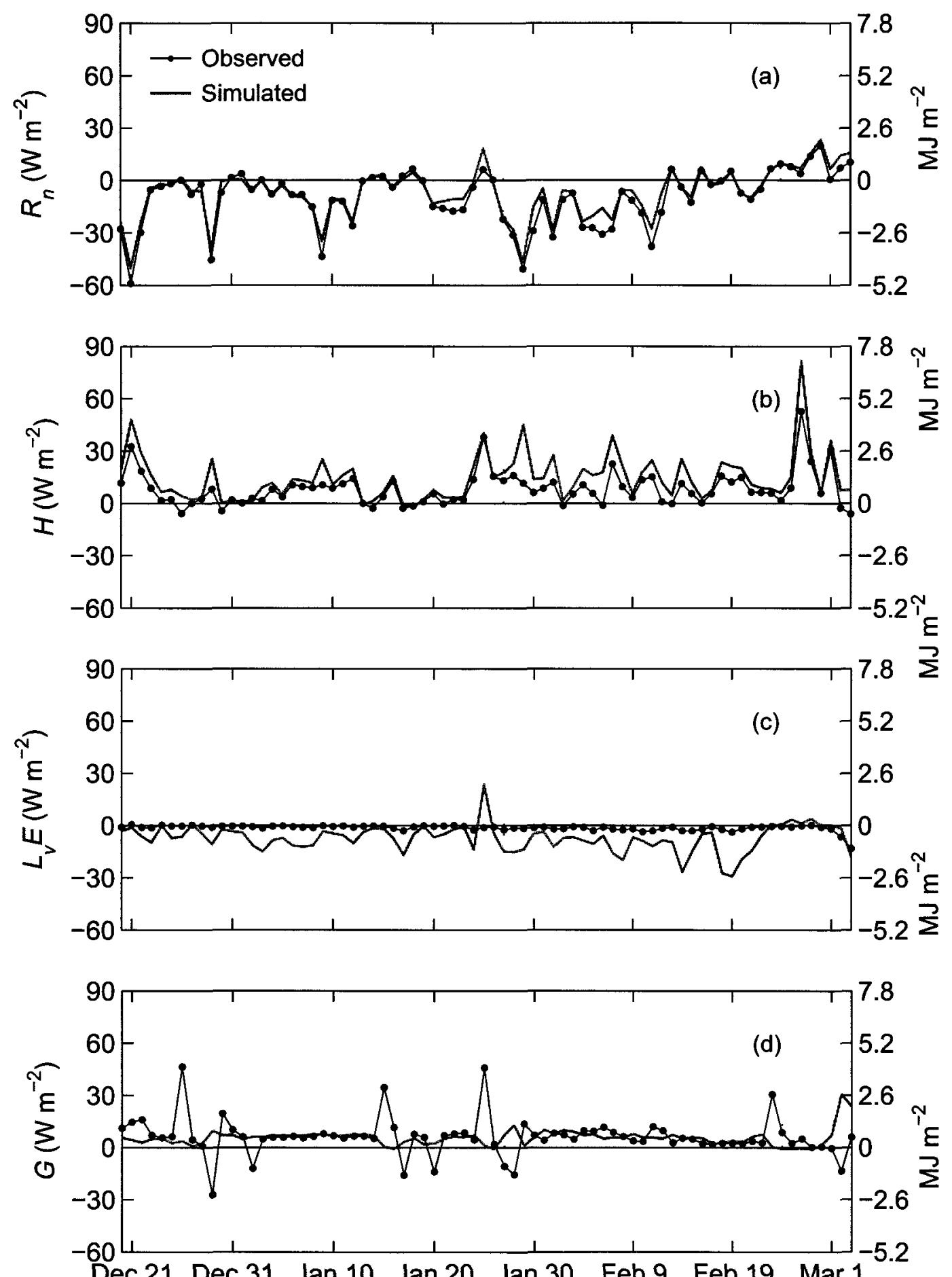

Figure 4.13: Measured (dotted line) and modelled (gray line) (a) net radiation $\left(R_{n}\right)$, (b) latent heat flux $\left(L_{v} E\right)$, (c) sensible heat flux $(H)$, (d) ground heat flux $(G)$, and (e) advected energy from rain $(M)$. 

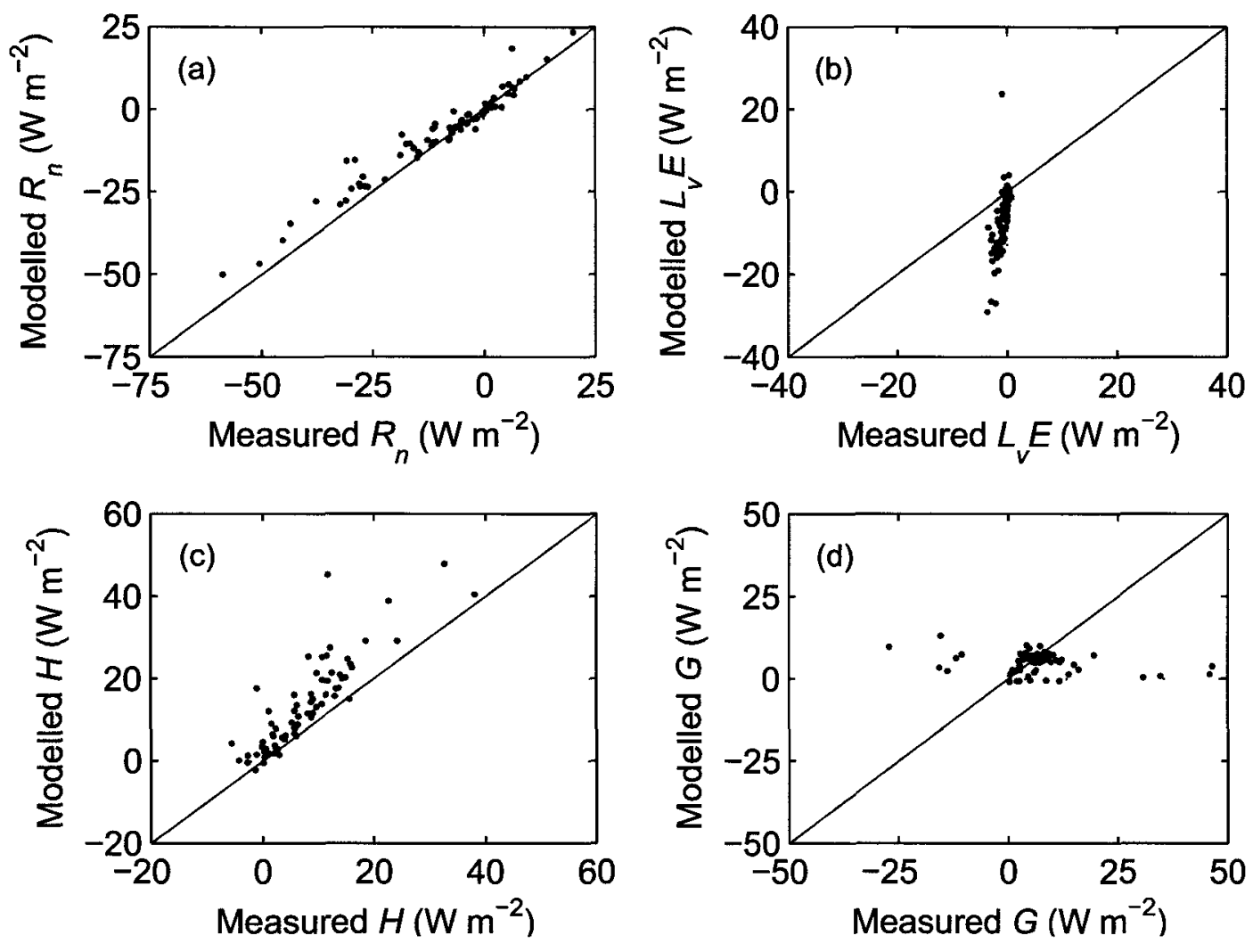

Figure 4.14: Comparison of daily mean (a) net radiation $\left(R_{n}\right)$, (b) latent heat flux $\left(L_{v} E\right)$, (c) sensible heat flux ( $H$ ), and (d) ground heat flux $(G)$ prior to the development of a patchy snow cover.

Table 4.4: Measured and modelled snow cover energy flux summary. Average measured and simulated energy flux, and coefficient of determination $\left(\mathrm{r}^{2}\right)$ for three periods of analysis (Early: 21 Dec - 26 Jan; Mid: 27 Jan - 23 Feb; Melt: 24 Feb - 4 March; Overall $\left.{ }^{*}: 21 \mathrm{Dec}-28 \mathrm{Feb}\right)$. Note that since energy fluxes are averaged over the analysis periods, they typically represent a wide range of values.

\begin{tabular}{llllllllllllll}
\hline & \multicolumn{3}{c}{$\begin{array}{c}R_{n} \\
\left(\mathrm{~W} \mathrm{~m}^{-2}\right)\end{array}$} & \multicolumn{3}{c}{$\begin{array}{c}L_{v} E \\
\left(\mathrm{~W} \mathrm{~m}^{-2}\right)\end{array}$} & \multicolumn{3}{c}{$\begin{array}{c}H \\
\left(\mathrm{~W} \mathrm{~m}^{-2}\right)\end{array}$} & \multicolumn{3}{c}{$\begin{array}{c}G \\
\left(\mathrm{~W} \mathrm{~m}^{-2}\right)\end{array}$} \\
\cline { 2 - 14 } Period & Obs. & Snobal & $\mathrm{r}^{2}$ & Obs. & Snobal & $\mathrm{r}^{2}$ & Obs. & Snobal & $\mathrm{r}^{2}$ & Obs. & Snobal & $\mathrm{r}^{2}$ \\
\hline Early & -9.8 & -8.1 & 0.95 & -0.5 & -5.2 & 0.22 & 6.8 & 11.2 & 0.86 & 7.7 & 5.1 & 0.03 \\
Mid & -14.9 & -11.1 & 0.93 & -1.7 & -11.6 & 0.38 & 8.6 & 16.9 & 0.59 & 5.7 & 6.2 & 0.01 \\
Melt & 9.4 & 12.7 & 0.81 & -2.8 & -1.1 & 0.89 & 14.5 & 23.8 & 0.92 & 1.2 & 7.6 & 0.28 \\
Overall & -10.3 & -7.8 & 0.95 & -1.0 & -7.2 & 0.44 & 8.4 & 14.6 & 0.83 & 6.6 & 5.2 & 0.06 \\
\hline
\end{tabular}

*Overall corresponds to the period when the snow cover was continuous $(21 \mathrm{Dec}-28$

Feb) since simulated and measured fluxes were representative of the same surface. 


\section{Turbulent Fluxes}

Throughout the simulation period, modelled daily mean $H$ compared reasonably well to EC-measured values (Figure 4.13b and Figure 4.14c), as indicated by the overall $\mathrm{r}^{2}$ of 0.83 (Table 4.4), however, simulated $H$ for all analysis periods was greater than EC-measured $H$, with an overall difference of $6.2 \mathrm{~W} \mathrm{~m}^{-2}$ (mean values 14.6 and $8.4 \mathrm{~W}$ $\mathrm{m}^{-2}$, respectively). The discrepancy between modelled and measured fluxes was smallest in the early period $\left(4.4 \mathrm{~W} \mathrm{~m}^{-2}\right.$, mean values 11.2 and $\left.6.8 \mathrm{~W} \mathrm{~m}^{-2} ; \mathrm{r}^{2}=0.86\right)$, but increased to $8.3 \mathrm{~W} \mathrm{~m}^{-2}$ following the large mid-winter ROS event (mean values 16.9 and $8.6 \mathrm{~W} \mathrm{~m}^{-}$ ${ }^{2}$ ). This was the result of nighttime fluxes being slightly over-predicted, and the magnitude of daytime fluxes being under-predicted during the mid period (Figure 4.15c). The variables also showed a weaker association during this period $\left(r^{2}=0.59\right)$. The largest difference between modelled and measured $H$ occurred during melt $\left(9.3 \mathrm{~W} \mathrm{~m}^{-2}\right.$, mean values 14.6 and $8.4 \mathrm{~W} \mathrm{~m}^{-2}$ ) when daytime fluxes were over-predicted (Figure 4.13b).

Modelled daily mean latent heat fluxes were substantially greater in magnitude than EC-measured $L_{v} E$ (Figure 4.13c and Figure 4.14b), and there was a poorer association between simulated and measured fluxes compared to $R_{n}$ and $H$ (overall $\mathrm{r}^{2}=$ 0.44 ) (Table 4.4). This was due to the model over-predicting daytime $L_{v} E$, as nighttime values were simulated with reasonable accuracy (Figure 4.15d). The discrepancy between modelled and measured $L_{\nu} E$ increased following the 24-26 January ROS event and, as with the other surface fluxes, exhibited the greatest difference during the mid period $\left(9.9 \mathrm{~W} \mathrm{~m}^{-2}\right.$, mean values -11.6 and $-1.7 \mathrm{~W} \mathrm{~m}^{-2}$ ) (Table 4.4). In terms of mass flux, this corresponds to a modelled sublimation rate of $0.35 \mathrm{~mm} \mathrm{~d}^{-1}$, whereas measured 
rates were only $0.05 \mathrm{~mm} \mathrm{~d}^{-1}$. However, the coefficient of determination was greater in the mid period than in the early period $\left(r^{2}=0.38\right.$ and 0.22 , respectively). The only period where measured $L_{v} E$ was greater in magnitude than modelled values was during melt, as predominantly positive $L_{v} E$ (i.e. condensation) were simulated early in the melt period, whereas measured values were largely directed away from the snow cover (Figure 4.13c). Consequently, modelled daily average sublimation rates were smallest during melt $(0.04$ $\mathrm{mm} \mathrm{d}^{-1}$ ). Overall, there was a difference of $6.2 \mathrm{~W} \mathrm{~m}^{-2}$ between simulated and ECmeasured $L_{v} E$ (mean values -7.2 and $-1.0 \mathrm{~W} \mathrm{~m}^{-2}$, respectively), which corresponds to a cumulative sublimation difference of $13.6 \mathrm{~mm}$ or $0.19 \mathrm{~mm} \mathrm{~d}^{-1}$. This is a considerable difference, as it is approximately $86 \%$ of the $0.22 \mathrm{~mm} \mathrm{~d}^{-1}$ value simulated by the model.

\section{Ground Heat Flux}

Modelled ground heat flux was smaller than measurements suggest (Figure 4.13d), with an overall difference of $1.4 \mathrm{~W} \mathrm{~m}^{-2}$ (mean values 5.2 and $6.6 \mathrm{~W} \mathrm{~m}^{-2}$ ), or relative bias of $-22 \%$ (Table 4.4 ). In addition, the association between the variables was very weak (overall $\mathrm{r}^{2}=0.06$ ) (Figure $4.14 \mathrm{~d}$ ). This can in part be explained by the fact that the model does not consider the energy involved in the phase change of water when calculating $G$, resulting in considerably less variability in the modelled ground heat flux (Figure 4.13d). Unlike the other EB components, the discrepancy between modelled and simulated $G$ was lowest in the mid period $\left(1.2 \mathrm{~W} \mathrm{~m}^{-2}\right.$, mean values 5.2 and $4.0 \mathrm{~W} \mathrm{~m}^{-2}$, respectively). The difference in the ground heat flux estimation was highest during melt ( $6.4 \mathrm{~W} \mathrm{~m}^{-2}$; mean values 7.6 and $1.2 \mathrm{~W} \mathrm{~m}^{-2}$, respectively), which is primarily due to large nighttime flux modelled during the last 4 days of the simulation, as snow temperatures 
cooled during the evening, increasing the temperature gradient between the soil and the snowpack. This explains the large difference in modelled and measured daily mean $G$ observed at the end of melt (Figure 4.13d). However, the large positive nighttime modelled $G$ did not generate any melt as it was offset by radiative cooling, resulting in an overall loss of energy from the snow cover during the night. 

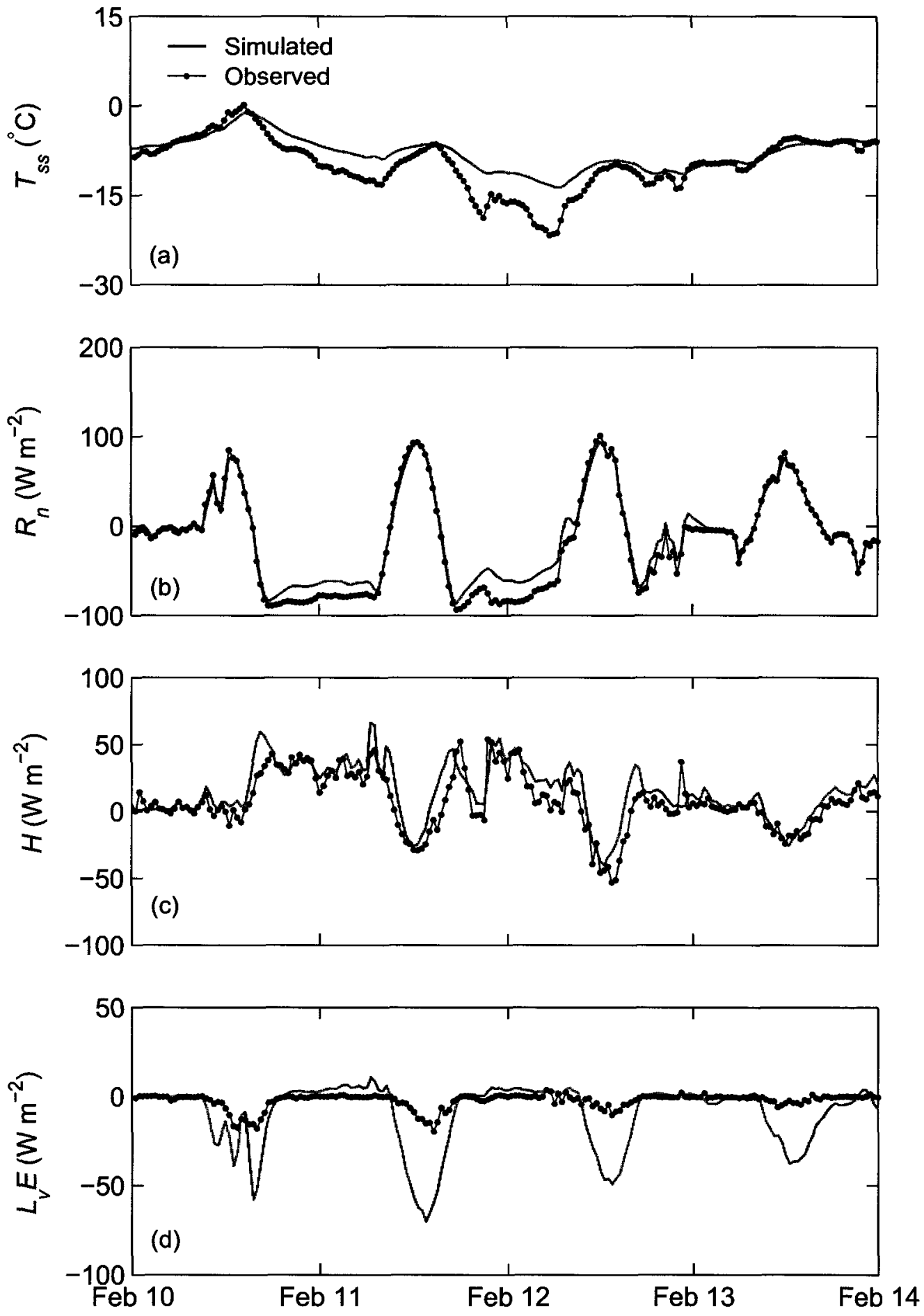

Figure 4.15: Measured (dotted line) and modelled (grey line) (a) snow surface temperature $\left(T_{s s}\right)$, (b) net radiation $\left(R_{n}\right)$, (c) sensible heat flux $(H)$, and (d) latent heat flux $\left(L_{v} E\right)$ for select days during the mid period, illustrating typical diurnal trends. 


\subsection{Discussion}

\subsection{Snow Cover Energy Balance}

\subsubsection{Pre-Melt Energy Balance}

The ground heat flux is often considered a negligible component of the daily or weekly energy balance of a snowpack when compared to radiative and turbulent fluxes (Male and Gray, 1981; Oke, 1987), which has led to many distributed modelling approaches to assume a ground temperature of $0^{\circ} \mathrm{C}$. This assumption is contradicted by my results that showed $G$ comprised an important component of the snow cover EB during the accumulation period (Figure 4.5a and Figure 4.6), and therefore played an important role in controlling the internal energy content of the snow cover prior to melt. Thus, in addition to being a sizeable source of energy to the snow cover early in the winter (e.g. Marks and Dozier, 1992; Link and Marks 1999a; Sensoy et al. 2006), G remained important throughout the accumulation season (Figure 4.6).

Integrating the contribution of $G$ over the snow accumulation season resulted in a considerable positive energy flux from the ground to the snowpack (39.1 MJ m $\mathrm{m}^{-2}$ to the snow cover, or $25 \%$ of total energy exchanges). This was nearly equal to $H$ with regards to determining the energy of the snow cover, as the cumulative input from $H$ prior to melt was $43.1 \mathrm{MJ} \mathrm{m}^{-2}$, or $27 \%$ of energy transfer. The large input from $G$ reflects the positive ground temperatures maintained at depth at this site throughout the winter.

This is the first study that reports relative measured $G$ contributions of this magnitude. Mazurkiewicz et al. (2008) found that $G$ comprised a significant percentage of the energy input to the snowpack (between $18 \%$ and $29 \%$ ) in the Pacific North West, 
where the soil remained above freezing throughout the winter, but this was based on modelled fluxes with no direct observations to support this result. In addition, they note that some bias from the soil temperature measurements may have overestimated $G$. Smith et al. (2008) found that in a year without extensive soil freezing prior to snowpack development, accumulated snowmelt, as measured with lysimeters, ranged from 11 to $107 \mathrm{~mm}$ ( 3 to $35 \%$ of peak SWE) while daily maximum air temperatures were well below zero, suggesting that $G$ generated the mid-winter snowmelt. Again, no measurements of soil heat flux were reported. Therefore, in environments with warm ground temperatures, $G$ plays an important role in controlling the energy status of the snow cover and should be considered in modelling studies to accurately characterize the mass and energy balance of the snowpack throughout the winter.

During mid-winter, the snow cover was warmed by sensible heat and cooled by sublimation (latent heat). Turbulent exchange was dominated by $H$ while $L_{v} E$ was small in the pre-melt season, and when integrated over this period, contributed less than $4 \%$ of the overall energy. This differs from the typical mid-winter balance between $H$ and $L_{v} E$ reported by Marks et al. $(1998 ; 1999 ; 2008)$ for mid-continental subalpine sites. However, this pattern is similar to results reported for a flat, homogeneous prairie snow cover. Helgason (2009) observed that a large proportion ( 65\%) of 30-minute average latent heat fluxes were near zero, with fluxes rarely exceeding $-15 \mathrm{~W} \mathrm{~m}^{-2}$, whereas $H$ was somewhat larger with fluxes typically less than $30 \mathrm{~W} \mathrm{~m}^{-2}$.

Mean sublimation rates prior to melt were consequently small, ranging from $\sim 0-$ $0.11 \mathrm{~mm} \mathrm{~d}^{-1}$, with an average of $0.03 \mathrm{~mm} \mathrm{~d}^{-1}$. This is low relative to values reported in the Canadian Prairies during blowing snow events $\left(1.2-1.8 \mathrm{~mm} \mathrm{~d}^{-1}\right.$ (Pomeroy and 
Essery, 1999)), and subalpine sites of the Rocky Mountains of Colorado (0.41 $\mathrm{mm} \mathrm{d}^{-1}$ (Molotch et al., 2007) and $0.21 \mathrm{~mm} \mathrm{~d}^{-1}$ (Marks et al., 2008)), but closer to values reported by Helgason (2009) and Male and Granger (1979) for prairie snow covers. Male and Granger (1979) found that sublimation rates averaged $0.1 \mathrm{~mm} \mathrm{~d}^{-1}$, but could be as low as $0.02 \mathrm{~mm} \mathrm{~d}^{-1}$.

As reported by Marks et al. (1998) and Link and Marks (1999a), $R_{n}$ was generally the dominant energy balance term prior to melt, comprising on average $43 \%$ of energy exchanges (Figure 4.6), and $R_{n}$ was largely directed away from the snow surface as it was dominated by thermal radiation (Figure 4.4).

\subsubsection{Snowmelt Energy Balance and Local Advection}

As reported by Marks and Winstral (2001) for the ridge site, $H$ was the dominant form of energy input to the snow cover during melt, since melt occurred early in the season when $R_{n}$ was still small. The ground heat flux was a small component of the EB during melt, as is typically observed (e.g. Male and Gray, 1981; Kuusisto, 1986; Pomeroy, 1998), since soil temperatures were near $0{ }^{\circ} \mathrm{C}$ with melt water removing the remaining temperature gradient (Dingman, 1994). Whereas Pohl and Marsh (2006) found that local advection contributed $\sim 28 \%$ to the melt energy at an Arctic site in northwestern Canada, this study found that it only comprised $10 \%$ of the total energy available for melt.

There is, however, uncertainty with regards to the fluxes calculated during melt. Measurements of air temperature and wind speed used to calculate $H$ and $L_{v} E$ were made at 2 and $3 \mathrm{~m}$, respectively, which is outside the IBL that develops over snow 
patches; according to equation (5b) from Granger et al. (2006), even for a snowpatch with a fetch of $10 \mathrm{~m}$, the IBL would only grow to a height of $0.87 \mathrm{~m}$. Also, there were no direct measurements of snow surface and bare ground temperatures or net radiation over snow patches. In addition, $P_{s}$ was roughly estimated based on the visual inspection of images taken by the camera mounted on the tower. Consequently, on a daily time step, there was disagreement between melt as estimated from the energy balance (i.e. equation (3.18)) versus melt as estimated from the water balance (i.e. SWE derived from the sonic depth sampler and snowfall) (Figure 5.1a). However, over the entire melt period, the energy available for melt as calculated from the energy balance $\left(\overline{\Delta Q}_{\text {sum of EB components }}\right)$ was within $20 \%$ of that calculated from the water balance $\left(\overline{\Delta Q}_{\text {water balance }}\right)$ (Table 4.1$)$, which is well within the errors of the energy balance terms; errors in $H+L_{v} E$ alone are typically within $\pm 25 \%$ on a daily basis (Moore, 1983). There was also relatively good agreement $\left(\mathrm{RMSD}=17.5 \mathrm{~W} \mathrm{~m}^{-2} ; \mathrm{r}^{2}=0.89\right)$ between the average sensible heat flux from a patchy surface $\left(H_{c}\right)$ as measured by the EC system and as calculated from (Neumann and Marsh, 1998) (Figure 5.1b):

$$
H_{c}=(H+A) P_{s}+H_{b} P_{b}
$$

Figure 5.1b provides some confidence in estimated $H, H_{b}$, and $A$, although $H_{c}$ as calculated from equation (5.1) is somewhat greater than EC measurements. 

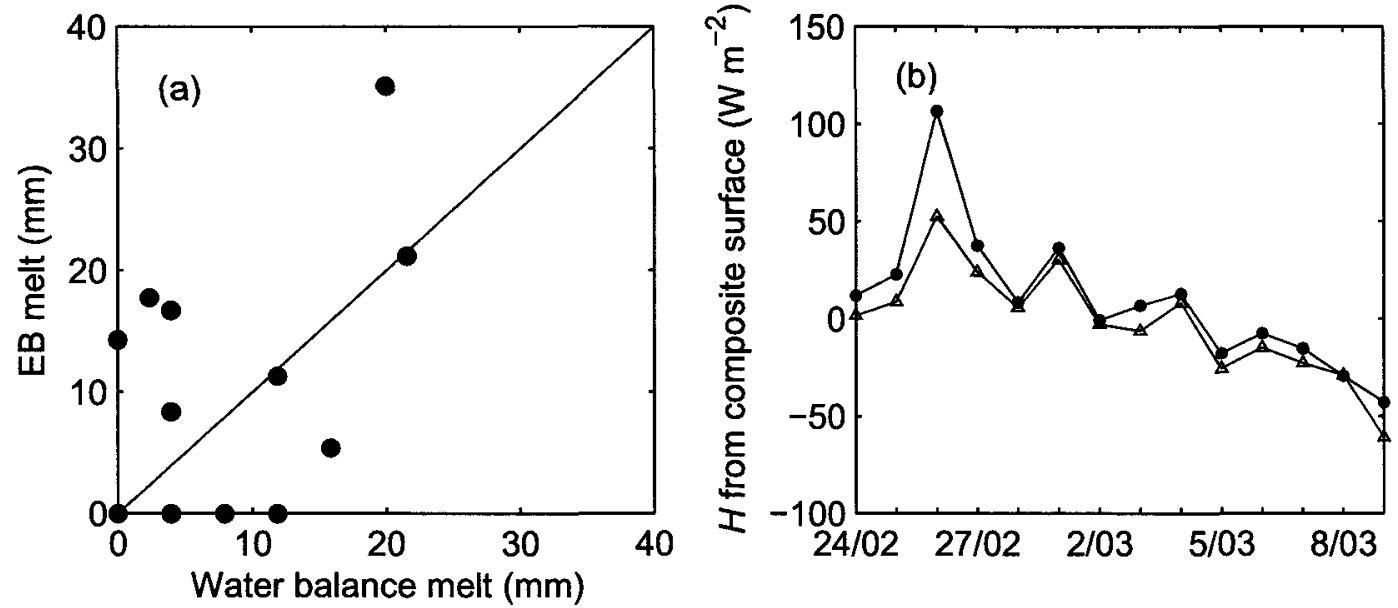

Figure 5.1: (a) Comparison of daily melt rate calculated as the residual of the energy balance and daily melt calculated from the water balance, and (b) comparison of $H_{c}$ as measured from the eddy covariance system (line with triangles) and as estimated from equation (5.1) (line with circle).

\subsection{Causes of the Energy Imbalance}

The measurements reported in this study revealed that the internal energy changes of the snowpack were inconsistent with the summation of the measured energy fluxes. This suggests a considerable deficit in the measurement approach or a gap in our understanding of the mechanisms of how the snow cover exchanges energy with the environment. Several studies have discussed the energy balance closure problem at snow-free sites (Wilson et al., 2002; Barr et al., 2006; Foken 2008). From an assessment of the energy balance of the FLUXNET sites, Wilson et al. (2002) suggest that lack of closure is typically due to the following factors: (a) sampling errors due to different measurement source areas; (b) systematic bias in instrumentation; (c) loss of low and high frequency information in the turbulent fluxes; and (d) neglected energy sinks or neglected advection of scalars. These points are considered in the context of this study. 
The instruments do have different measurement source areas, ranging from less than $1 \mathrm{~m}^{-2}$ for the ground heat flux and snow temperatures, to 200 to $1500 \mathrm{~m}^{-2}$ for the turbulent fluxes. Although the site was relatively homogeneous and had extensive fetch, the ground heat flux was measured in one location only and could have varied spatially, particularly between hummocks and hollows due to differences in snow depth and soil moisture. Nonetheless, EB closure with discrepancies less than $20 \%$ have been achieved in much more heterogeneous snow-free landscapes (e.g. Turnipseed et al., 2002).

To minimize systematic instrumental errors, data were subjected to rigorous verification procedures and were corrected where applicable (Section 3). During cold winter periods, the largest source of radiation error is due to the formation of rime on the sensors or snow that falls during light winds, blocking upward-facing sensors. These were not considered large sources of error as the relative humidity of the air was generally less than $90 \%$ with respect to ice during periods when EB closure was assessed, and little snow fell during these periods. Only incoming solar radiation could be compared with a nearby sensor (SP LITE, Kipp \& Zonen, Netherlands), and there was good agreement between the sensors $\left(K \downarrow_{C N R 1}=1.02 K \downarrow_{\text {SPLITE }}+2.27 \mathrm{~W} \mathrm{~m}^{-2}, \mathrm{r}^{2}=0.99\right)$. In the absence of any other nearby radiation measurements to discredit collected data, it is assumed that the radiometer was operating within specifications $( \pm 10 \%$ of daily totals).

The combination method used to calculate the ground heat flux is sensitive to the reference depth $\left(z_{\mathrm{r}}\right)$ and soil thermal conductivity $(\lambda)$ (Halliwell and Rouse, 1987), and is constrained by the ability to accurately determine changes in volumetric heat capacity for each soil layer (Sauer and Horton, 2005). The energy balance closure varied slightly with 
$z_{\mathrm{r}}$, with somewhat better closure for all periods and slightly less scatter for a reference depth of $0.30 \mathrm{~m}$ vs. $0.50 \mathrm{~m}$. This supports the $0.30 \mathrm{~m}$ reference depth used in this study. $\lambda$ was estimated from de Vries' (1963) method, which is a widely used and validated method to calculate $\lambda$ (Sauer and Horton, 2005; Zhang et al., 2008). As the total water content varied little during the periods under consideration, the volumetric heat capacity for the soil layers is assumed to be reasonable, although there is uncertainty with respect to the total water content of the soil layers (Section 3.2.4). However, varying the total water content in each layer by $\pm 50 \%$ did not appreciably affect $G$ or closure.

Considerable uncertainty in measured $\Delta Q$ could in part explain the energy imbalance. Melt-out around the thermocouple wires from solar heating excluded the use of temperature measurements in the upper levels of the snowpack, thermocouple heights may have been inexact due to the weight of the overlying snow causing deflection in the thermocouple wire, and it is assumed that the snow density had an uncertainty of about \pm $30 \mathrm{~kg} \mathrm{~m}^{-3}$. However, uncertainties in $\Delta Q$ alone only account for a portion of the large energy balance closure discrepancy.

With respect to turbulent fluxes, errors can be classified as being either instrumental or meteorological in nature (Massman and Lee, 2002). During winter periods, when stable conditions prevail and turbulent motions shift toward relatively higher frequencies and become more intermittent, the lack of instrument response due to finite time constant, sensor separation, tube attenuation, and path-length averaging become important limitations. Meteorological limitations include gravity waves, advection, and aerodynamic or low turbulence issues, and can be determined by examining the turbulence characteristics (Foken and Wichura, 1996). 
Raw data were subjected to quality control routines, and data were corrected where applicable to minimize instrumental errors (Sections 3.2 and 3.3). There is some uncertainty with respect to the correction factor applied to $L_{v} E$ due to the poor fit of the transfer function applied during melt conditions (Figure 3.4c). To assess the quality of the $L_{v} E$ measured using the closed path system, 30-minute average $L_{v} E$ fluxes obtained from the LI-7000 closed-path IRGA were compared for a brief period during the 20102011 winter (9 - 31 January 2011) against fluxes measured using a LI-7200 enclosed path IRGA. Comparison between the two instruments gave good agreement $\left(L_{v} E_{\text {enclosed }}=0.94 L_{v} E_{\text {closed }}-0.35 \mathrm{~W} \mathrm{~m}^{-2}, \mathrm{r}^{2}=0.75\right.$ ) (Figure 5.2). Although losses in flux due to instrument constraints are inevitable, there is no compelling evidence to suggest that they are responsible for the large residuals observed in this study.

Reba et al. (2009) also evaluated eddy covariance data collected over three snowseasons and found no unique issues associated with applying the $\mathrm{EC}$ technique over snow-covered surfaces. In addition, Helgason (2009) found that at moderate to high wind speeds, turbulent fluxes were well defined by the 30 -minute averaging period, the co-spectra were similar to the neutral Kansas data (Kaimal et al., 1972), and there was no obvious reason to consider these fluxes as incorrect from turbulent characteristics alone. However, Helgason (2009) did observe a very large EB residual during mid-winter conditions; a closure $\sim 50 \%$ could be achieved during nighttime periods with strong wind speeds, but daytime turbulent fluxes were often of the opposite sign to the non-turbulent terms, indicating a serious non-closure problem. As suggested by snowpack temperatures that were not observed to cool in response to the predominantly negative radiation balance, Helgason (2009) suggested that an unmeasured transfer of sensible 
heat was occurring which was strongly correlated with the longwave radiation balance. A conceptual hypothesis was developed to explain this relationship in which the effective area for heat transfer scales with the thermal radiation balance, and enables penetrative convective heat transfer to play a dominant role in the surface EB. Although this explains why Helgason (2009) observed the greatest energy imbalance during clear daytime periods, in this study, the EB closure was lowest during nighttime periods, and the EB residuals were not observed to scale with net longwave radiation. This suggests the model proposed by Helgason (2009) is not supported by the results of this research.

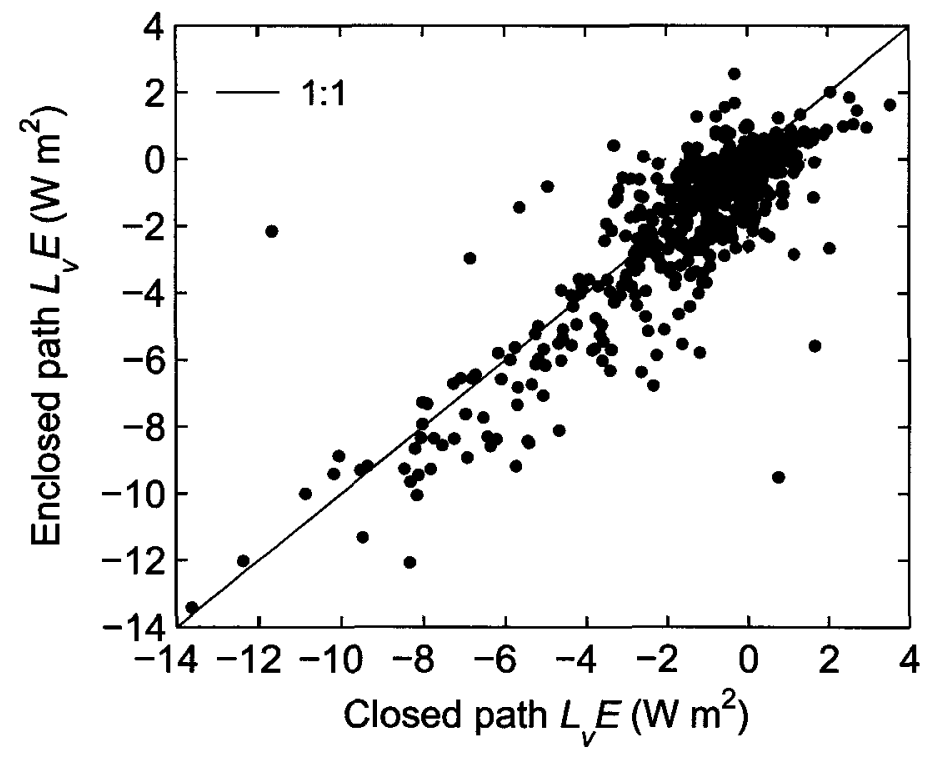

Figure 5.2: Comparison of 30-minute latent heat flux $\left(L_{v} E\right)$ measurement from the LI7000 closed path IRGA against the LI-7200 enclosed path IRGA. Data are from 9-31 January 2011. 
The exact cause of the imbalance could not be determined precisely. Part of the imbalance can be attributed to instrumental and experimental errors, particularly with respect to $\Delta Q$, while the rest is perhaps related to the low degree of turbulent mixing that occurs over snow surfaces. However, the exact cause of the poor energy balance closure remains unclear and future study of this problem is warranted.

\subsection{Modelled vs. Measured Fluxes}

This is one of the few studies where continuous measurements of all components of the EB are available to compare with modelled fluxes. In particular, few measurements of turbulent fluxes of heat and water over a snow cover exist for model comparison or validation (Marks et al., 2008). Possible explanations for discrepancies between modelled and measured energy and mass balances are discussed below, while Sections 5.3.1 and 5.3.2 provide an evaluation of the algorithms used by the model to simulate the ground heat flux and turbulent fluxes, and provide recommendations for future parameterization strategies.

The magnitude of $R_{n}$ and $G$ were under-predicted throughout the modelled period, while the magnitude of the turbulent fluxes, particularly $L_{v} E$, were considerably over-predicted. Discrepancies between modelled and measured fluxes generally increased following the early period, and the association between the variables typically decreased. This can in part be attributed to poorer agreement between modelled and measured snow surface temperatures $\left(T_{s s}\right)$ when the snow cover was shallow. During this period, SNOBAL over-predicted the magnitude of nighttime $T_{s s}$ and somewhat under-estimated the magnitude of daytime $T_{s s}$ (Figure 4.15a). Consequently, the 
magnitude of $R_{n}$ was under-predicted, and since the modelled temperature gradient between the snow surface and the air was greater than the observed temperature gradient, there was a larger discrepancy between modelled and measured turbulent fluxes.

It is important to note that the roughness length for momentum $\left(z_{0}\right)$ was set as a constant for the entire simulation (Section 3.3). However, following the large mid-winter ROS event, shrubs on hummock tops protruded noticeably above the snow surface, increasing surface roughness. Based on field measurements from 12 and 25 February, shrubs protruded on average between 0.10 and $0.04 \mathrm{~m}$, respectively above the snow. To more accurately simulate turbulent fluxes, $z_{0}$ should be variable in future work.

However, estimating $z_{0}$ and $d_{0}$ for this surface is complicated by the variable height of the shrubs protruding above the snow cover, which varies both temporally and spatially due to snow accumulation and redistribution, and the microtopography of the site. Future work should investigate a formulation for $z_{0}$ and $d_{0}$ in this environment.

Shrubs protruding above the snow surface also influence surface temperatures (e.g. Mahrt and Vickers, 2005a; Lee and Marht, 2004; Pomeroy et al., 2006), increasing surface temperatures during the day, and emitting longwave radiation to the sky and snow surface. The influence of shrubs on $T_{s s}$ was not considered in SNOBAL, and likely explains part of the increased discrepancy between modelled and measured fluxes during the mid period.

SNOBAL simulated complete melt 5 days earlier than the sonic depth measurement and 8 days earlier than area-averaged measurements. Part of this discrepancy can be attributed to lower snow accumulation in SNOBAL at the onset of melt (Figure 4.12a), and to considerable melt generated on 26 February $\left(23 \mathrm{~mm} \mathrm{~d}^{-1}\right)$, due 
to a large simulated sensible heat flux (Figure 4.13b), while the rest is likely attributed to the spatial variation in snow depth at the site as snow depth was greater in hollows than on hummocks. At the bog, hummocks were largely snow-free by 5 March (Appendix A), which is only one day later than complete ablation simulated by SNOBAL. Since SNOBAL is a point snow energy balance model, it cannot accurately simulate melt at the site due to the patchy snow cover that develops during melt as a result of the hummockhollow microtopography. Although SNOBAL does not explicitly account for advected heat from snow-free areas, it is implicitly accounted for in the sensible heat calculation, which uses measured air temperature and wind speed (Marks and Winstral, 2001).

\subsubsection{Ground Heat Flux}

The ground heat flux in SNOBAL is calculated from the vertical temperature gradient between the soil and lower snow layers, and their effective thermal conductivities (equation (3.26)). This simplified equation is based on the assumption that soil and snow temperatures near their interface are generally very similar, and consequently the soil and snow layers represent homogeneous layers with steady state heat flow in contact with each other (Marks and Dozier, 1992). Soil thermal conductivity $\left(K_{g}\right)$ in SNOBAL is also set as a constant, although soil thermal conductivity often varies temporally due largely to changes in soil moisture volume and phase composition (Sauer and Horton, 2005).

To test the sensitivity of modelled $G$ to soil thermal conductivity, the model was re-run using $K_{g}$ set to $0.15 \mathrm{~W} \mathrm{~m}^{-1} \mathrm{~K}^{-1}$ (dry peat soil), $0.56 \mathrm{~W} \mathrm{~m}^{-1} \mathrm{~K}^{-1}$ (near saturated peat soil), and $1.2 \mathrm{~W} \mathrm{~m}^{-1} \mathrm{~K}^{-1}$ (frozen near saturated peat soil). The difference in $G$ was less 
than $10 \%$ when integrated over the modelled period when $K_{g}$ changed from $0.15 \mathrm{~W} \mathrm{~m}^{-1}$ $\mathrm{K}^{-1}$ for a dry peat soil to $1.2 \mathrm{~W} \mathrm{~m}^{-1} \mathrm{~K}^{-1}$ for a near saturated and frozen peat soil (Figure 5.3a). Therefore, although $K_{g}$ may be highly variable in time, the assumption of a constant $K_{g}$ in the model is justifiable. Similarly, an inaccurate estimate of the thermal conductivity of the soil or snowpack does not appreciably affect modelled $G$.

SNOBAL was also run using soil temperatures from several depths $\left(z_{g}=0.10\right.$, 0.20 , and $0.40 \mathrm{~m}$ ). The simulated ground heat flux was found to be highly sensitive to the temperature gradient, as $G$ varied by more than $67 \%$ when averaged over the simulation period when using different $z_{g}$ values (Figure 5.3b). It is therefore recommended to use accurate soil temperature measurements and precisely determine the depth of the soil temperature measurement when using SNOBAL, especially with shallower soil temperature measurements since the temperature gradient is more variable with time near the surface. Equation (3.26) also assumes a uniform linear heat gradient (i.e. constant $G$ with depth) in the soil column. However, this assumption is often violated as soils cool throughout the winter (Lamontagne, 2009). Therefore, to accurately represent $G, z_{g}$ should be relatively near the soil-snow interface. Several studies have used soil temperature at depths between 0.30 and $0.50 \mathrm{~m}$ (e.g. Marks and Dozier, 1992; Marks et al., 1998; Link and Marks, 1999a), however, a depth between 0.10 and $0.20 \mathrm{~m}$ appears more appropriate (Figure 5.3b). 

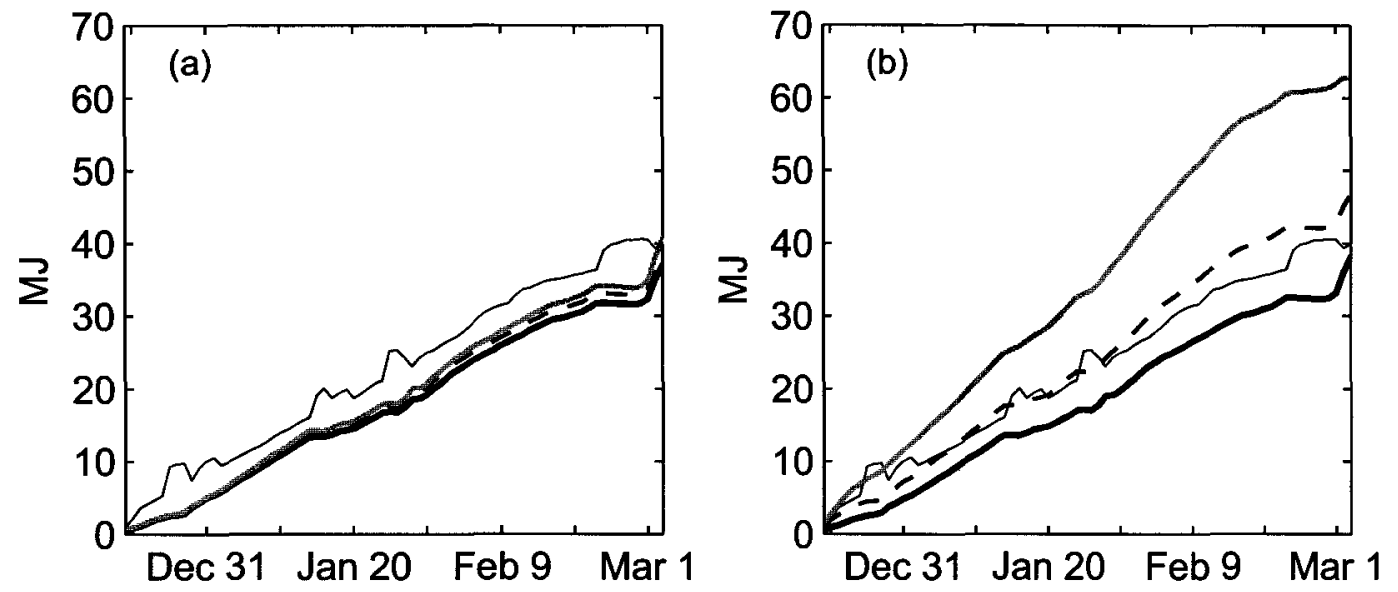

Figure 5.3: Cumulative measured (thin black line) and SNOBAL simulated ground heat flux with (a) varying thermal conductivity: $K_{g}=0.15 \mathrm{~W} \mathrm{~m}^{-1} \mathrm{~K}^{-1}$ (thick black line); $K_{g}=$ $0.56 \mathrm{~W} \mathrm{~m}^{-1} \mathrm{~K}^{-1}$ (dashed line); and $K_{g}=1.2 \mathrm{~W} \mathrm{~m}^{-1} \mathrm{~K}^{-1}$ (grey line); and (b) varying depth of the soil measurement: $0.10 \mathrm{~m}$ (thick black line); $0.20 \mathrm{~m}$ (dashed line); and $0.40 \mathrm{~m}$ (grey line).

\subsubsection{Turbulent fluxes}

In an attempt to reduce the discrepancy between measured and modelled turbulent fluxes observed in Section 4.4.2, the bulk transfer equations used in SNOBAL (equations (3.28) - (3.30), with $L$ estimated from measurements), were run off-line using several different parameterization schemes. The period from 5-20 January was selected for this analysis as shrubs were largely buried below the snow surface. Under these conditions, the zero plane displacement $\left(d_{0}\right)$ is effectively negligible, as is generally assumed for snow-covered surfaces (Moore, 1986; Andreas, 1987), and the roughness length for momentum $\left(z_{0}\right)$ could be derived from eddy-covariance measurements. In cases of nearneutral conditions $(|\zeta|<0.1), \psi_{M}$ can be neglected, and $z_{0}$ was derived from equation (3.28). Since $z_{0}$ was quite variable during periods of near-neutral conditions, an average 
value was used. The mean value of $z_{0}$ was $5.0 \times 10^{-3} \mathrm{~m}$, which is in the upper range of $z_{0}$ values measured over various snow and ice covered surfaces (Moore, 1984; Dingman, 1994). During this period, air temperatures ranged from $-20.8^{\circ} \mathrm{C}$ to $2.8^{\circ} \mathrm{C}$, with cooler temperatures early in this period, and temperatures often rising above $0^{\circ} \mathrm{C}$ following 15 January. Mean wind speed during this period was $2.6 \mathrm{~m} \mathrm{~s}^{-1}$, with higher wind speeds, exceeding $5 \mathrm{~m} \mathrm{~s}^{-1}$, during precipitation events. Conditions were generally stable during this period, with highly stable periods during cold nights, and unstable conditions often developing during mid-day periods. The different effective parameterization schemes are discussed separately below:

Case 1: $S N O B A L$ off-line. Bulk transfer equations from SNOBAL were used, with a fixed values of $z_{0}=5.0 \times 10^{-3} \mathrm{~m}$. As assumed in the model, $z_{0}=z_{H}=z_{Q}$, and the stability functions are from Brutsaert (1982). In addition, $d_{0}$ was assumed to be negligible as the shrubs were largely buried below the snow cover, and excluding $d_{0}$ had minimal effects on modelled turbulent heat fluxes.

Case 2: Different $\psi_{M}, \psi_{H}$, and $\psi_{Q}$ corrections. For stable conditions, the stability functions of Holtslag and De Bruin (1988) were used instead of those from Brutsaert (1982), since these equations are often considered the most appropriate over a snow cover since they allow flux under very stable conditions (Andreas, 2002).

Case 3: Decreased roughness lengths for heat and water vapour. Although the values of $z_{0}, z_{H}$, and $z_{Q}$ are still a source of discussion in the literature, evidence suggests that $z_{H}$ and $z_{Q}$ are less than $z_{0}$ (Moore, 1983; Arck and Scherer, 2002). Here, a simple formulation for $z_{H}$ and $z_{Q}$ was used, where $z_{H}=z_{Q}=0.1 z_{0}$ (Essery, 1997; Pomeroy and Essery, 1999).

Case 4: Andreas (1987) model to predict $z_{H}$ and $z_{Q}$. The Andreas (1987) model is the only one specifically adapted to predict $z_{H}$ and $z_{Q}$ over snow and ice, and it often used in numerical modelling (e.g. Morris, 1989; Jordan et al., 1999). Here, this model was used to estimate $z_{H}$ and $z_{Q}$. For the chosen value of $z_{0}$ the modelled value of $C_{D} C_{H}{ }^{-1} \approx C_{D} C_{Q}{ }^{-1}$ and varied $\sim 1.4$ and 2.2 during neutral conditions, depending on wind speed. 
30-minute average measured vs. modelled $H$ and $L_{v} E$ estimated by the parameterization approaches described above are presented in Figure 5.4. Average $H$ and $L_{v} E$ for this period, 30-minute RMSD, as well as coefficients of determination $\left(\mathrm{r}^{2}\right)$ are provided in Table 5.1.
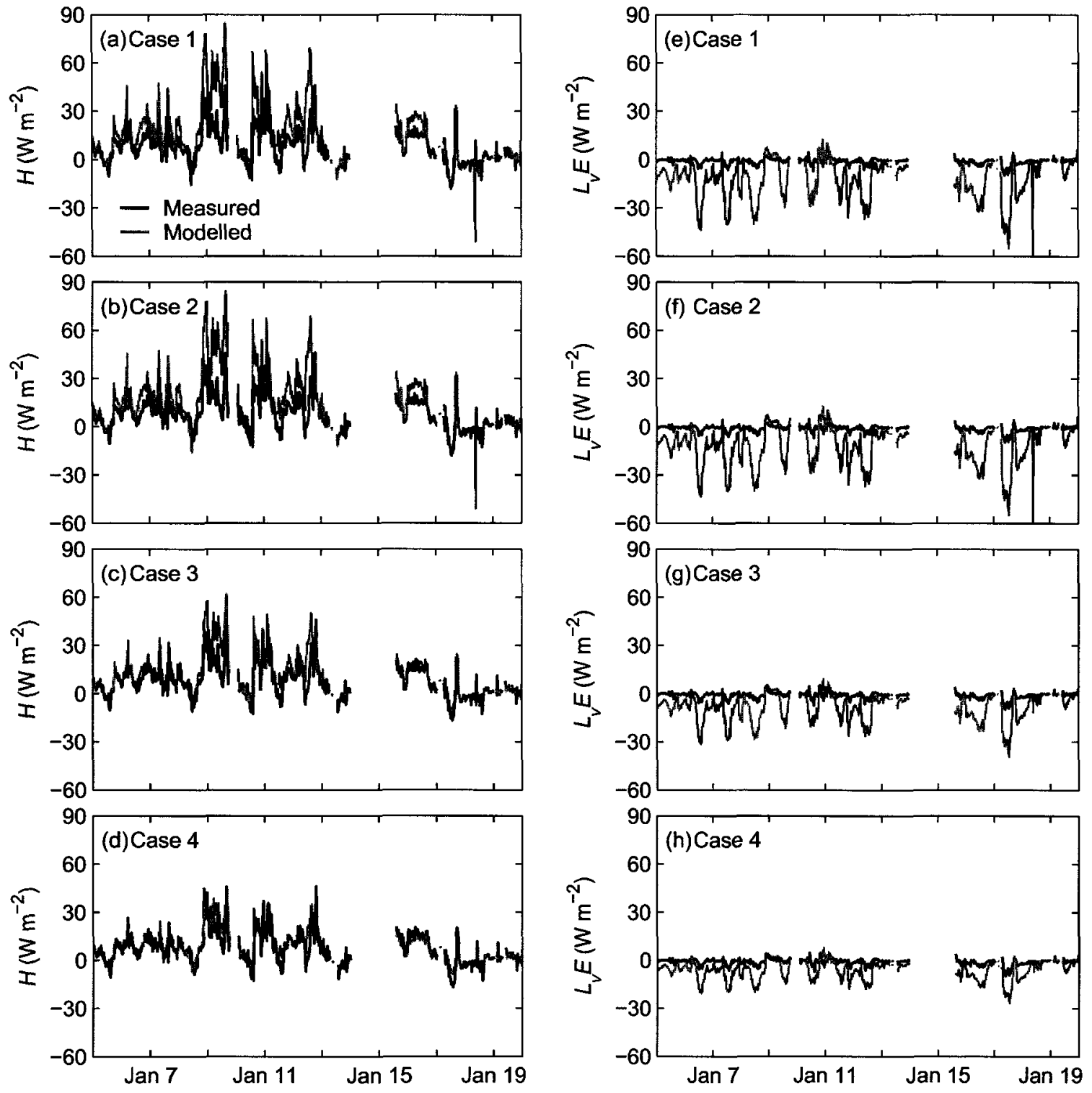

Figure 5.4: Estimation of measured (black line) and modelled (grey line) sensible (a $-\mathrm{d}$ ) and latent $(\mathrm{e}-\mathrm{h})$ heat fluxes using various bulk transfer parameterization scenarios. 
As expected based on results obtained in Section 4.4.2, turbulent fluxes in Case 1 were considerably over predicted; mean modelled $H$ was nearly twice as large as measured values, and average simulated $L_{v} E$ was an order of magnitude greater than mean measured $L_{v} E$, due to the over-prediction of daytime fluxes (Figure 5.4b). Changing the stability functions during stable conditions (Case 2) resulted in minimal changes to modelled turbulent fluxes. The functions of Holtslag and De Bruin (1988) and Brutsaert (1982) are similar for $0 \leq \zeta \leq 0.5$, and since stability was often in this range, turbulent fluxes simulated in Case 2 differed little from Case 1 . The slightly larger mean sensible heat flux in Case 2 relative to Case 1 is due to the fact that the profile functions of Holtslag and De Bruin (1988) allow flux under very stable conditions, which occurred during cold and calm nights. Under the current conditions, turbulent fluxes predicted by SNOBAL would not benefit from changing the $\psi_{M}, \psi_{H}$, and $\psi_{Q}$ functions to those of Holtslag and De Bruin (1988) during stable conditions. Simulated fluxes improved somewhat when $z_{H}$ and $z_{Q}$ were set as a fraction of $z_{0}$ (Case 3), however, there was still a notable difference between modelled and measured mean $H\left(4.8 \mathrm{~W} \mathrm{~m}^{-2}\right.$, mean values 11.4 and $8.0 \mathrm{~W} \mathrm{~m}^{-2}$, respectively), and an even greater difference in mean $L_{v} E\left(8.5 \mathrm{~W} \mathrm{~m}^{-2}\right.$, mean values -9.2 and $-0.7 \mathrm{~W} \mathrm{~m}^{-2}$, respectively). The most successful simulation was Case 4, as this option had the smallest difference between modelled and measured turbulent fluxes, the lowest RMSD of all cases, and the highest $r^{2}$. Sensible heat fluxes were particularly well simulated, with a difference between modelled and measured average $H$ of $0.6 \mathrm{~W} \mathrm{~m}^{-2}$ (mean values 8.6 and $8.0 \mathrm{~W} \mathrm{~m}^{-2}$, respectively). However, daytime latent heat fluxes remained noticeably over-predicted (Figure 5.4h), 
and the RMSD $\left(7.2 \mathrm{~W} \mathrm{~m}^{-2}\right)$ remained large relative of measured $L_{v} E$. Although similar results to Case 4 could be achieved when Case 1 was re-run using a smaller roughness length more typical of a deep uniform snow cover (e.g. $z_{0}=0.0005 \mathrm{~m}$ ), a roughness length of $0.005 \mathrm{~m}$ is likely more appropriate for this surface since the majority of measured $z_{0}$ ranged between $0.001-0.01 \mathrm{~m}$. Therefore, for conditions similar to the ones presented in this research, turbulent fluxes simulated by SNOBAL could be improved by reducing $z_{H}$ and $z_{Q}$ relative $z_{0}$, and it is recommended using the Andreas (1987) model over more simple parameterization schemes (e.g. Essery, 1997).

Table 5.1: Performance of bulk transfer parameterization schemes.

\begin{tabular}{|c|c|c|c|c|c|c|}
\hline & \multirow{2}{*}{\multicolumn{2}{|c|}{$\begin{array}{l}H \\
\text { RMSD } \\
\left(\mathrm{W} \mathrm{m}^{-2}\right)\end{array}$}} & \multirow[b]{2}{*}{$r^{2}$} & \multicolumn{3}{|c|}{$L_{y} E$} \\
\hline & & & & $\begin{array}{c}\text { Mean } \\
\left(\mathrm{W} \mathrm{m}^{-2}\right)\end{array}$ & $\begin{array}{l}\text { RMSD } \\
\left(\mathrm{W} \mathrm{m}^{-2}\right)\end{array}$ & $r^{2}$ \\
\hline Case 1 & 15.6 & 13.3 & 0.73 & -11.9 & 15.7 & 0.55 \\
\hline Case 2 & 16.0 & 13.5 & 0.73 & -11.8 & 15.7 & 0.55 \\
\hline Case 3 & 11.4 & 7.6 & 0.74 & -8.4 & 10.6 & 0.57 \\
\hline Case 4 & 8.6 & 5.2 & 0.75 & -6.0 & 7.2 & 0.57 \\
\hline Measured & 8.0 & & & -0.7 & & \\
\hline
\end{tabular}

The inability to significantly reduce the discrepancy between modelled and measured $L_{v} E$ and the large RMSD noted for 30-minutes fluxes (when compared to measured values), suggests that the physics of the energy exchange is not being adequately captured. Mahrt and Vickers (2005a) also found that the moisture flux calculated using bulk transfer equations was less than EC measurements at a grass site 
with a complete snow cover. They suggested several possible explanations for this occurrence, including: (a) sparse protruding grass blades, which do not appreciably affect snow cover measurements, may partially shelter the snow, reducing the moisture flux below potential evaporation which is predicted by bulk transfer equations, and (b) the moisture flux from older snow may be less than potential due to interference by particles on the snow surface. Although it was assumed that shrubs were largely buried below the snow surface, it was observed in the field that taller shrubs on hummock tops did protrude slightly above the snow surface, and therefore these explanations may be a possibility, but cannot be estimated quantitatively. $L_{v} E$ estimation techniques would therefore greatly benefit from a more thorough understanding of energy exchange mechanisms during mid-winter periods, and also from the recognition of the role that the porous nature of the snowpack has on vapour exchange. 


\subsection{Conclusion}

Snow surface energy exchanges were measured and modelled for a complete snow season in a shrub-covered bog in eastern Ontario. Whereas the ground heat flux is often thought of as negligible in snow energy budgets, this study found that measured ground heat flux was a large contributor to the EB, comprising $25 \%$ of the energy exchanges when integrated over the accumulation period. This is nearly equal to the sensible heat flux with regards to determining the energy of the snow cover, which comprised $27 \%$ of the pre-melt snow cover energy balance. The large input from the ground heat flux reflects the positive soil temperatures maintained at depth throughout the winter. Inputs from $G$ could be even greater in years with a thicker snowpack since this generally slows the rate of cooling in the ground and results in warmer ground temperatures. Net radiation was the dominant energy balance term prior to melt, comprising on average $43 \%$ of the energy exchanges, and was largely directed away from the snowpack due to emissions of longwave radiation from the snow cover. Latent heat fluxes were minor throughout the accumulation season and were also negative.

Sensible heat flux dominated the snowmelt energy balance, comprising $52 \%$ of the energy balance. Net radiation only comprised $15 \%$ of the total energy since melt-out occurred early in the year. $L_{v} E$ was largely directed away from the snowcover during this period, and local advection comprised about $10 \%$ of the energy exchanges. Contributions from $G$ were minor during snowmelt, but as $G$ played an important role in controlling the energy status of the snow cover prior to melt, it should be adequately considered in modelling studies to accurately characterize the mass and energy balance of the snowpack in this type of environment. There was uncertainty with respect to the 
fluxes estimated during melt due to spatial heterogeneity of the snow pack and future study is needed to more accurately quantify the role of local advection in this hummockhollow microtopography.

Measurements of all the snow cover energy balance terms revealed that there was a large energy balance residual, which exceeded the residual typically found at this site during summer. The exact cause of the imbalance could not be determined, but may have related to uncertainties or errors in measurements of all the energy fluxes as well as the determination of the rate of change in internal snowpack energy. In particular, there were uncertainties associated with the turbulent fluxes measured during typically calm conditions over the smooth snow surface. Further study of the limitations of EC methodology and instrumentation during winter is warranted.

This is one of the few studies where continuous measurements of all surface energy exchanges for a snow cover are available to compare with modelled fluxes. When comparing measured and modelled fluxes, it was found that the magnitude of net radiation and ground heat flux were somewhat underpredicted, while turbulent fluxes (especially $L_{v} E$ ) were considerably over-predicted. In addition, the discrepancy between modelled and measured fluxes increased following the late January ROS event due to a poorer agreement between modelled and measured snow surface temperatures when the snow cover was shallow. Based on the evaluation of the algorithms used by the model to simulate the ground heat flux and turbulent fluxes, two recommendations for future development and application of SNOBAL are:

1) Soil temperature measurements used in SNOBAL should be accurate, the measurement depth should be precisely known, and it should be close to the soil- 
snow interface (between 0.10 and $0.20 \mathrm{~m}$ ) to avoid violating the assumption of a uniform linear heat gradient.

2) To improve turbulent fluxes, $z_{H}$ and $z_{Q}$ should be less than $z_{0}$, as theory predicts over snow-covered surfaces (Andreas, 2002), and it is recommended to use the Andreas (1987) model over more simple parameterization schemes (e.g. Essery, 1997).

The inability to significantly reduce the discrepancy between modelled and measured $L_{v} E$ indicates that a more thorough understanding of energy exchange mechanisms during winter is warranted, as is the recognition of the role that the porous nature of the snowpack has on vapour exchange. 


\subsection{References}

Adkinson A. 2009. Responses of Sphagnum Productivity and Net Ecosystem Exchange of $\mathrm{CO}_{2}$ to Modifications of Moss Moisture Content in an Ombrotrophic Bog. MSc Thesis, Geography and Environmental Studies, Carleton University, Ottawa.

Anderson EA. 1976. A point energy and mass balance model of a snow cover. NWS Technical Report 19. National Oceanic and Atmospheric Administration, Washington, DC. $150 \mathrm{pp}$

Andreas EL. 1987. A theory for the scalar roughness and the scalar transfer coefficients over snow and sea ice. Boundary-Layer Meteorology 38: 159-184.

Andreas EL. 2002. Parameterizing scalar transfer over snow and ice: a review. Journal of Hydrometeorology 3(4): 417-432.

Arck M, Scherer D. 2002. Problems in the determination of sensible heat flux over snow. Geografiska Annaler: Series A, Physical Geography 84(3-4):157-169.

Aubinet M, Grelle A, Ibrom A, Rannik U, Moncrieff J, Foken T, Kowalski AS, Martin PH, Berbigier P, Bernhofer C, Clement R, Elbers J, Granier A, Grunwald T, Morgenstern K, Pilegaard K, Rebmann C, Snijders W, Valentini R, Vesala T. 2000. Estimates of the annual net carbon and water exchange of forests: The EUROFLUX methodology. Advances in Ecological Research 30: 113-175.

Baker DG, Skaggs RH, Ruschy DL. 1991. Snow depth required to mask the underlying surface. Journal of Applied Meteorology 30(3): 387-392.

Baldocchi D, Hincks BB, Meyers TP. 1988. Measuring biosphere-atmosphere exchanges of biologically related gases with micrometeorological methods. Ecology 69(5): 1331-1340.

Barr AG, Morgenstern K, Black TA, McCaughey JH, Nesic Z. 2006. Surface energy balance closure by the eddy-covariance method above three boreal forest stands and implications for the measurement of $\mathrm{CO} 2$ flux. Agricultural and Forest Meteorology 140: 322-337.

Bubier J, Crill P, Mosedale A. 2002. Net ecosystem $\mathrm{CO}_{2}$ exchange measured by autochambers during the snow-covered season at a temperate peatland. Hydrological Processes 16(18): 3667-3682.

Bengtsson L.1980. Evaporation from a snow cover: Review and discussion of measurements. Nordic Hydrology 11: 221-234.

Brutsaert W. 1982. Evaporation into the atmosphere. Kluwer Academic Publishers, 299 pp. 
Brutsaert W. 2005. Hydrology: An Introduction. Cambridge University Press, 605 pp.

Calanca P. 2001. A note on the roughness length for temperature over melting snow and ice. Quarterly Journal of the Royal Meteorological Society 127: 255-260.

Cline DW. 1997. Snow surface energy exchanges and snowmelt at a continental, midlatitude Alpine site. Water Resources Research 33(4): 689-701.

Colbeck SC, Anderson EA, Bissel VC, Crook AG, Male DH, Slaughter CW, Wiesnet DR. 1979. Snow accumulation, distribution, melt, and runoff. EOS, Transactions, American Geophysical Union 60(21): 465-474.

Colbeck SC. 1982. An overview of seasonal snow metamorphism. Reviews of Geophysics and Space Physics 20(1): 45-61.

De Vries, D.A. 1963. Thermal properties of soil. In: Physics of Plant Environment, van Dijk WR (ed.). North Holland Publishing: Amsterdam, pp. 210- 235.

Dimitrov DD, Robert GF, Lafleur PM, Humphreys RE. 2010. Modeling the Subsurface Hydrology of Mer Bleue Bog. Soil Science Society of America 74: 680:694.

Dingman SL. 2002. Physical Hydrology, $2^{\text {nd }}$ ed. Prentice Hall, 600 pp.

Dozier J, Warren SG. 1982. Effect of viewing angle on the infrared brightness temperature of snow. Water Resources Research 18(5): 1424-1434.

Dunne T, Price AG, Colbeck SC. 1976. The generation of runoff from subarctic snowpacks. Water Resources Researcg 12:677-685.

Environment Canada. 2010. 1971-2000 Canadian climate normals, Ottawa,ON.

Essery R. 1997. Modelling fluxes of momentum, sensible heat and latent heat over heterogeneous snow cover. Quarterly Journal of the Royal Meteorological Society 123 (543):1867-1883.

Essery R. 1999. Parametrization of Heterogeneous Snowmelt. Theoretical and Applied Climatology 62(1): 25-30.

Essery R, Granger R, Pomeroy J. 2006. Boundary-layer growth and advection of heat over snow and soil patches: modelling and parameterization. Hydrological Processes 20(4): 953-967.

Etchevers P, Martin E, Brown R, Fierz C, Lejeune Y, Bazile E, Boone A, Dai YJ, Essery R, Fernandez A, Gusev Y, Jordan R, Koren V, Kowalczyk E, Nasonova NO, Pyles RD, Schlosser S, Shmakin AB, Smirnova TG, Strasser U, Verseghy D, Yamazaki T, Yang ZL. 2004. Validation of the energy budget of an alpine 
snowpack simulated by several snow models (SnowMIP project). Annals of Glaciology 38: 150-158.

Falge E et al. 2001. Gap filling strategies for long term energy flux data sets. Agricultural and Forest Meteorology 107(1): 71-77.

Fassnacht SR. 2004. Estimating Alter-shielded gauge snowfall undercatch, snowpack sublimation, and blowing snow transport at six sites in the coterminous USA. Hydrological Processes 18(18): 3481-3492.

Flerchinger GN. 2000. The simultaneous heat and water (SHAW) Model: Technical Documentation. Technical Report NWRC 2000-09. Boise, Idaho. Northwest Watershed Research Center. USDA Agricultural Research Service.

Foken T, Wichura B. 1996. Tools for quality assessment of surface-based flux measurements. Agricultural and Forest Meteorology 78: 83-105.

Fraser CJD, Roulet NT, Lafleur M. 2001. Groundwater flow patterns in a large peatland. Journal of Hydrology 246(1-4): 142-154.

Garen D, Marks D. 2005. Spatially distributed energy balance snowmelt modeling in a mountainous river basin: estimation of meteorological inputs and verification of model results Journal of Hydrology 315: 126-153.

Garratt JR. 1992. The Atmospheric Boundary Layer. Cambridge University Press, 316 pp.

Gold LW, Williams GP. 1961. Energy balance during the snow melt period at an Ottawa site. UGGI, AIHS. Assemblée générale de Helsinki. Commission des Neiges et Glaces, pp. 288-294.

Gorham E. 1991. Northern Peatlands: Role in the carbon cycle and probable responses to climatic warming. Ecological Applications 1(2): 182-195.

Granger RJ, Pomeroy JW, Parviainen J. 2002. Boundary-layer integration approach to advection of sensible heat to a patchy snow cover. Hydrological Processes 16 (18): 3559-3569.

Granger RJ, Essery R, Pomeroy JW. 2006. Boundary-layer growth over snow and soil patches: field observations. Hydrological Processes 20(4): 943-951.

Gray DM, Landine PG. 1987. Albedo model for shallow prairie snow covers. Canadian Journal of Earth Sciences 24: 1760-1768.

Gray DM, Landine PJ. 1988. An energy-budget snowmelt model for the Canadian Prairies. Canadian Journal of Earth Sciences 25(9): 1292-1303. 
Green, I., and D. Stephenson, 1986: Criteria for comparison of single event models. Hydrological Sciences Journal 31: 395-411.

Halliwell D H, Rouse WR. 1987. Soil heat flux in permafrost: Characteristics and accuracy of measurement. Journal of Climatology 7(6): 571-584.

Harding RJ, Pomeroy JW. 1996. The energy balance of the winter Boreal landscape. Journal of Climate 9(11): 2778-2787.

Hayashi M, Hirota T, Iwata Y, Takayabu I. 2005. Snowmelt energy balance and its relation to foehn events in Tokachi, Japan. Journal of the Meteorological Society of Japan 83: 783-798.

Helgason WD. 2009. Energy fluxes at the air-snow interface. PhD Thesis, Geography and Planning, University of Saskatchewan, Saskatoon.

Holtslag AAM, De Bruin HAR. 1988. Applied modeling of the nighttime surface energy balance over land, Journal of Applied Meteorology 27: 689-704.

Jordan R.1991: A one-dimensional temperature model for a snow cover: Technical documentation for SNTHERM.89. U.S. Army Cold Regions Research and Engineering Laboratory Special Rep. 91-16, 49 pp.

Kaimal JC, Wyngaard JC, Izumi Y, Cotè OR. 1972. Spectral characteristics of surface layer turbulence. Quarterly Journal of the Royal Meteorological Society 98: 563589.

Kaimal J, Finnigan, J. 1994. Atmospheric Boundary Layer Flows: Their Structure and Measurement. Oxford University Press, $289 \mathrm{pp}$.

King JC, Anderson PS. 1994. Heat and water vapour fluxes and scalar roughness lengths over an Antarctic ice shelf. Boundary-Layer Meteorology 69: 101-121.

Kojima K, Ishikawa N, Motoyama H, Yamada Y. 1985. Evaporation rate of snow at the surface of a snow cover - observation in Sapooro and Moshiri, Hokkaido. Low Temperature Science A44: 49-62.

Kuusisto E. 1986. The energy balance of a melting snow cover in different environments. IAHS Publication 155: 37-45.

Lafleur PM, Roulet NT, Admiral SW. 2001. Annual cycle of $\mathrm{CO}_{2}$ exchange at a bog peatland. Journal of Geophysical Research 106: 3071-3081.

Lafleur PM, Roulet NT, Bubier JL, Frolking S, Moore TR. 2003. Interannual variability in the peatland-atmosphere carbon dioxide exchange at an 
ombrotrophic bog. Global Biogeochemical Cycles 17(2):

doi:10.1029/2002GB001983.

Lafleur PM, Hember RA, Admiral SW, Roulet NT. 2005. Annual and seasonal variability in evapotranspiration and water table at a shrub-covered bog in southern Ontario, Canada. Hydrological Processes 19 (18):3533-3550.

Lamontagne, A. 2009. Characterization and quantification of ground heat flux for late season shallow snow. MSc Thesis, Hydrologic Sciences, Boise State University, Boise.

Laudon H, Sjöblom V, Buffam I, Seibert J, Mörth M. 2007. The role of catchment scale and landscape characteristics for runoff generation of boreal streams. Journal of Hydrology 344(3-4): 198-209.

Lee YH, Mahrt L. 2004. An evaluation of snowmelt and sublimation over short vegetation in land surface modelling. Hydrological Processes 18(18): 3543-3557.

Leuning R, Judd MJ. 1996. The relative merits of open- and closed-path analysers for measurement of eddy fluxes. Global Change Biology 2: 241-253.

Liebethal C, Huwe B, Foken T. 2005. Sensitivity analysis for two ground heat flux calculation approaches. Agricultural and Forest Meteorology 132(3-4): 253-262.

Link TE, Marks D. 1999a. Point simulation of seasonal snow cover dynamics beneath boreal forest canopies. Journal of Geophysical Research 104(D22): 27841-27857.

Link T, Marks D. 1999b. Distributed simulation of snowcover mass- and energybalance in the Boreal forest. Hydrological Processes 13:2439-2452.

Liston GE. 1995. Local advection of momentum, heat, and moisture during the melt of patchy snow covers. Journal of Applied Meteorology 34(7): 1705-1715.

Liston GE, Sturm M. 2002. Winter precipitation patterns in arctic Alaska determined from a blowing-snow model and snow-depth observation. Journal of Hydrometeorology 3: 646-659.

Mahrt L. 1998. Stratified atmospheric boundary layers and breakdown of models, Theoretical and Computational Fluid Dynamics 11: 263-279.

Mahrt L. 1999. Stratified atmospheric boundary layers, Boundary-Layer Meteorology 90: $375-396$.

Mahrt L, Vickers D. 2005a. Moisture fluxes over snow with and without protruding vegetation. Quarterly Journal of the Royal Meteorological Society 131(607): 1251-1270. 
Mahrt L, Vickers D. 2005b. Boundary-layer adjustment over small-scale changes of surface heat flux. Boundary-Layer Meteorology 116(2): 313-330.

Male DH, Granger R. 1979. Energy mass fluxes at the snow surface in a prairie environment. Proc. Modeling of Snow Cover Runoff, Colbeck S, Ray M (eds.), Hanover, NH, U.S. Army Cold Regions Research and Engineering Laboratory: 101-124.

Male DH, Gray DM. 1981. Snowcover ablation and runoff. In: Handbook of Snow, Gray, DM (ed.). The Blackburn Press: Caldwell, New Jersey.

Marks D, Dozier J, Davis RE. 1992. Climate and energy exchange at the snow surface in the alpine region of the Sierra Nevada 1. Meteorological Measurements and Monitoring. Water Resources Research 28(11): 3029-3042.

Marks D, Dozier J. 1992. Climate and energy exchange at the snow surface in the alpine region of the Sierra Nevada 2. Snow cover energy balance. Water Resources Research 28(11): 3042-3054.

Marks D, Kimball J, Tingey D, Link T. 1998. The sensitivity of snowmelt processes to climate conditions and forest cover during rain-on-snow: a case study of the 1996 Pacific Northwest flood. Hydrological Processes 12(10-11): 1569-1587.

Marks D, Domingo J, Susong D, Link T, Garen D. 1999. A spatially distributed energy balance snowmelt model for application in mountain basins. Hydrological Processes 13(12-13): 1935-1959.

Marks D, Link T, Winstral A, Garen D. 2001. Simulating snowmelt processes during rain-on-snow over a semi-arid mountain basin. Annals of Glaciology 32: 195-202.

Marks D, Winstral A. 2001. Comparison of snow deposition, the snow cover energy balance, and snowmelt at two sites in a semiarid mountain basin. Journal of Hydrometeorology 2(3): 213-227.

Marks D, Winstral A, Flerchinger G, Reba M, Pomeroy J, Link T, Elder K. 2008. Comparing simulated and measured sensible and latent heat fluxes over snow under a pine canopy to improve an energy balance snowmelt model. Journal of Hydrometeorology 9(6): 1506-1522.

Marsh P, Pomeroy JW. 1996. Meltwater fluxes at an arctic forest-tundra site. Hydrological Processes 10(10):1383-1400.

Martinec J, Rango A, Roberts R.1998. Snowmelt Runoff Model (SRM) user's manual. Geographica Bernensia P35. Department of Geography. University of Berne: 84 pp. 
Massman WJ, Lee X. 2002. Eddy covariance flux corrections and uncertainties in longterm studies of carbon and energy exchanges. Agricultural and Forest Meteorology 113: 121-144.

Mazurkiewicz AB, Callery DG, McDonnell JJ. 2008. Assessing the controls of the snow energy balance and water available for runoff in a rain-on-snow environment. Journal of Hydrology 354(1-4): 1-14.

Mitsch WJ, Gosselink, JG. 2007. Wetlands. John Wiley and Sons, 582 pp.

Molotch NP, Blanken PD, Williams MW, Turnipseed AA, Monson RK, Margulis SA. 2007. Estimating sublimation of intercepted and sub-canopy snow using eddy covariance systems. Hydrological Processes 21(12): 1567-1575.

Moore C. 1986. Frequency response corrections for eddy correlation systems. Boundary-Layer Meteorology 37, 17-35, high frequency loss sensor response pathlength averaging sensor separation.

Moore DR. 1983. On the use of bulk aerodynamic formulae over melting snow. Nordic Hydrology 14: 193-206.

Moore TR, Bubier JL, Frolking SE, Lafleur PM, Roulet NT. 2002. Plant biomass and production and $\mathrm{CO} 2$ exchange in an ombrotrophic bog. Journal of Ecology 90(1): 25-36.

Morris EM. 1989. Turbulent transfer over snow and ice. Journal of Hydrology 105(34): 205-223.

Nakai Y, Sakamoto T, Terajima T, Kitamura K, Shirai T. 1999. Energy balance above a boreal coniferous forest: a difference in turbulent fluxes between snow-covered and snow-free canopies. Hydrological Processes 13(4): 515-529.

Neumann N, Marsh P. 1998. Local advection of sensible heat in the snowmelt landscape of Arctic tundra. Hydrological Processes 12(10-11): 1547-1560.

Ohmura, A. 1982. Climate and energy balance on the arctic tundra. International Journal of Climatology 2(1): 65-84.

Oke TR. 1987. Boundary Layer Climates, $2^{\text {nd }}$ ed. Routledge, 435 pp.

Olyphant GA, Isard SA. 1988. The role of advection in the energy balance of late-lying snowfields: Niwot Ridge, Front Range, Colorado. Water Resource Research 24 (11): 1962-1968.

Pluss C, Mazzoni R. 1994. The role of turbulent heat fluxes in the energy balance of high alpine snow cover. Nordic Hydrology 25: 25-38 
Pohl S, Marsh P. 2006. Modelling the spatial-temporal variability of spring snowmelt in an arctic catchment. Hydrological Processes 20(8): 1773-1792.

Pohl S, Marsh P, Pietroniro A. 2006a. Spatial-temporal variability in solar radiation during spring snowmelt. Nordic Hydrology 37: 1-19.

Pohl S, Marsh P, Liston G. 2006b. Spatial-temporal variability in turbulent fluxes during spring snowmelt. Arctic, Antarctic, and Alpine Research 38(1): 136-146.

Pomeroy JW, Gray DW, Landine PG. 1993. The Prairie Blowing Snow Model: characteristics, validation, operation. Journal of Hydrology 144(1-4): 165-192.

Pomeroy JW, Gray DM. 1995. Snowcover Accumulation, Relocation and Management, National Hydrological Research Institute Science Report, 7, Environment Canada, Saskatoon, Canada, 144 pp.

Pomeroy, J. W. and Granger, R. J. 1997. Sustainability of the western Canadian boreal forest under changing hydrological conditions. I. snow accumulation and ablation. Sustainability of Water Resources under Increasing Uncertainty, IAHS Publ. 240, IAHS Press, Wallingford. 237-242.

Pomeroy JW, Gray DM, Shook KR, Toth B, Essery RLH, Pietroniro A, Hedstrom N. 1998. An evaluation of snow accumulation and ablation processes for land surface modelling. Hydrological Processes 12(15): 2339-2367.

Pomeroy JW, Essery RLH. 1999. Turbulent fluxes during blowing snow: field tests of model sublimation predictions. Hydrological Processes 13(18): 2963-2975.

Pomeroy JW, Li L. 2002. Prairie and arctic areal snow cover mass balance using a blowing snow model. Journal of Geophysical Research 105(21): 26619-26634.

Pomeroy JW, Toth B, Granger RJ, Hedstrom NR, Essery RLH. 2003. Variation in surface energetics during snowmelt in a subarctic mountain catchment. Journal of Hydrometeorology 4(4): 702-719.

Pomeroy JW, Bewley DS, Essery DS, Hedstrom NR, Link T, Granger RJ, Sicart JE, Ellis CR, Janowicz JR. 2006. Shrub tundra snowmelt. Hydrological Processes 20 (4):923-941.

Pomeroy JW, Gray DM, Brown T, Hedstrom NR, Quinton WL, Granger RJ, and Carey SK. 2007. The cold regions hydrological model: a platform for basing process representation and model structure on physical evidence. Hydrologica Processes 21(19): 2650-2667. 
Reba ML, Link TE, Marks D, Pomeroy J. 2009. An assessment of corrections for eddy covariance measured turbulent fluxes over snow in mountain environments. Water Resources Research 45:W00D38.

Roulet NT, Lafleur PM, Richard PJH, Moore TR, Humphreys ER, Bubier J. 2007. Contemporary carbon balance and late Holocene carbon accumulation in a northern peatland. Global Change Biology 13(2): 397-411.

Rutter, N. et al. 2009. Evaluation of forest snow processes models (SnowMIP2). Journal of Geophysical Research 114 (D6): D06111.

Sauer TJ, Hatfield JL, Prueger JH, Norman JM. 1998. Surface energy balance of a corn residue-covered field. Agricultural and Forest Meteorology 89(3-4): 155168.

Sauer TJ, Horton R. 2005. Micrometeorology in Agricultural systems. American Society of Agronomy, Agronomy Monograph no. 47.

Sensoy A, Sorman AA, Tekeli AE, Sorman AU, Garen DC. 2006. Point-scale energy and mass balance snowpack simulations in the upper Karasu basin, Turkey. Hydrological Processes 20(4):899-922.

Shook K, Gray DM. 1997. Snowmelt resulting from advection. Hydrological Processes 11(13): 1725-1736.

Smith RS, Moore RD, Weiler, M. 2008. Spatio-temporal Variability in Midwinter Snowmelt Generated by Ground Heat Flux: Implications for Catchment Hydrology. American Geophysical Union, \#H21L-05.

Susong D, Marks D, Garen D. 1999. Methods for developing time-series climate surfaces to drive topographically distributed energy- and water-balance models. Hydrological Processes 13: 2003-2021.

Tarboton D.G., Luce C.H. 1996. Utah Energy Balance Snow Accumulation and Melt Model (UEB), Computer model technical description and users guide: Utah Water Research Laboratory and USDA Forest Service Intermountain Research Station.

Turnipseed AA, Anderson DE, Blanken PD, Baugh WM, Monson RK. 2002. Airflows and turbulent flux measurements in mountainous terrain: Part 1. Canopy and local effects. Agricultural and Forest Meteorology 119(1-2): 1-21.

Warren SG, Wiscombe WJ. 1980. A Model for the spectral albedo of snow. II: Snow containing atmospheric aerosols. Journal of the Atmospheric Sciences 3(12): 2734-2745.

Warren SG. 1982. Optical properties of snow. Reviews of Geophysics 20(1): 67-89. 
Wilson K, Goldstein A, Falge E, Aubinet M, Baldocchi D, Berbigier P, Bernhofer C, Ceulemans R, Dolman H, Field C, Grelle A, Ibrom A, Law BE, Kowalski A, Meyers T, Moncrieff J, Monson R, Oechel W, Tenhunen J, Valentini R, Verma S. 2002. Energy balance closure at FLUXNET sites. Agricultural and Forest Meteorology 113:223-243.

Winstral A, Marks D. 2002. Simulating wind fields and snow redistribution using terrainbased parameters to model snow accumulation and melt over a semi-arid mountain catchment. Hydrological Processes 16: 3585-3603.

Wiscombe WJ, Warren SG. 1980. A Model for the spectral albedo of snow. I: Pure snow. Journal of the Atmospheric Sciences 37(12): 2712-2733.

Weisman RN. 1977. Snowmelt: A two-dimensional turbulent diffusion model. Water Resources Research 13(2): 337-342.

Yen YC. 1965. Heat transfer characteristics of naturally compacted snow. Technical Report 166. US Army Cold Regions Research and Engineering Laboratory, Hanover. 9 pp.

Zhang T. 2005. Influence of the seasonal snow cover on the ground thermal regime: An overview. Reviews of Geophysics 43: RG4002.

Zhang, Y, Carey S.K., Quinton, W.L. 2008. Evaluation of the algorithms and parameterizations for ground thawing and freezing simulation in permafrost regions. Journal of Geophysical 113(D17): D17116. 


\section{Appendix A: Snowmelt Timelapse}

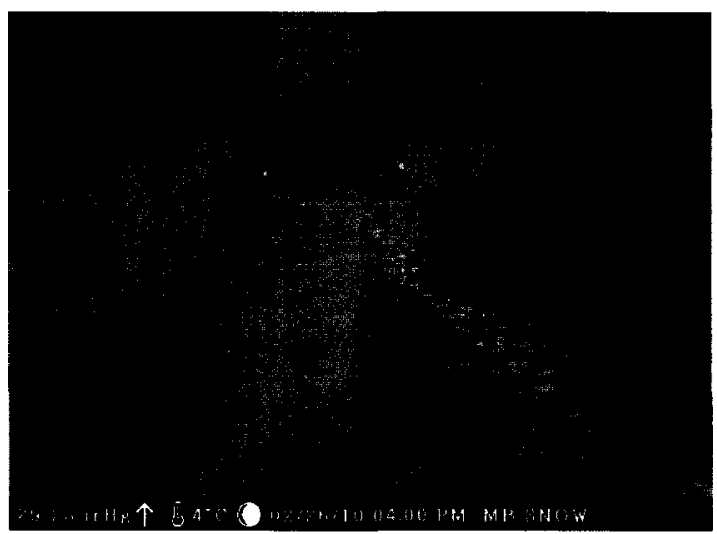

Figure A1: 26 February 2009 16h

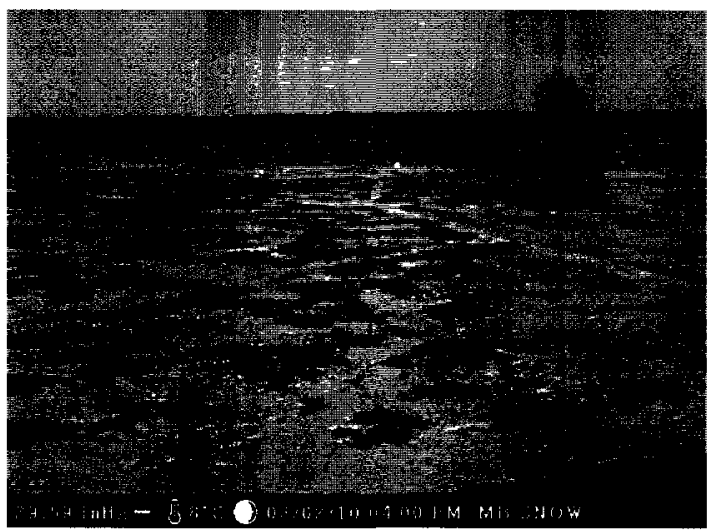

Figure A3: 2 March 2010 16h

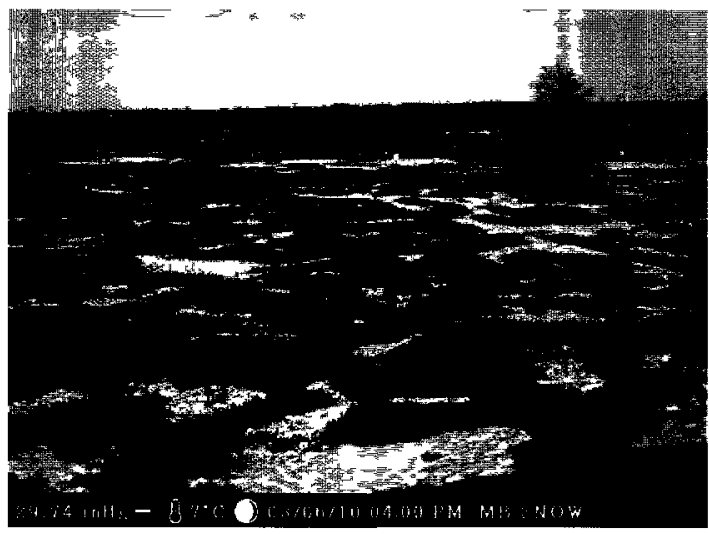

Figure A5: 6 March 2010 16h

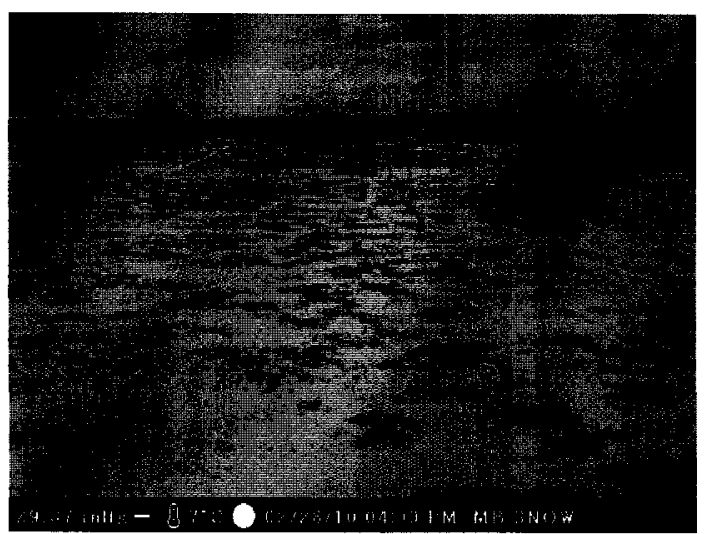

Figure A2: 28 February 2009 16h

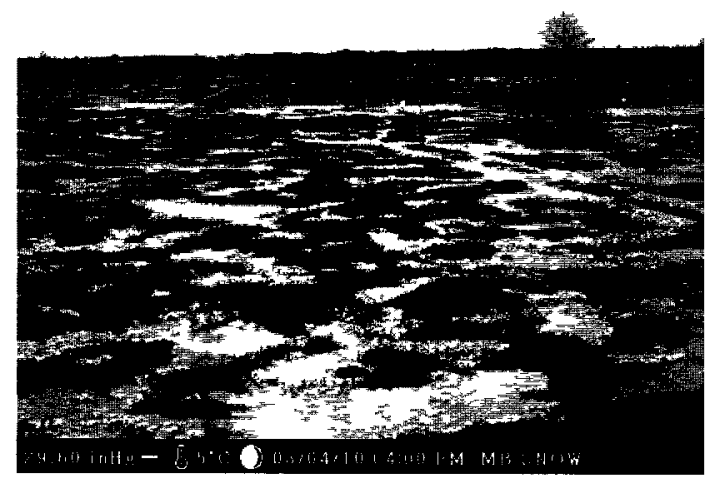

Figure A4: 4 March 2010 16h
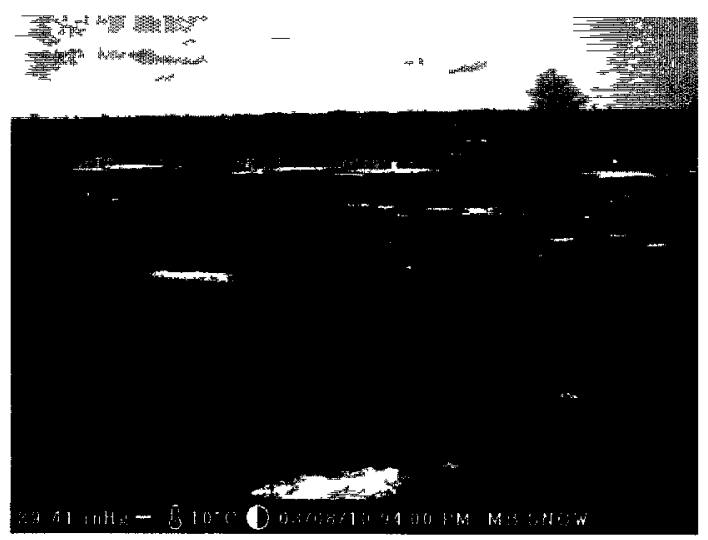

Figure A6: 8 March 2010 16h 


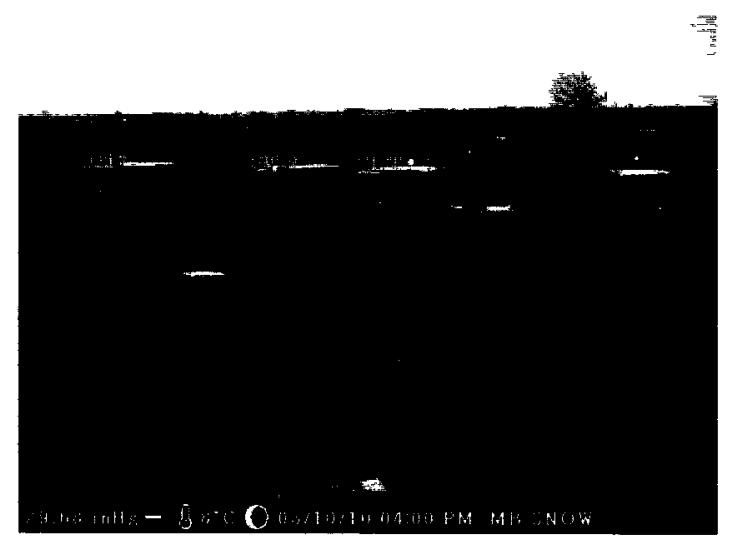

Figure A7: 10 March 2010 16h

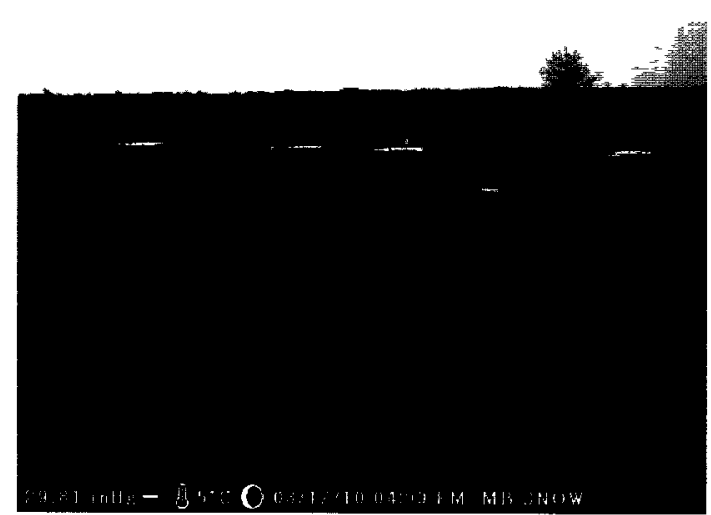

Figure A8: 12 March 2010 16h 